\title{
If a Bird Flies in the Forest, Does Anyone Hear it? Avian Flight Sound Cues and Hearing in Lepidoptera
}

\author{
By \\ Jean-Paul G. Fournier

\begin{abstract}
A thesis
submitted to the Faculty of Graduate and Postdoctoral Affairs in partial fulfillment of the requirements for the degree of Master of Science in Biology
\end{abstract} \\ Carleton University \\ Ottawa, Ontario
}

(C) 2011

Jean-Paul G. Fournier 


$\begin{array}{ll}\begin{array}{l}\text { Library and Archives } \\ \text { Canada }\end{array} & \begin{array}{l}\text { Bibliothèque et } \\ \text { Archives Canada }\end{array} \\ \begin{array}{l}\text { Published Heritage } \\ \text { Branch }\end{array} & \begin{array}{l}\text { Direction du } \\ \text { Patrimoine de l'édition }\end{array} \\ \begin{array}{l}\text { 395 Wellington Street } \\ \text { Ottawa ON K1A ON4 } \\ \text { Canada }\end{array} & \begin{array}{l}\text { 395, rue Wellington } \\ \text { Ottawa ON K1A ON4 } \\ \text { Canada }\end{array}\end{array}$

Your file Votre référence

ISBN: 978-0-494-81698-1

Our file Notre référence

ISBN: $978-0-494-81698-1$

NOTICE:

The author has granted a nonexclusive license allowing Library and Archives Canada to reproduce, publish, archive, preserve, conserve, communicate to the public by telecommunication or on the Internet, loan, distribute and sell theses worldwide, for commercial or noncommercial purposes, in microform, paper, electronic and/or any other formats.

The author retains copyright ownership and moral rights in this thesis. Neither the thesis nor substantial extracts from it may be printed or otherwise reproduced without the author's permission.
AVIS:

L'auteur a accordé une licence non exclusive permettant à la Bibliothèque et Archives Canada de reproduire, publier, archiver, sauvegarder, conserver, transmettre au public par télécommunication ou par l'Internet, prêter, distribuer et vendre des thèses partout dans le monde, à des fins commerciales ou autres, sur support microforme, papier, électronique et/ou autres formats.

L'auteur conserve la propriété du droit d'auteur et des droits moraux qui protège cette thèse. $\mathrm{Ni}$ la thèse ni des extraits substantiels de celle-ci ne doivent être imprimés ou autrement reproduits sans son autorisation.
In compliance with the Canadian Privacy Act some supporting forms may have been removed from this thesis.

While these forms may be included in the document page count, their removal does not represent any loss of content from the thesis.
Conformément à la loi canadienne sur la protection de la vie privée, quelques formulaires secondaires ont été enlevés de cette thèse.

Bien que ces formulaires aient inclus dans la pagination, il n'y aura aucun contenu manquant.

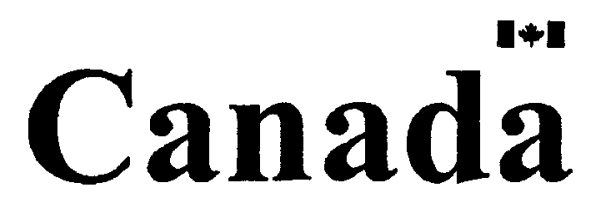




\begin{abstract}
Insectivorous birds exert a strong selection pressure on insects. Insects have many anti-predator mechanisms that they employ in response to avian predation. The least investigated of these mechanisms is the use of hearing. I tested the hypothesis that insects can hear the sounds produced by attacking birds. The bird flight sound cues of two insectivorous species, the black-capped chickadee, Poecile atricapillus, and the eastern phoebe, Sayornis phoebe, were found to be pulsed, broad-frequency sounds with peak frequencies in the sonic range, but also with a large ultrasonic component. Bird flight sound cues are produced at biologically relevant intensities $(\sim 75 \mathrm{~dB}$ at $30 \mathrm{~cm})$ and are audible to the human ear from over three meters away. Physiological recordings of the moth, Trichoplusia ni, demonstrated that they are capable of hearing the bird flight cues at natural distances at which a bird would attack. This study provides the first evidence of insects detecting the passive flight cues of an avian predator.
\end{abstract}




\section{Acknowledgements}

I would like to thank my committee members Dr. John Lewis and Dr. Jeff Dawson for their input and recommendations throughout my Master's thesis. Specifically, I would like to thank Dr. Lewis for sparking my interest in neuroscience and introducing me to the incredible field of neuroethology. If it were not for you taking the time to answer all my questions and directing me to Dr. Jayne Yack, I would not be writing these words right now. I thank Dr. Jeff Dawson for showing me what a true scientist really is. The field of neuroethology is multidisciplinary and requires a wide range of skills and techniques to ultimately explain the neural basis of behaviour. I am envious of the vast amounts of information this scientist has at the ready for any troubled "lesser" scientist. There were countless times I approached Dr. Dawson with a problem and he not only supplied me with an answer, but sat me down and gave me a complete lesson regarding the topic on his white-board. I really appreciate the time you took to do that for me.

More than anyone, I have to thank my supervisor, Dr. Jayne Yack, for taking me on as a graduate student and allowing me to take on an amazing project that was number one on my list. I had no intentions of ever working with insects. Now I couldn't imagine a life without them. Outside of Academia, I have officially become the weird bug guy who captures moths and puts them in his pocket for "later use". It is because of you, Dr. Yack, and your lab, that I have become this person and I thank you for that. You have taught me so much, not only about insect bioacoustics, but about research and the life of a scientist. I love this life and though it is an incredible amount of work that never ends, it is meaningful and exciting. I am very grateful you saw the love of biology I have in me and allowed me to work in your lab and with great people. 
I would like to thank the entire Yack lab for showing me the ropes and helping me get started here. Specifically, I have to thank Sen Sivalinghem. First of all, he is a walking encyclopedia of all things science and more. Sen you made doing physiology all night a pleasure (not that doing physiology all night isn't a pleasure in itself) and I thank you for being a good friend. I thank Ed Bruggink for enthusiastically helping with butterfly and moth rearing. When busy or stressed there was no better way to clear my mind than to have a good conversation with you in the greenhouse. I thank Mike Jutting for help with all things electronic. I would also like to thank Jennifer Mongrain and Matt Jackson for their help at QUBS with collecting moths. I thank my family and friends for their support and for believing in me. Lastly, I would like to thank Dr. James Fullard for allowing me to use his lab and equipment at QUBS and most of all for joking with me that my project would never work. It felt fantastic proving him wrong. The short time I knew him was a pleasure.

Funding for this study was provided to Dr. J. E. Yack by the Natural Sciences and Engineering Research Council and the Canadian Foundation for Innovation (CFI). Funding to J-P Fournier was provided by Carleton University. 


\section{Table of Contents}

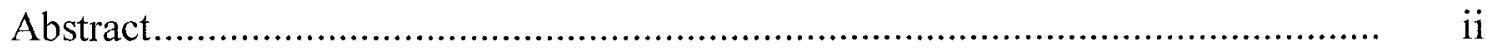

Acknowledgements ............................................................................... iii

Table of Contents .................................................................................... v

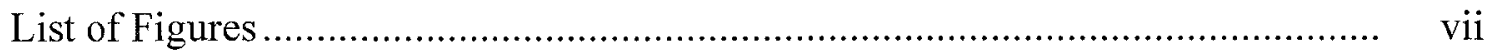

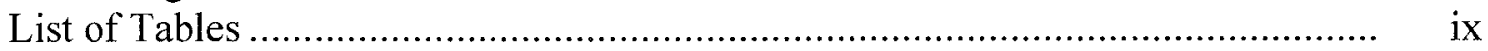

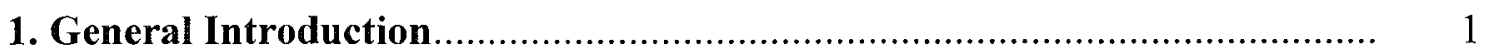

1.1 Hearing in Lepidoptera ...................................................................... 3

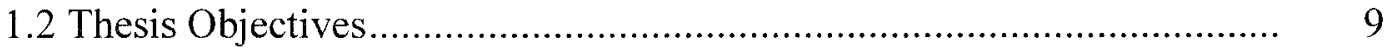

2. Acoustic Signals and Cues Associated with Flight in Insectivorous Birds .... 11

2.1 Introduction ................................................................................. 11

2.1.1 Active Signals and Passive Cues of Insectivorous Predators ........ 11

2.1.2 Acoustic Cues Produced by Avian Predators ............................... 15

2.1.3 Chapter Objectives .................................................................. 21

2.2 Materials and Methods.................................................................... 22

2.2.1 Animals and Location............................................................ 22

2.2.2 Setup of Audio and Video Recordings....................................... 23

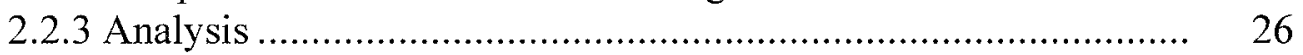

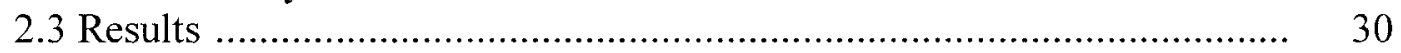

2.3.1 General Foraging Flight Characteristics..................................... $\quad 30$

2.3.2 Temporal Analysis ............................................................. 42

2.3.3 Spectral Analysis.................................................................... 44

2.3.4 Sound Level Analysis............................................................... 45

2.4 Discussion ............................................................................ 46

2.4.1 Variation in the Foraging Techniques of the Eastern Phoebe ...... 47

2.4.2 Foraging Techniques of the Black-Capped Chickadee ................. 49

2.4.3 Avian Flight Sound Cues.......................................................... $\quad 50$

2.4.4 Comparison of Avian Flight Sound Cues and Signals ................. 52

3. Are Insects Capable of Detecting Avian Flight Sound Cues?....................... 56

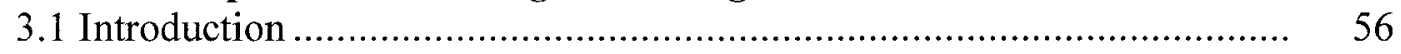

3.1.1 Insect Ears: Single or Multi-Functional ................................... 57

3.1.2 Could Insects be Listening for Passive Cues from Predators? ..... $\quad 60$

3.1.3 Chapter Objectives .............................................................. 62

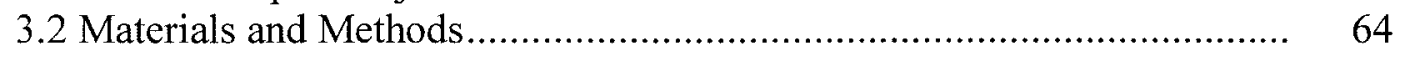

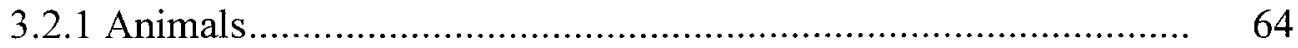

3.2.2 Extracellular Physiology ......................................................... 64

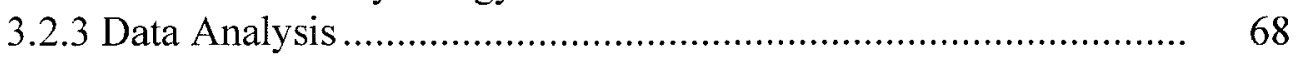

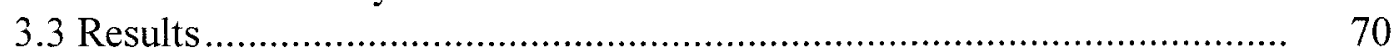

3.3.1 Are Moths Capable of Hearing Bird Flight Sounds? .................. $\quad 70$

3.3.2 Bird Flight Sound Playbacks ...................................................... $\quad 72$

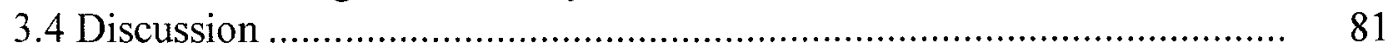


3.4.1 Are Bird Flight Sounds Relevant to Moths?.

81

3.4.2 Are Bird Flight Sounds Capable of Eliciting a Behavioural Response in Moths? 83

3.4.3 Detection Distances ................................................................. 86

3.4.4 A2 Cell Firing Patterns - A Possible Safety Mechanism............. $\quad 88$

4. General Conclusion

91

5. References 


\section{List of Figures}

1.1 Phylogeny of the Lepidoptera ............................................................. 5

1.2 Location and external morphology of the tympanal organs found in Lepidoptera............................................................................... 7

2.1 Bird flight sound recordings set-up ..................................................... 25

2.2 Comparison of filtered and unfiltered eastern phoebe (Sayornis phoebe) flight sound cues ..................................................................................... 33

2.3 Eastern phoebe (Sayornis phoebe) direct attack (1) .................................. 34

2.4 Eastern phoebe (Sayornis phoebe) direct attack (2) ................................... 35

2.5 Eastern phoebe (Sayornis phoebe) "swift-like" attack ................................ 36

2.6 Eastern phoebe (Sayornis phoebe) hover attack (1) .................................. 37

2.7 Eastern phoebe (Sayornis phoebe) hover attack (2) .................................. 38

2.8 Eastern phoebe (Sayornis phoebe) aerial glean attack................................. 39

2.9 Black-capped chickadee (Poecile atricapillus) take-off flight ................... 40

2.10 Black-capped chickadee (Poecile atricapillus) approach and take-off flight.

3.1 Typical sensory response to sound stimuli from extracellular nerve recordings from IIIN1b's A1 cell in Trichoplusia ni.................................. $\quad 70$

3.2 Audiograms from extracellular nerve recordings of IIIN1b's Al cell in Trichoplusia ni

3.3 Comparison of Trichoplusia ni audiogram to Sayornis phoebe flight sound power spectrum

3.4 Representative traces of the response of Trichoplusia ni's auditory receptors (A1 and A2 cells) to the flight sounds produced by an approaching Sayornis phoebe.

3.5 Measurements of Trichoplusia ni's Al cell response to single flight cycle playbacks of Sayornis phoebe 
3.6 Trichoplusia ni neural response to a Sayornis phoebe playback at increasing sound levels

3.7 Trichoplusia ni A1 cell inter-spike intervals elicited by full Sayornis phoebe flight playbacks ...................................................................... 


\section{List of Tables}

2.1 Temporal characteristics of eastern phoebe (Sayornis phoebe) and black-capped chickadee (Poecile atricapillus) foraging techniques

2.2 Spectral characteristics of eastern phoebe (Sayornis phoebe) and black-capped chickadee (Poecile atricapillus) foraging techniques

2.3 Summary of bird flight signal characteristics

3.1 Summary of Trichoplusia ni A1 cell neural response characteristics to single flight cycle playbacks

3.2 Summary of Trichoplusia ni A1 and A2 cell neural response characteristics to multiple flight cycle playbacks. 


\section{Chapter 1}

\section{General Introduction}

In the class Insecta there is a high diversity of hearing organs with equally diverse morphologies and functions. Insect hearing organs can be as simple as small hair-like structures that move in response to minute particle displacements, to larger, more complex tympanal ears with associated chordotonal organs (Hoy and Robert, 1996; Yack, 2004; Yack and Dawson, 2008). Insect hearing organs can be found on almost every part of the insect body, such as the legs, wings, abdomen, thorax, and antennae. A sense of hearing provides insects with the ability to detect and evade predators, identify and capture prey, locate and select mates, create and maintain territories, as well as coordinate social interactions (Yager, 1999; Yack, 2004; Yack and Dawson, 2008). There are four main forms of acoustic organs in insects: the trichoid sensilla or "hairs"; the Johnston's organ of the antennal pedicel; the subgenual organ, a substrate vibration receptor; and lastly, the tympanal ear. Each of these sensory organs functions to detect different forms of external stimuli, whether it be solid borne vibrations transmitted through solid medium, near-field sound transmitted through liquid or air media, or far-field sound transmitted through liquid or air media (Tautz and Markl, 1978; Romer and Tautz, 1992; Yack, 2004). Trichoid sensilla are found in Lepidoptera, Diptera, Hemiptera, and Orthoptera (Romer and Tautz, 1992). They function to detect faint air currents or nearfield sounds (Yack, 2004). For example, crickets use trichoid sensilla to detect the near-

field components of conspecific song (Kamper, 1984). The Johnston's organ is a near field sound-detecting organ found in many Diptera species and some Hymenoptera species. For example, female fruit flies (Drosophilidae) use this organ to detect near-field 
sounds produced by the wing-beats of males (Murphy, 2010). Subgenual organs are found in many insect orders and function as a substrate vibration detector (Straub and Lakes-Harlan, 2010). Tympanal ears are found in Orthoptera, Hemiptera, Diptera, Dictyoptera, Coleoptera, Neuroptera, and Lepidoptera (Yack, 2004). They function to detect far-field sounds over a wide range of frequencies (Hoy and Robert, 1996). My research focuses on the latter form of insect hearing organ, the tympanal ear.

Tympanal ears are the most complex and diverse of all known insect hearing organs. Collectively they can detect far-field sounds from distances over a kilometer away, are sensitive to a frequency range over $100 \mathrm{kHz}$, and intensity ranges over $100 \mathrm{~dB}$ SPL (Michelsen, 1979; Yager, 1999; Yack and Dawson, 2008). Tympanal hearing has been discovered in no fewer than seven insect orders, and new receptors continue to be discovered (Hoy and Robert, 1996; Yack, 2004). Typically, three sub-structures are required in order to classify an insect hearing organ as a tympanal ear: 1) a tympanal membrane or ear drum composed of thinned exoskeleton; 2) an enlarged tracheal air sac, which the tympanal membrane is stretched over; 3 ) chordotonal organs that are attached directly or indirectly to the tympanal membrane (Yack and Fullard, 1993; Yack, 2004). Tympanal ears, like other forms of insect hearing organs, are mechanoreceptors. The thinned area of exoskeleton, the tympanal membrane, is physically displaced when sound waves impinge upon it. The associated chordotonal organ is responsible for converting the mechanical stimuli into nerve impulses (Yack, 2004).

The overall objective of my thesis is to examine the role of insect tympanal ears as detectors of passive cues generated by approaching avian predators. To explore this potential role, I will use tympanal hearing organs in the Lepidoptera as a model system. 
Lepidopteran tympanal ears range from being complex with many sensory cells ( $>20$ for some butterflies) to simple with only one sensory cell (Notodontidae moths) (Minet and Surlykke, 2003; Waters, 2003; Lane et al., 2008). The morphological diversity found in lepidopteran tympanal ears makes it an excellent model system for the study of insect acoustics. In the remaining part of this introduction I will provide an overview of hearing in Lepidoptera, followed by my specific research objectives.

\subsection{Hearing in Lepidoptera}

The order Lepidoptera comprises 46 superfamilies of which 43 are moths and three are butterflies (Figure 1.1) (Kristensen and Skalski, 1999). Hearing has been well studied in the order Lepidoptera, with tympanal ears having now been identified in seven superfamilies (Minet and Surlykke, 2003; Yack, 2004). Tympanal ears have been identified on the thorax (Noctuoidea), abdomen (Pyraloidea, Geometroidea, Drepanoidea, and Tineoidea), mouth-parts (Bombycoidea), and wings (Papilionoidea and Hedyloidea). Until recently, the majority of lepidopteran acoustic research has focused on moths (Yager, 1999; Minet and Surlykke, 2003; Waters, 2003; Yack, 2004). Butterfly hearing has received much less attention and until recently, butterflies were thought not to have a sense of hearing.

\subsubsection{Moth Hearing}

Moths have evolved tympanal ears a minimum of six times over the past 60 million years (Yack, 2004). These ears have been shown to function primarily for predator avoidance, but also for conspecific communication (Miller and Surlykke, 2001; Yack, 
2004). Moth ears are generally sensitive to high frequency sounds ( $>20 \mathrm{kHz}$ ) produced by the ultrasonic calls that bats use to locate prey (Fullard, 1990; Minet and Surlykke, 2003). Of the six moth superfamilies mentioned above, all are known to possess ears that function in bat avoidance (Roeder, 1962; Spangler, 1988; Fullard, 1998). Of these superfamilies, Noctuoidea has received the most experimental attention. The noctuid ear is among the simplest of all insect tympanal ears, with only one or two sensory neurons attached directly to the tympanal membrane (Figure 1.2). Both cells are broadly tuned to frequencies between 20 - 50 kHz (Fullard, 1988; Spangler, 1988; Yager, 1999). Some moths (e.g. Arctiidae and Pyralidae) produce ultrasonic clicks, and these moths also use hearing to communicate with conspecifics for mate attraction (Spangler, 1988; Minet and Surlykke, 2003). The moth-bat interaction has long been a prime example of predatorprey co-evolution (Waters, 2003). Despite how much is known about moth hearing, very little is known about hearing in butterflies. 


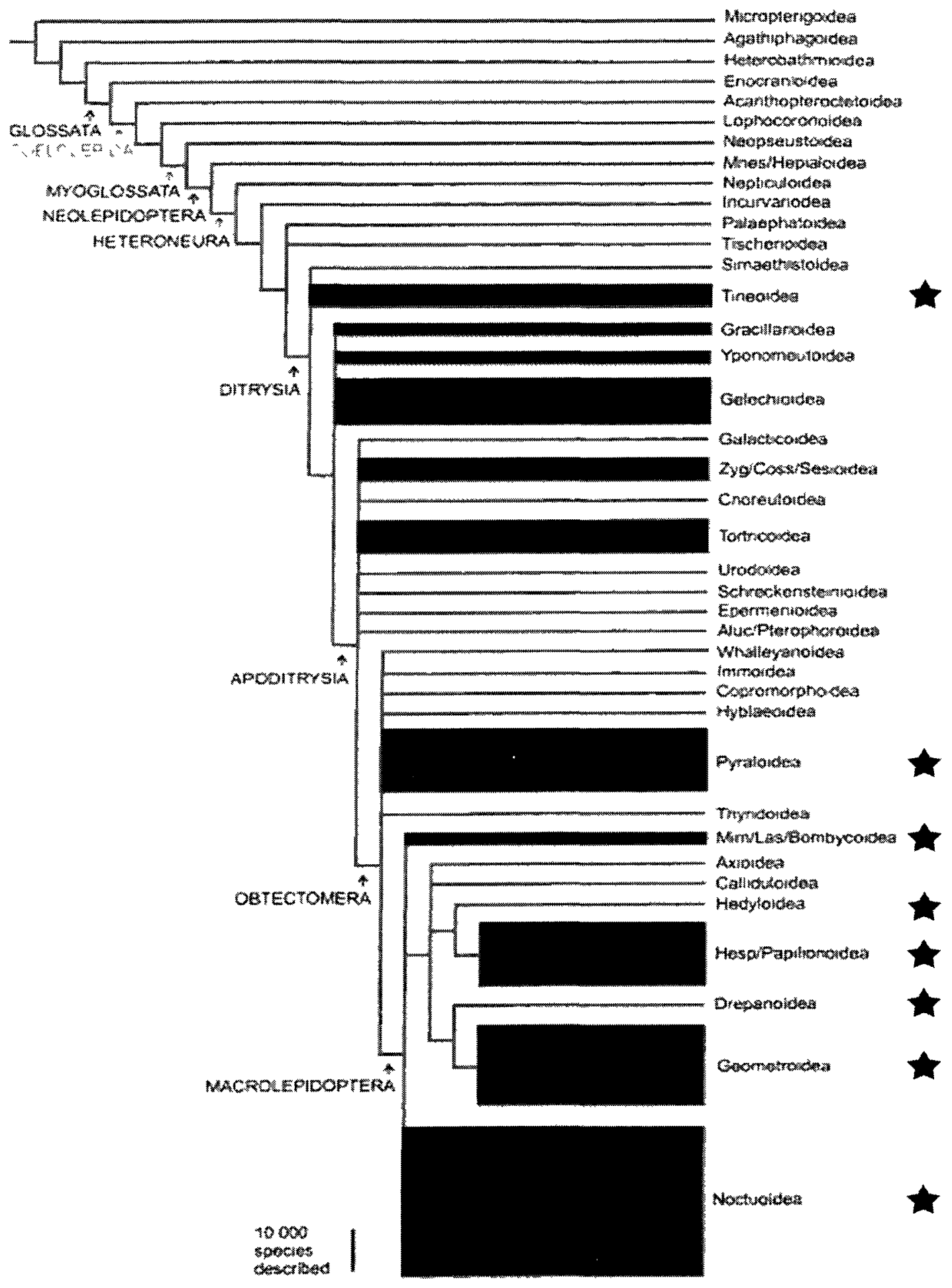

Figure 1.1. Phylogeny of lepidopteran superfamilies. The presence of tympanal hearing organs within a superfamily is indicated by a black star. Modified from Kristensen and Skalski, 1999. 


\subsubsection{Butterfly Hearing}

Butterflies comprise 3 of the 46 lepidopteran superfamilies: Hesperoidea, Hedyloidea, and Papilionoidea (Figure 1.1). The Hesperoidea, also known as Skippers, have not been shown to possess a hearing organ (Ackery et al., 1999), nor have they been reported to respond to sound. The Hedyloidea, also known as moth-butterflies or neotropical nocturnal butterflies (Ackery et al., 1999), have functional ears on their forewings that respond to ultrasound, similar to the ears of moths that function in bat avoidance (Yack and Fullard, 2000; Yack et al., 2007). There is increasing evidence that hearing in the Papilionoidea superfamily, also known as true butterflies, may be widespread within the Nymphalidae family (Otero, 1990; Lane et al., 2008; Lucas et al., 2009). This large family of butterflies comprises over 6000 species and is found all over the world (Ackery et al., 1999). The potential structure responsible for widespread hearing is the Vogel's organ. The Vogel's organ was first described morphologically by Vogel in 1912. This structure satisfies the morphological requirements of a typical insect tympanal hearing organ (Yack et al., 2000; Lane et al., 2008). The butterfly's ear has a thin membrane of cuticle that is stretched over a tracheal air sac on the forewing near the base of the cubital and subcostal veins. The membranous tympanum has multiple chordotonal organs (three in Morpho peleides) associated with it (Figure 1.2) (Lane et al., 2008). Comparative studies of the external morphology suggest that the Vogel's organ is widespread within some Nymphalidae subfamilies (Otero, 1990; Mahony, 2006; King, 2008). Nevertheless, little is known about the functional role this organ plays in butterfly behaviour. 

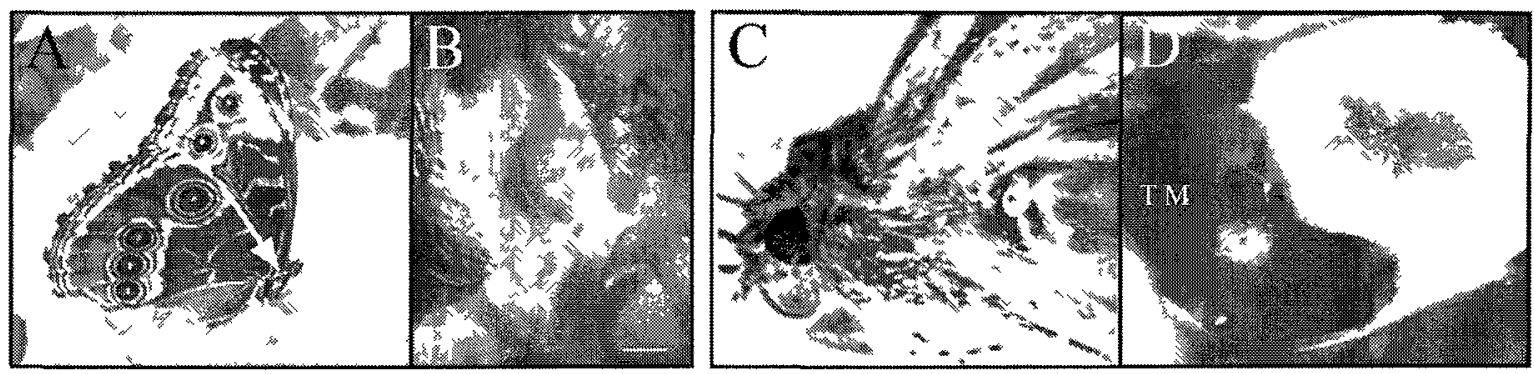

Figure 1.2. Location and external morphology of the tympanal organ found in butterflies and moths. A) Morpho peleudes butterfly shown in natural resting position. White arrow indicates location of tympanal organ on ventral surface of wing. Scale bar, $1 \mathrm{~cm}$. B) Close up of Vogel's Organ. Scale bar, 200um. Adapted from Lane et al., 2008. C) Noctuid moth specimen. White arrow indicates location of tympanal organ on moth's thorax. D) Close up of the moth tympanal organ. TM - Tympanal membrane. Adapted from Yack, 2004.

Hearıng has been formally studied in six Nymphalidae species to date: (Erebia euryale and Erebia manto (Satyrinae) (Ribaric and Gogala, 1996); Hamadryas feronia (Biblidinae) (Yack et al., 2000); Manataria maculata (Satyrinae) (Rydell et al., 2003); Pararge aegeria (Satyrinae) (Mahony, 2006); Morpho peleides (Satyrinae) (Lane et al., 2008; Lucas et al., 2009)). The functional role of hearing remains unclear in any of the six species studied, but proposed functions in different species include conspecific communication and bat avoidance. Hamadryas feronia produces sound with their wings, and hearing is believed to function in conspecific communication (Monge-Najera et al., 1998; Yack et al., 2000). During close proximity social interactions between two or more conspecifics, the butterflies will produce clicking sounds that are detectable by the Vogel's organ (Yack et al., 2000). In one species, hearing is thought to function in bat detection. Manataria maculata has been shown to respond behaviourally to short ultrasonic pulses with erratic evasive flight maneuvers (Rydell et al., 2003). Both Hamadryas and Manataria examples are atypical of the majority of Nymphalidae 
butterflies however, and are thought to be exceptions with respect to hearing, since Hamadryas produces sounds, and Manataria is crepuscular. Most nymphalid butterfly species are diurnal and mute; therefore, hearing unlikely functions in bat detection or conspecific communication. Recent physiological research on diurnal, mute nymphalid butterflies, such as the Morpho peleides and Caligo eurilochus, has shown that the Vogel's organ is most sensitive to sounds ranging between $2-4 \mathrm{kHz}$ with median thresholds of $58 \mathrm{~dB}$ SPL (Lane et al., 2008, Lucas, 2008; Lucas et al., 2009). Another diurnal, mute species of nymphalid butterfly, Pararge aegeria, possesses ears sensitive to sounds over a range from $1-18 \mathrm{kHz}$, with a best frequency of approximately $6.5 \mathrm{kHz}$ at 56.0 dB SPL (Mahony, 2006). Also, Ribaric and Gogala (1996) found that two other closely related species, Erebia euryale and Erebia manto, responded behaviourally to various sound stimuli of frequencies between $125 \mathrm{~Hz}$ to $16 \mathrm{kHz}$. The question that remains is this: What is the function of hearing in species that lack sound production and are not nocturnally active? A previous hypothesis, first suggested by Lane et al. (2008), stated that a low frequency butterfly ear would be beneficial in detecting the sounds produced by the flapping wings of an attacking bird or the vocalizations produced by near or attacking birds. This hypothesis is supported by the fact that butterflies are heavily depredated by birds (Young, 1971; Pinheiro, 1996). Also, since some birds have been shown to produce active signals during flight (Bostwick et al., 2009; Hingee and Magrath, 2009), it is possible that the mechanical movements of a bird's wings also produces passive sound cues that are detectable by insects. 


\subsection{Thesis Objectives}

The original objective of this thesis, in September 2008, was to test the hypothesis that butterflies are detecting the flight sounds and/or calls of attacking birds. In performing a background literature search, I realized that there was very little literature on bird flight sounds at all. Of the few investigations into the sounds produced by bird flight, all reported on bird flight sounds produced by species with highly modified feather structures. These were studies performed on birds that produced sound for a specific function, such as communication (Prum, 1998; Coleman, 2008), or in the case of owls, the flight feather modifications responsible for the absence of sound (Lilley, 1998; Bachmann et al., 2007). The weakness in the background literature was that no studies had been performed to record and characterize the passive sounds that flight feathers produce during flight. It was decided that the sound of bird flight as a bird approaches an insect prey needed first to be documented and characterized before playbacks of these sounds to live insects could be carried out. Therefore, the first objective of my thesis shifted to documenting the attack sounds of insectivorous birds as they approached insect prey. More specifically, my objective was to obtain flight sounds produced by insectivorous birds as they attack an insect. These findings form Chapter two of my thesis. The second objective was to play back these sounds to a neural preparation of an insect. The acoustic characteristics of bird flight sound showed a wide range of frequencies, which posed the possibility that any insect with tympanal ears, not just butterflies, may be capable of detecting bird flight sound. Given the seasonality of local butterflies, and the expense and permit issues with ordering tropical butterflies, I shifted to the readily available noctuid moth, Trichoplusia ni, as my study specimen. Therefore, 
my second objective was to examine the moth's auditory response to bird flight sound to test the hypothesis that insects can hear bird flight sounds. These findings form chapter three of my thesis. Chapter four is the general conclusion of my thesis which discusses the major findings, lays out potential functions of bird flight sound and its detection, and provides future study recommendations. 


\section{Chapter 2}

\section{Acoustic Signals and Cues Associated with Flight in Insectivorous Birds}

\subsection{Introduction}

As described in the previous chapter, insect ears are used in a variety of behaviours, such as conspecific communication, host-parasite interactions, and predatorprey detection (Yager, 1999; Stumpner and von Helversen, 2001; Yack and Dawson, 2008). For example, auditory reception and processing of conspecific acoustic signals during mate attraction, recognition, and choice have been extensively studied in several Orthoptera species (e.g. crickets, katydids, and grasshoppers) (Michelsen and Larsen, 1985; Bailey, 1990; Field and Matheson, 1998; Yager, 1999). Also well studied is the sensory ecology of predator-prey interactions; specifically, the use of acoustic signaling and reception for detecting and avoiding predators (Miller and Surlykke, 2001; Gerhardt and Huber, 2002). This chapter will focus on the function of insect hearing to detect the passive cues of avian predators. I will first review the literature on active hunting signals and passive cues made by predators in general, and how insects use these sounds to avoid attack. Then I will focus specifically on the passive acoustic cues generated by the wing movements of avian predators while in flight.

\subsubsection{Active Signals and Passive Cues of Insectivorous Predators}

A true signal is an action, behaviour, chemical, visual display, or sound that is produced by the signaler and alters the behaviour of the receiver (Maynard Smith and Harper, 2003). I will use the term "active signal" for signals that are intentionally produced by the signaler. Active signals such as bird vocalizations are used to 
communicate with other birds in a variety of contexts (Kroodsma and Byers, 1991). The songs of many male songbirds are intentionally produced sounds that are directed towards potential mates and may alter her behaviour (i.e. selecting him as her mate). A "passive cue" differs in that the signaler does not produce the cue intentionally (Maynard Smith and Harper, 2003). Passive cues do not serve a communicative function, yet may still be used by a receiver as a guide to future action (Hasson, 1994). The passive sounds produced by a predator walking over dry leaves and twigs on the forest floor are by no means intentional; however, these sounds may be detected by others. For example, whitebrowed scrubwren nestlings are capable of detecting the passive cues produced by their

primary predator, the pied currawong, walking over nearby leaf litter (Magrath et al., 2007; Haff and Magrath, 2010). Here I will focus on the active hunting signals and passive cues produced by insectivorous predators while foraging.

\subsubsection{Active Hunting Signals Produced by Predators}

Acoustic signals used by predators in pursuit of prey include bat echolocation and vibrational sounding (Fenton and Fullard, 1979; Otten, 2000; Otten et al., 2000). The most studied of these is bat echolocation and the co-evolution of insect hearing and bat hunting strategies (Miller and Surlykke, 2001; Minet and Surlykke, 2003; Waters, 2003). Many insectivorous bats use high intensity, frequency modulated echolocation calls in the $20-40 \mathrm{kHz}$ range (Fenton and Fullard, 1979). These signals are used not only for navigation but also as a hunting strategy. Tympanate hearing structures have evolved multiple times in moths that function in detecting the ultrasonic echolocation calls of insectivorous bats (Treat, 1955; Fullard, 1987; Yack, 2004). Other insects which possess 
hearing structures dedicated to bat detection include mantises, green lacewings, nocturnal butterflies of the Hedyloidea superfamily, as well as some beetle species (Hoy et al., 1989; Forest et al., 1997; Yager et al., 2000; Yack et al., 2007). The ability of prey to detect and successfully evade bat predation has influenced bat echolocation strategies, thereby creating a co-evolutionary arms race between predator and prey (Rydell et al., 1995).

Parasitic wasps also produce active acoustic hunting signals when foraging for insect prey. For example, parasitic wasps of the genus Pimpla use modified antennae to drum on wood surfaces that conceal their cocooned lepidopteran prey (Wackers et al., 1998; Otten, 2000). Subgenual organs on their legs receive the echo, produced by the drumming antennae, when it is reflected off of hidden pupae. The seismic vibrations created by the wasps are actively produced and potentially detected by prey. Currently, however, there is no evidence of prey detecting these signals. Active hunting signals have received scientific study as they are often associated with some overt behaviour (i.e. intense calling and drumming of appendages). Much less is understood about systems where the foraging sounds produced by predators are less conspicuous.

\subsubsection{Passive Cues Produced by Predators}

In comparison to bioacoustic studies of the active signals of predators, only a handful of studies have attempted to characterize the spectral and temporal properties of

the passive cues produced by predators (Barth, 2002; Platzen \& Magrath, 2004; Haff and Magrath, 2010). Passive acoustic cues can be air-borne and/or substrate-borne vibrations elicited during locomotion (i.e. walking, flying), which causes environmental 
disturbances (Gnatzy and Kamper, 1990; Bacher et al., 1996; Castelanos and Barbosa, 2006; Goerlitz et al., 2008). Despite the few documented cases of insects using passive cues in predator and prey recognition, there is great opportunity for them to do so. Goerlitz et al. (2008) recorded and characterized the sounds produced by a variety of insects walking on multiple substrates. They determined that the acoustic characteristics of passive cues varied depending on the substrate, insect mass, walking speed, humidity, and amount of background noise present in their environment. In general, passive acoustic cues were found to be broadband and lacked perceivable temporal structure (Platzen \& Magrath, 2004; Goerlitz et al., 2008; Haff and Magrath, 2010). Some insects are known to utilize these passive acoustic cues. For example, Bacher et al. (1996) have shown that leaf miners, Phyllonorycter malella, perform evasive behaviour upon detecting the passive seismic vibrations produced by the parasitoid wasp, Sympiesis sericeicornis, when it probes leaves in search of prey. Other insects are capable of detecting the passive acoustic cues produced the wings of an approaching predator (Tautz and Markl, 1978; Taylor, 2008). For example, some caterpillars, such as Barathra brassicae, have filiform hairs on their abdomen which are capable of detecting the nearfield airborne vibrations caused by the wings of an approaching predatory wasp (Tautz and Markl, 1978). Fossorial moles are also known to produce substrate vibrations when tunneling through the ground in search of invertebrate prey (Catania, 2008). Earthworms have been demonstrated to take evasive action (i.e. surfacing response) once they detect vibrations (Catania, 2008; Mitra et al., 2009). Interestingly, some species of birds and turtles are thought to exploit this anti-predator response by mimicking these cues (Tinbergen, 1960; Kaufmann, 1986). It is possible that insectivorous birds produce 
passive acoustic cues while approaching insect prey, and it would be highly adaptive if insects could detect these predatory cues. To my knowledge, the passive acoustic cues produced by birds in flight have not been studied. Therefore, characterizing these cues will be the focus of the chapter.

\subsubsection{Acoustic Cues Produced by Avian Predators}

Bird vocalizations have long been an area of research focus in the fields of ornithology and bioacoustics. The study of non-vocal avian sounds has received much less attention. There are numerous anecdotal reports of male birds producing "wing noises" during courtship displays; however, these sounds were not recorded or characterized (Darwin, 1871; Chapman, 1935; Stettenheim, 1976; Bertram, 1977). Only in the past decade have scientists begun to characterize bird flight sounds or "feather sonations" (as defined in Bostwick and Prum, 2003). Of the species studied acoustically thus far, all are investigations into the feather sonations produced by birds with specially modified wings. I am interested in documenting the acoustic cues available to insects that are produced by foraging avian predators with unmodified wing structures. Although there is no quantitative evidence of birds producing sounds in regular flight, it is inferred by the reports of owls reducing the sounds that their wings produce (Graham, 1934). The fact that owls have evolved structural modifications of their feathers to produce silent flight implies that the "normal" feather design produces sound. In a comparison of air flow over the wings of ducks and owls it was found that the former produced turbulent flow, resulting in sound production, and the latter produced laminar flow, resulting in almost no noise emission (Neuhaus et al., 1973). Before I review what is currently known 
about bird flight sounds, I will introduce the group of birds whose flight sounds I will investigate, as well as describe their interactions with insects.

\subsubsection{Feeding Habits of Insectivorous Birds}

Birds are major predators of insects and therefore exert a strong selection pressure against them (Kettlewell, 1973; Bowers et al., 1985; Chai, 1996). There are many bird species that specialize on insects. However, even generalist species that feed primarily on fruits, seeds, and nectar, will also eat insects and select them over other food options, as they are an effectively nutritious diet (Snow, 1971). To illustrate this, Poulin et al. (1994) performed a study in Venezuela to determine the diets of an array of land birds, such as frugivores, insectivores, nectarivores, and granivores, from a variety of different habitats. Of all 68 species studied, only two species of these birds were found not to eat insects.

The enormous diversity of bird species, the habitats they live in, the insect prey available, and bill shape, results in a huge variety of insect capturing methods (Remsen and Robinson, 1990). Birds such as robins specialize in pulling insects and other invertebrates from the soil (Eiserer, 1980). Warblers, tanagers, and vireos feed on caterpillars and other larvae found on trees (Airola and Barrett, 1985). Shorebirds dig in the sand for aquatic insects (Baker, 1977). Woodpeckers, chickadees, and nuthatches peck under bark for various larvae (Airola and Barrett, 1985; Remsen and Robinson, 1990). True avian insectivores specialize in insect capture techniques and are efficient predators of many insect species (Fitzpatrick, 1980).

Swifts (Apodidae), swallows (Hirundinidae), nightjars (Caprimulgidae) and flycatchers (Tyrannidae) are insectivorous birds that have become specialized predators of flying insects and so have developed advanced methods of capturing them. Birds from 
these families all specialize in an insect foraging technique known as "aerial hawking" or "sallying" (Bartlett, 1956). By definition it involves a bird pursuing and capturing a flying insect while in flight (Skutch, 1967). Aerial hawking can be divided into two general attack methods: a "swallow- or swift-like" attack and a "flycatcher-like" attack. The first method is performed by swifts, swallows, and nocturnal nightjars, which pursue flying insect prey with their mouths wide open, and intercept them in mid-air (Bartlett, 1956). Flycatchers, instead, wait on a perch for passing insects and once spotted, fly towards the prey, halting in a flutter to grasp the insect with its beak before returning to a perch to consume its prey (Bartlett, 1956). Another foraging technique used by flycatchers is "aerial gleaning", this technique involves the bird capturing insects on a substrate, such as leaves, bark, or rocks. The flycatcher, while on its perch, will locate prey resting on the substrate surface and will fly out to capture the insect from the substrate, usually while still in flight (Fitzpatrick, 1980). This chapter focuses on flycatchers, as these birds were easier to record in the wild, since they do not travel great distances to forage (as do swallows and swifts), and are diurnal (unlike nightjars). For a comparison of foraging technique between generalist and specialist and its effect on flight sound characteristics, a generalist insectivore, the black-capped chickadee, was also investigated.

\subsubsection{Do Birds Produce Sound During Flight?}

I predict that bird flight does produce sound. As stated earlier, birds require special-sound reducing feather modifications for them to produce silent flight (Bachmann et al., 2007). Therefore, the unmodified wing structures of non-owl avian species must 
produce sound. I will briefly review the silent flight of owls, and also discuss what is known of birds that seem to have exploited the sound-producing qualities of their feathers for conspecific communication.

\section{Silent Owl Flight}

Owls (Tytonidae and Strigidae) provide an interesting example of a predatory bird actively reducing the passive flight sounds that its wings produce. Owls hunt small rodents, which possess extremely good hearing above $2 \mathrm{kHz}$, and have therefore evolved a silent method of hunting (Willott, 2001; Bachmann et al., 2007). Graham (1934) discovered owl feathers to differ from all other birds in three distinct ways:

1 - The leading edge feathers of the wing are serrated and stiff, producing a comb-like structure.

2 - The trailing edge feathers of the wing form a fringe.

3 - The upper wing surface has a velvet-like covering, while the lower wing surface and legs are covered in a thick down.

Graham found that the removal of these structures resulted in flight sounds of increased amplitude. The sound-reducing qualities of these three structures have been investigated and are being applied to ultra-quiet aircraft research and the construction of a biomimetic airplane wing (Kroeger et al., 1971; Lilley, 1999; Bachmann et al., 2007). While owls have evolved feather modifications for increased stealth while foraging, other birds have evolved feather modifications for conspecific communication. 


\section{Alarm Signals}

By far one of the most common forms of feather sonation is the "wing whistle", defined by Bostwick (2006) as sounds produced by feather vibrations when air is forced through flight feathers. The family Columbidae, including doves and pigeons, are particularly well known for their production of conspicuous wing whistles during take off (Coleman, 2008; Hingee and Magrath, 2009). Sound production has been attributed to one of the pigeon's greatly attenuated primary feathers (Higgins \& Davies, 1996), which is a feature found in many birds that produce wing whistles (Bostwick \& Zyskowski 2001). Wing whistles in these species are thought to communicate to conspecifics and possibly heterospecifics, a sense of danger or presence of a predator, as they are produced most intensely during steep, high velocity take off (Coleman, 2008).

\section{Courtship Signals}

Snipes, woodcocks, hummingbirds, and manakins all produce flight sounds during courtship displays (Straw et al., 1994; Prum, 1998; McCloskey and Thompson, 2000; Clark, 2008). Prum (1998) was the first to record bird flight/wing sounds and he discovered 41 species of manakins (Pipridae) that have evolved sound-producing modifications to their feathers, which function in courtship displays. He characterized the sounds as being of short duration (individual elements $<500 \mathrm{~ms}$ ) and of broad frequency $(100 \mathrm{~Hz}-10 \mathrm{kHz})$. The feather-produced sounds may be of a greater frequency range than Prum and others have actually found since the use of a low sampling rate (i.e. figure spectrograms suggest $44 \mathrm{kHz}$ or less sampling rate) for audio recordings have prevented researchers from discovering or analyzing frequency components above $22 \mathrm{kHz}$. Of the few bird flight sound papers published thus far, the authors have concluded that birds use 
percussive and/or resonance mechanisms to generate their repertoire of feather-produced sounds (Bostwick and Prum, 2003; Clark, 2008; Coleman, 2008; Hingee and Magrath, 2009).

I have discussed how some birds use modified feathers to produce sound for the function of conspecific communicating. In contrast, owls have evolved feather modifications to produce near silent flight, which allows them to become "acoustically cryptic" to their prey. The fact that owls have actively reduced their flight sounds suggests that there is normally information available to prey when a bird approaches it in flight. The passive flight sounds of birds with unmodified feathers have not been characterized; therefore, I will document these sounds in the first chapter of my thesis.

\subsubsection{Avian Vocalizations}

Another avian signal available to eared insect prey is bird vocalization. Almost all species of birds use songs and calls to attract potential mates, to define and defend territories, and to maintain group cohesion in flocks (Kroodsma and Byers, 1991). Some species of swallow have been found to call to one another while foraging for flying insects (Brown et al., 1991). The function of these calls has been hypothesized to increase the individual's, as well as the group's foraging efficiency, since by recruiting more swallows, the insect swarm can be better tracked. Bird vocalizations have certainly received a great deal of study due to the fact they contain frequencies in the range of 50 $\mathrm{Hz}$ to $15 \mathrm{kHz}$ and therefore are capable of being detected by humans (Catchpole and Slater, 2003). Many of the insects preyed upon by avian predators, such as butterflies, crickets, and locusts, are also sensitive to the range of frequencies within bird calls (Kamper, 1984; Robert, 1989; Lane et al., 2008). Few studies have investigated the anti- 
predator responses of insects to avian vocalizations; however, Lohrey et al. (2009) found wolf spiders (Araneae: Lycosidae) to cease courtship and movement when presented with bird call playbacks. Ribaric and Gogala (1996) hypothesized the low frequency ear of some nymphalid butterflies functioned in detecting avian vocalizations. Also, the blue morpho butterfly, Morpho peleides, has been demonstrated to physiologically respond to bird vocalizations (Mongraine, 2009). Avian vocalizations, in addition to the flight sounds of an approaching bird, may be an important predatory cue used by many eared insects in predator avoidance.

\subsubsection{Chapter Objectives}

The primary focus of this chapter is to characterize the flight sounds produced by the wings of insectivorous birds. The first objective was to videotape and record the sounds produced by two species of birds as they forage. I chose to examine the flight sounds of a bird with a generalist diet, the black-capped chickadee (Poecile atricapillus), which employs a variety of foraging techniques, as well as a bird with a more specialized insectivorous diet and capturing technique, the eastern phoebe (Sayornis phoebe). The second objective was to describe both bird's flight sounds with respect to their spectral, temporal, and intensity characteristics. This study will provide valuable information on the acoustic characteristics of bird flight and provide us with recordings of a novel predatory sound cue. 


\subsection{Materials and Methods}

\subsubsection{Animals and Location}

Two avian species were studied with respect to the sounds they made while foraging. The first, the black-capped chickadee (Poecile atricapillus) is a small (10-14 g), passerine songbird with an omnivorous diet. Chickadees inhabit a variety of landscapes, from urban areas to dense forests. They will forage for seeds, nuts, berries, and during the summer, insects (Smith, 1997). Chickadees can be found pecking and prying open the bark of trees to find insects. They will also forage on the forest floor, thrashing through leaf litter for insects and can even be seen catching flying insects on the wing (Robinson and Holmes, 1982). Chickadees prefer woodland habitats where they live in mixed species flocks (Smith, 1997). Audio and video recordings of chickadees were performed in such a habitat, the Mer Bleue $\operatorname{Bog}\left(45^{\circ} 22^{\prime} \mathrm{N} 75^{\circ} 30^{\prime} \mathrm{W}\right)$ in southeastern Ottawa, Ontario, during the time period of January 2009 to May 2010. I obtained a Land Access Permit (Permit \# 10006) from the NCC-Greenbelt division to perform audio and video recordings of wildlife.

The second avian species studied was the eastern phoebe (Sayornis phoebe), a small (16-21 g) tyrant flycatcher which is primarily an aerial insectivore. Phoebes inhabit forests and are usually found along forest edges or where forest meets water (Weeks, 1994). During the breeding season, when nestlings are developing ( $\sim 16$ days), both phoebe parents share the responsibility of feeding their chicks (Christ, 1958). For this period of time phoebes hunt for flying insects from dawn until dusk and remain close $(<20 \mathrm{~m})$ to their nest (personal observation). Audio and video recordings of phoebes took place near the buildings and forests surrounding Queen's University Biological Station 
(QUBS) $\left(44^{\circ} 34 \mathrm{~N}, 76^{\circ} 19 \mathrm{~W}\right)$ near Chaffey's Locks, Ontario, between the months of May and August of 2009 and 2010. I obtained a CCAC Permit (Permit \# AUP B10-15) from Carleton University to attract and feed phoebes, as well as to perform audio and video recordings.

\subsubsection{Set-up of Audio and Video Recordings}

Flight sounds were recorded from both black-capped chickadees and eastern phoebes. Chickadee flight sounds were recorded using a handfull of seed to entice them towards the microphone (Figure 2.1.A). Seed was used in place of insects (easier and cheaper to obtain). As the chickadee flew up to my hand, then flew away, its flight sounds were recorded using one of two microphones held in the opposite hand, approximately $15 \mathrm{~cm}$ away. Chickadee flight recordings were obtained using a customized version of the Avisoft CM16 microphone (2 - $200 \mathrm{kHz})$ (Berlin, Germany). The recorded bird flight sound was saved as a .WAV file on a Fostex-FR2 field recorder (Gardena, CA, USA), using a 16-bit, $192 \mathrm{kHz}$ sampling rate. A Sony HandyCam HDR12 video camera (Tokyo, Japan) was set on a tripod approximately $3-5 \mathrm{~m}$ away and positioned towards myself to capture the incoming and outgoing flight of the chickadees. A Sony ECM-MS907 $(100 \mathrm{~Hz}-15 \mathrm{kHz})$ microphone was connected to the video camera in order to record and monitor flight sound and behaviour simultaneously.

Eastern phoebe flight was recorded at four separate locations on the QUBS property. To attract the birds to the recording set-up, local moth species between $3-10$ $\mathrm{cm}$ in wingspan were wild-caught using mercury vapour light traps at QUBS and used within 24 hours of capture. Moths were tethered between the abdomen and thorax with fine cotton thread and suspended from a branch that was in clear view of the hunting 
phoebes and less than $10 \mathrm{~m}$ from the nest. Moths were placed between the recording microphone and the bird's hunting perch in order to maintain a constant approach angle to the microphone. An Earthworks QTC40 microphone (4 Hz - $40 \mathrm{kHz}$ ) (Milford, NH, USA) was used as the main recording microphone during the summer of 2009 recordings. In order to extend the frequency range of bird flight sound recordings a customized Avisoft CM16 microphone $(2-200 \mathrm{kHz})$ with windsock attached was used as the main recording microphone during the summer of 2010. Initial recordings were made using an Audio-technica ATM10a microphone (20 Hz - $18 \mathrm{kHz}$ ) (Akron, OH, USA) but these recordings were discontinued because frequencies above $18 \mathrm{kHz}$ were not represented. Audio recording equipment was inconspicuously positioned $30 \mathrm{~cm}$ or $50 \mathrm{~cm}$ from the tethered moth in the leaves and branches of a tree (Figure 2.1.B). Distances between the bird and microphone were determined at each location by measuring the distance of the recording microphone to the tethered moth. Two conventional Sony Steady Shot DCRTRV19 digital video cameras were positioned within 5 - 10 meters from the tethered moth, at $90^{\circ}$ angles from one another (see Video Analysis). A Sony ECM-MS907 (100 $\mathrm{Hz}-15 \mathrm{kHz}$ ) microphone was connected to one video camera in order to record flight sound and behaviour simultaneously. This set-up allowed me to temporally match the video footage with audio recordings made with the recording microphone (i.e. Earthworks or Avisoft microphone). All recording equipment was set up approximately 30 minutes in advance of placing the tethered moth on a branch, in sight of the phoebe's hunting perch, in order to allow the birds to acclimate to the changes in their surroundings. 


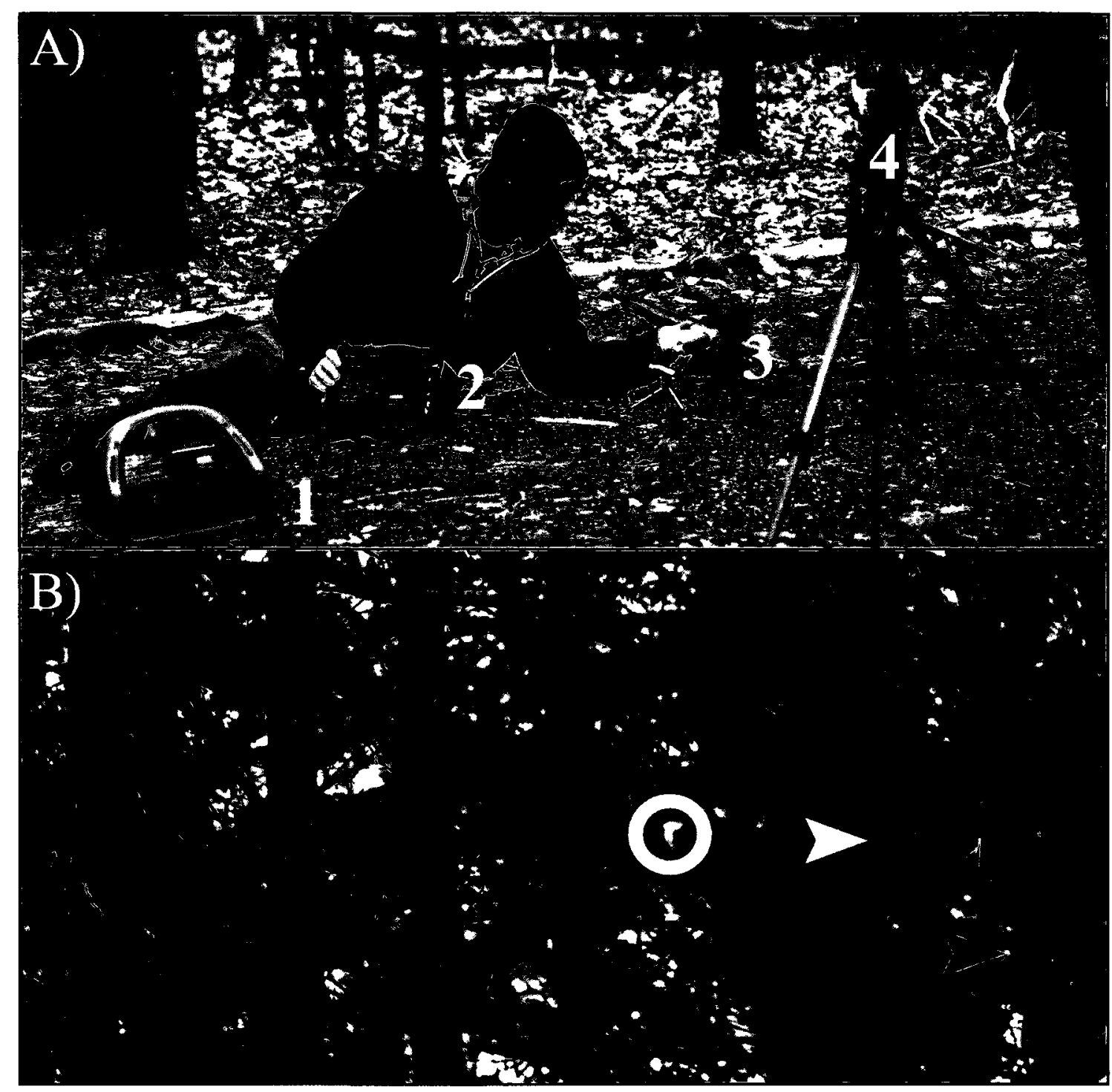

Figure 2.1. Bird flight sound recording set-up. A) Recording set-up for black-capped chickadee (Poecile atricapillus) at Mer Bleue Bog, Ottawa, Ontario. 1-Power supply, 2Fostex FR2 field recorder, 3-Avisoft microphone, 4-Sony Video camera. B) Recording set up for eastern phoebe (Sayornis phoebe) at QUBS, Chaffey's Locks, Ontario. Arrows indicate microphone positions: White - Avisoft microphone, Black - Sony ECM microphone. White circle indicates position of tethered moth used to attract birds. 


\subsubsection{Analysis}

Video footage of both birds' foraging was used to describe the birds' foraging behaviours. Audio recordings were used to characterize the flight sounds produced by the phoebe and the chickadee while attacking a tethered moth or landing at a feeding station, respectively.

\subsubsection{Video Analysis}

Videos were analyzed to determine the various behaviours exhibited by birds as they foraged. Video allowed me to determine if birds employed a variety of foraging techniques, how often particular techniques were employed, and the type of flight used during foraging. Using two video cameras simultaneously for a greater angle of view, a better estimate of the bird's position relative to the microphone was obtained. This allowed me to determine if the bird approached the microphone at relatively the same angle for each attack during a recording session. Video footage was temporally matched with audio recordings in order to determine which movements of the bird's wings correlated to sound production. Using Raven Pro 1.3 software (Cornell Lab of Ornithology, Ithaca, New York) the audio recording from the video footage was aligned temporally with the audio recording from recording microphone (Earthworks or Avisoft) used for audio analysis. This allowed for frame by frame analysis of the bird's foraging tactic, wing movements, and resulting sound production. Video footage was edited in iMovie 7.1.4 (Apple Computer, Inc., Cupertino, CA, USA) and organized by species and foraging tactic. 


\subsubsection{Audio Analysis}

Sound files were analyzed using Raven Pro 1.3 (Charif et al., 2007) software to characterize the temporal, spectral, and intensity features of bird flight sounds. The bird flight sounds described in this chapter are composed of short duration, broad-frequency pulses. Pulse duration and frequency range are complicated to characterize in these types of sounds as there is no distinct feature indicating the beginning or end of a pulse, and recordings were performed in the field with ambient background noise present. For this reason I only analyzed sound characteristics which could be reproduced by others with identical recording equipment.

\section{Temporal}

The relative duration (s) and wing-beat frequency $(\mathrm{Hz})$ were measured for phoebe foraging events, while only wing-beat frequency was measured for chickadee foraging events. For phoebes, relative duration is defined as the period of time during an attack that sounds were detected above background noise, up until the point of capturing the insect. This is not an absolute measurement of attack duration as it is dependent on the sensitivity of the microphone being used and the angle at which the bird approaches the microphone. I use a relative measurement of duration to determine if there is variation in the length of phoebe attacks and to compare between foraging techniques. The relative duration value I have measured is not intended to estimate how much time an insect may have to detect bird flight sounds but to compare if one foraging tactic is temporally different than another. The Earthworks QTC40 microphone recordings, at a distance of $50 \mathrm{~cm}$ from the tethered moth, were used to perform relative duration measurements. The average wing-beat frequency (WBF) is defined as the number of wing-beat cycles (i.e. 
wing-beat $=$ up and down stroke of the wings) per second. To measure and compare the WBF between the various foraging techniques a $500 \mathrm{~ms}$ sample was taken from the point of capture (phoebe) or to the point of landing (chickadee).

\section{Spectral}

Frequency analysis was performed on representative flight cycles from each successful recording (phoebe $\mathrm{n}=10$, chickadee $\mathrm{n}=5$ ). Before conducting the analysis, audio tracks from the Earthworks microphone were high pass filtered for frequencies below $500 \mathrm{~Hz}$ (Hingee and Magrath, 2009). Environmental background noise (i.e. wind, rustling leaves, etc.) had energy in this frequency range whereas the bird flight sound cue did not (see Results, Figure 2.2). The Avisoft microphone is not sensitive to frequencies below $\sim 2 \mathrm{kHz}$ and therefore did not require filtering. Recordings of phoebe flight were made separately with the Earthworks and Avisoft microphones in order to cover as much of the sound's frequency range as possible (Earthworks: $4 \mathrm{~Hz}-40 \mathrm{kHz} \&$ Avisoft: $2 \mathrm{kHz}$ - $96 \mathrm{kHz}^{*}$ (*due to the limitation of the audio recorder's sampling rate, 192 $\div 2$ )). Chickadee recordings made with the Avisoft microphone were used for spectral analysis. For each species, measurements were made to determine: 1) the frequency bandwidth $(\mathrm{kHz})$; 2) the peak frequency $(\mathrm{kHz})$; and 3) the intensity (dB SPL). Frequency measurements were made on single flight cycle spectrograms with a temporal grid of $2.67 \mathrm{~ms}$ with a 50 per cent overlap, a frequency grid resolution of $188 \mathrm{~Hz}$ with a Discrete Fourier Transform (DFT) size of 512 samples in a Hann window function. Frequency analysis could not be separated into male and female attacks, as both sexes were active foragers and very similar in plumage and size (Christ, 1958). 


\section{Sound Levels}

Phoebe flight sound level was later calibrated against a tone of known sound level. By recording a $1 \mathrm{kHz}$ pure tone (which is approximately the same peak frequency of phoebe flight; see Results, Figures 2.2 and 2.6) at various intensities, using the same microphone, recording device, and recording distance, I was able to compare the waveforms of the pure tone with the waveform of the actual phoebe flight recordings. Plotting the pure tone sound level (dB SPL) against the sound level unit in Raven Pro1.3 software $(\mathrm{kU})$ on a graph, I used the formula of the line of best fit to estimate the natural intensity of phoebe flight in nature. Chickadee flight sound level (dB SPL) was measured in the field, using a Bruel and Kjaer Type 2239 sound level meter (A weighting - RMS) (Naerum, Denmark). To determine the flight sound cue's sound level relative to background noise levels I measured a section of the natural ambient background noise before and after the recorded flight signal and compared them using Raven Pro 1.3.

\subsubsection{Statistical Analysis}

All statistical analysis was performed using SPSS V13.0 (IBM, New York, NY, USA). Independent t-tests were run on phoebe flight sound means of relative duration and peak frequency among various foraging techniques for recordings made with the earthworks QTC microphone. ANOVAs were used to determine differences in wing-beat frequency (WBF) between phoebe foraging techniques and the single chickadee technique. 


\subsection{Results}

\subsubsection{General Foraging Flight Characteristics}

As outlined in the introduction, flycatchers have been reported to employ two primary methods of attacking flying insects; aerial hawking or "sallying", and aerial gleaning. I witnessed both forms of attack during my recording trials but found phoebes to use multiple variations of the aerial hawking technique. I defined these variations of aerial hawking as direct attacks, swift-like attacks, and hover attacks and will briefly describe the behaviour of each of these attack methods based on my video recordings.

Direct attacks are described as the phoebe taking off from its perch, flying directly towards its prey, and capturing it with its beak. At the moment of capture the phoebe comes to a brief halt before flying backwards for a short distance, then returning to normal forward flight on its way back to a perch (Figures 2.3 and 2.4). A swift-like attack is similar to the direct attack in that the bird directly approaches the prey very quickly, yet unlike the direct attack, the phoebe employs a "fly-through" approach in which it does not come to a halt when capturing the insect in its beak (Figure 2.5). This technique was performed with such velocity, that the video camera's frame rate was not fast enough to capture the bird's wing motions. This form of attack is more fitting of a "swallow or swift-like" attack reviewed earlier. Hover attacks can be described as an extension of the direct attack method of capture. Instead of continuous direct flight and capture of the prey, the phoebe will come to a halt before contacting the prey item and begin to hover in front of it. The phoebe maintains the hover for a short period of time $(\sim 800 \mathrm{~ms}$, i.e. the difference in time between a direct and hover attack, see Table 2.1) before darting forward with its beak to capture the insect. This is followed by a short period of 
backwards flight before returning to its perch (Figures 2.6 and 2.7). I also witnessed a single aerial gleaning attack that was performed in the same manner previously described by other researchers (Fitzpatrick, 1980). This form of attack only occurred when the fluttering moth landed on substrate (i.e. foliage). The attacking phoebe flew towards the moth on the foliage and hovered beside it before plucking the insect from the foliage (Figure 2.8).

A total of 32 attacks were recorded from four nesting pairs of phoebes $(\mathrm{N}=8$ (eight individuals: four males and four females)) between the months of June and July, 2009, as well as a single outing in June, 2010. Phoebes attacked the tethered moths using aerial hawking techniques (i.e. direct, swift-like, or hover $)(n=31)$ the majority of the time and only once used the aerial gleaning technique $(n=1)$. Of the 32 attacks on tethered moths, 30 were successful. The 2 unsuccessful attacks involved the bird approaching the tethered prey and hovering before it, but instead of completing the attack by grasping the prey in its beak, it retreated. These 2 failures involved very large prey, a luna moth (Actias luna), with a wingspan greater than $10 \mathrm{~cm}$. Of the 31 aerial hawking attacks on tethered moths, 17 were direct attacks, one was a swift-like attack, 11 were hover attacks, and 2 were instances where the birds utilized both direct and hover attack techniques. Birds that required two attempts to successfully capture prey first employed direct attacks followed by hover attacks.

Upon review of all phoebe foraging data, a temporal trend in foraging technique was observed. In 4 of the 5 phoebe recording sessions the phoebe pairs $(\mathrm{N}=8)$ began aerial hawking events with the hover attack technique and in 3 of the 5 recording sessions the pair ended with the direct attack technique. 
Black-capped chickadees were seen to make use of a variety of foraging tactics as described in previous reports (Remsen and Robinson, 1990). I witnessed them peck bark like a woodpecker, pry under bark to find insects and larvae, catch flying insects from the air, and eat seed at a feeding station or from a human's hand. The latter foraging technique was formally studied using audio and video recordings of individual chickadees ( $\mathrm{N}=11$ (individual animals), $\mathrm{n}=11$ (one sample from each animal)) (Figure 2.9). Chickadee flight can be described as "flap and bound" or "bounding" flight, where the bird will gain altitude with a few very quick wing-beats, then descend slightly while bounding with wings folded against the body, followed again by a few quick wing-beats (Rayner, 1985). The audio recordings analyzed in this section are comprised of the chickadee flying toward and landing on the recorder's hand, then taking-off in flight.

\section{NOTE:}

Flight recordings made with the Earthworks QTC40 $(40 \mathrm{~Hz}-40 \mathrm{kHz})$ microphone were found to have a low frequency component (i.e. $<500 \mathrm{~Hz}$ ) with very high energy (Figure 2.2). This low frequency component was mirrored by the background noise which also showed a large peak in energy at low frequencies (Figure 2.2.A). As this frequency component was most likely composed primarily of ambient background noise, I hi-pass filtered all phoebe flight sound recordings made with the earthworks microphone at $500 \mathrm{~Hz}$ (Figure 2.2.B). 


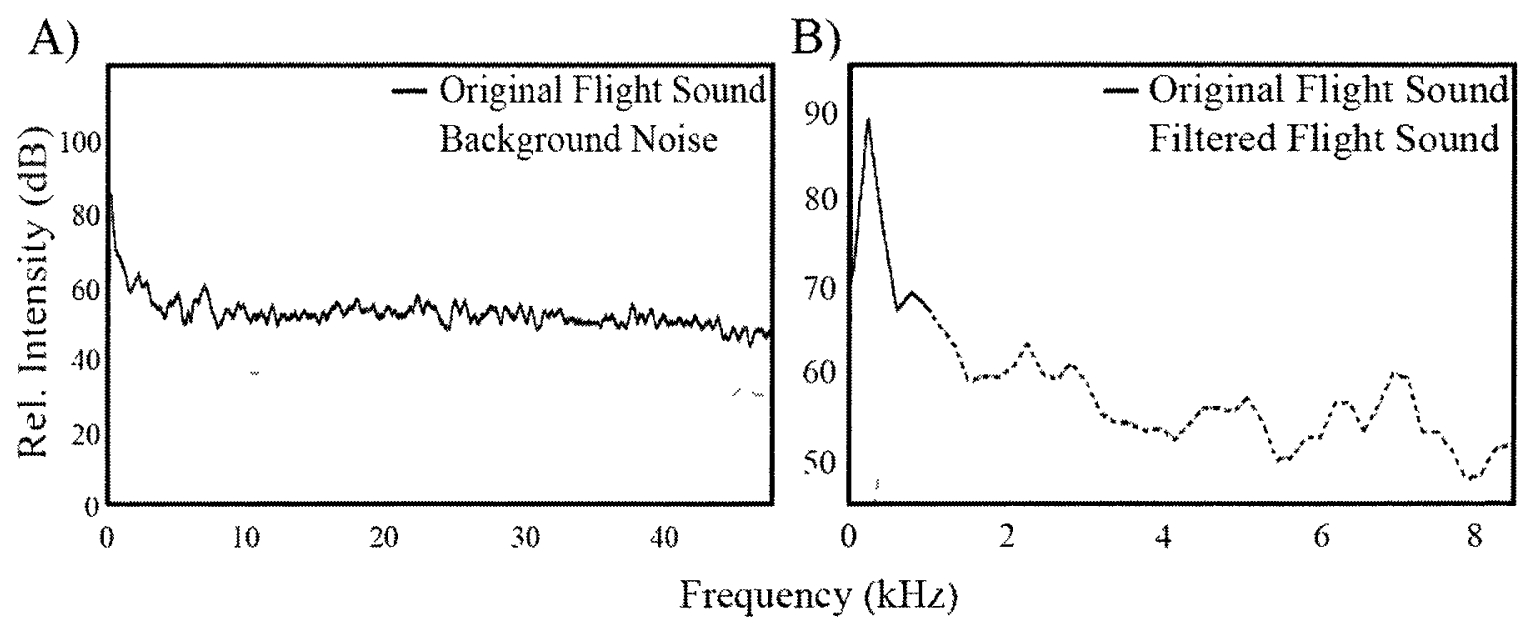

Figure 2.2. Comparison of a representative filtered and unfiltered eastern phoebe (Sayornis phoebe) flight sound cue recorded with Earthworks QTC40 microphone. A) Power spectrum of a single unfiltered (i.e. original) phoebe flight cycle (black trace) and a section of the ambient background noise (grey trace) that was present prior to flight recording. B) Expanded view at low frequency portion of the power spectrum of the original phoebe flight cycle (black trace) presented in (A) and a $500 \mathrm{~Hz}$ hi-passed filtered version (grey trace) of the original used for analysis in this chapter. Filtering was performed using Raven Pro 1.3 software. 


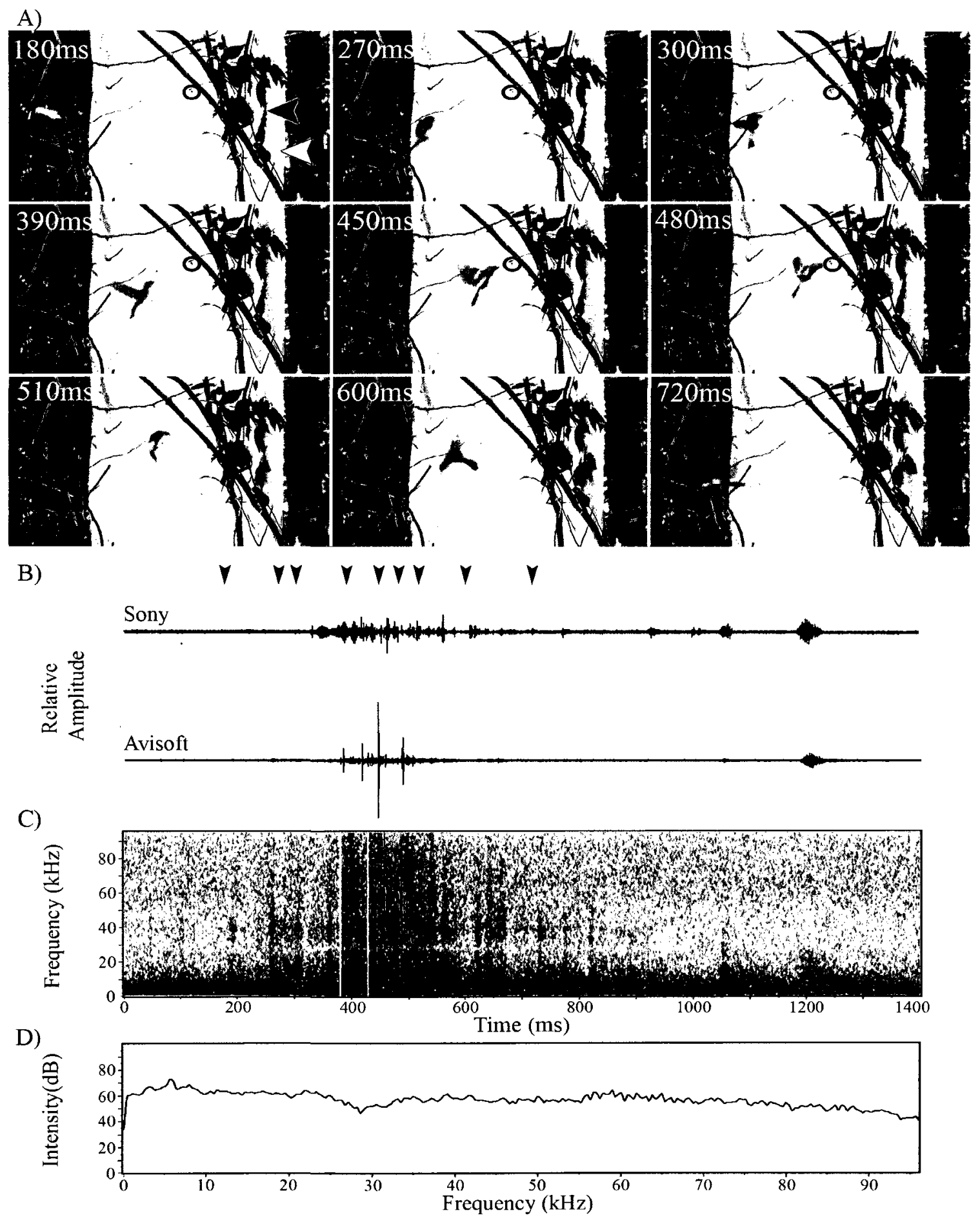

Figure 2.3. Eastern phoebe (Sayornis phoebe) performing a direct attack on a tethered moth (moth is circled in black). A) Select video frames of the attack at QUBS. Time values correspond to the black arrows on the waveforms in (B). Phoebe enters and leaves the video frame within $650 \mathrm{~ms}$. Moth is captured by phoebe in $6^{\text {th }}$ video frame (at $480 \mathrm{~ms}$ ). White arrow in first frame indicates position of Sony ECMMS907 microphone. Black arrow indicates position of Avisoft CM16 microphone with windsock. B) Waveforms of the audio files recorded during the phoebe's attack. Black arrows indicate the video frames in (A). C) Spectrogram of the audio file recorded using the Avisoft microphone. D) Power spectrum of a single flight cycle (upstroke + downstroke outlined with white lines in (C)) prior to capture of insect. 
A)

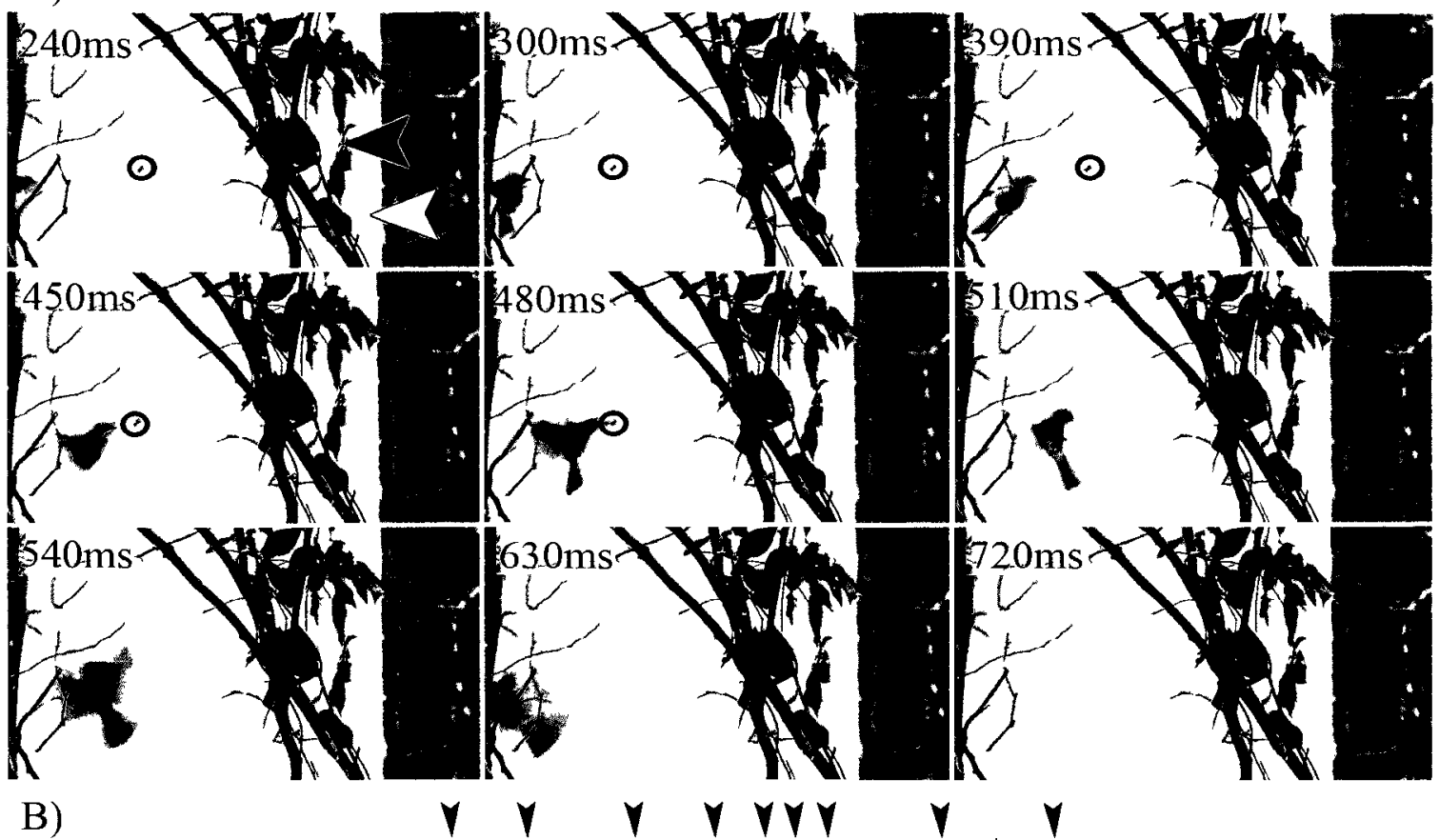

B)

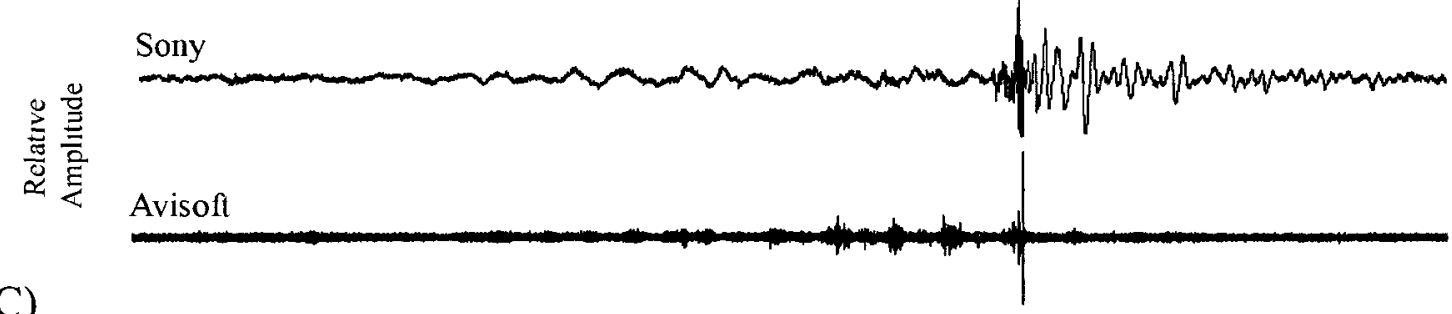

C)

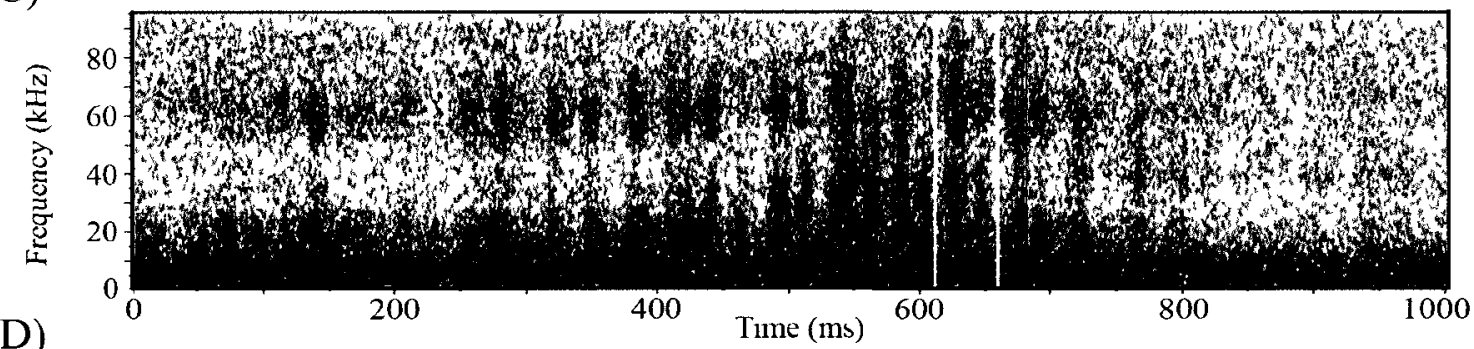

D)

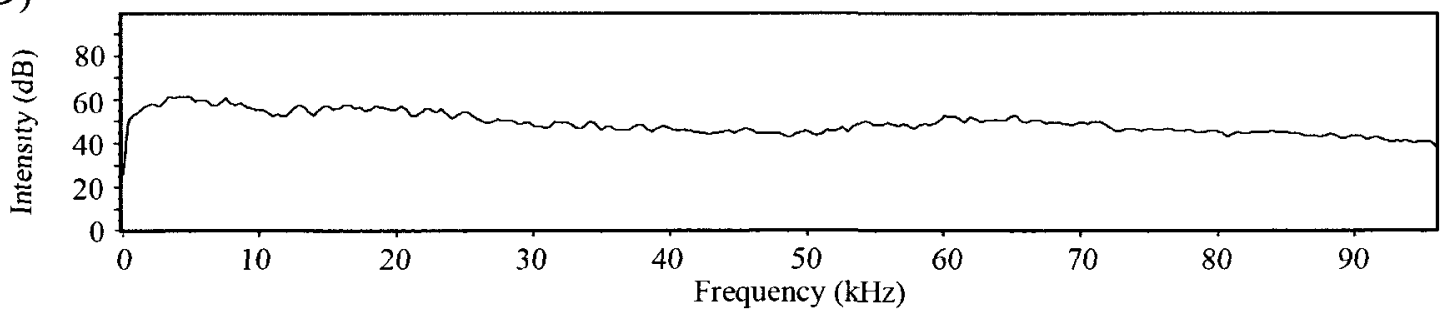

Figure 2.4. Eastern phoebe (Sayornis phoebe) performing a direct attack on a tethered moth (moth is circled in black). A) Select video frames of the attack at QUBS. Time values correspond to the black arrows on the waveforms in (B). Phoebe enters and leaves the video frame within $700 \mathrm{~ms}$. Moth is captured by phoebe in $5^{\text {th }}$ video frame (at $510 \mathrm{~ms}$ ). White arrow in first frame indicates position of Sony ECMMS907 microphone. Black arrow indicates position of Avisoft CM16 microphone with windsock. B) Waveforms of the audıo files recorded during the phoebe's attack. Black arrows indicate the video frames in (A). C) Spectrogram of the audio file recorded using the Avisoft microphone. D) Power spectrum of a single flight cycle (outlined with white lines in (C)). 

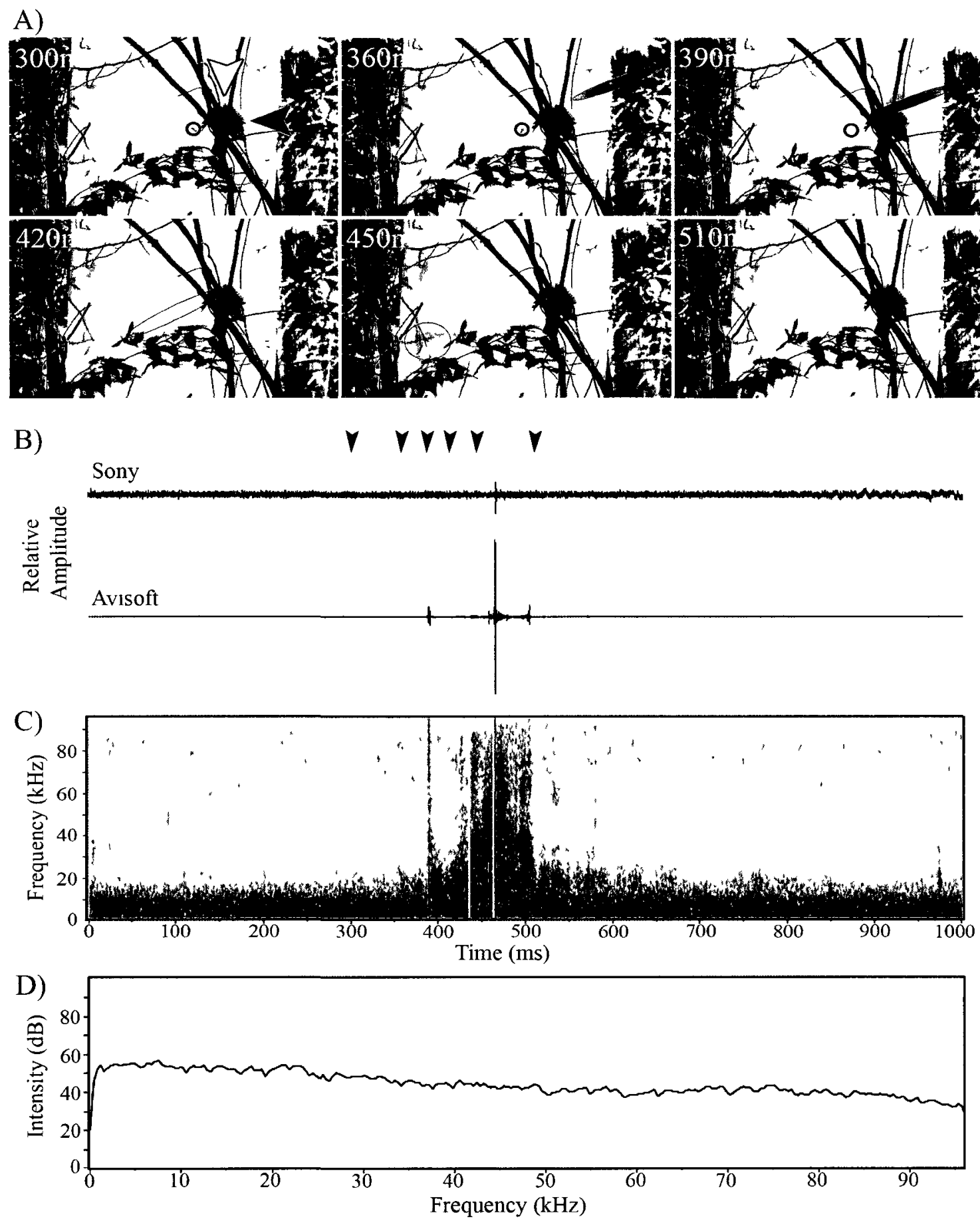

Figure 2.5. Eastern phoebe (Sayornis phoebe) performing a "swift-like" attack on a tethered moth (moth is circled in black, phoebe is shaded in grey due to speed of attack, it only registers as a blur). A) Select video frames of the attack at QUBS. Time values correspond to the black arrows on the waveforms in (B). Phoebe enters and leaves the video frame within $100 \mathrm{~ms}$. Moth is captured by phoebe in $4^{\text {th }}$ video frame (at $420 \mathrm{~ms}$ ). This was the fastest attack form witnessed. Open arrow in first frame indicates position of Sony ECM-MS907 microphone. Black arrow indicates position of Avisoft CM16 microphone. B) Waveforms of the audio files recorded during the phoebe's attack. Black arrows indicate the video frames in (A). C) Spectrogram of the audio file recorded using Avisoft microphone. D) Power spectrum of a portion of gliding flight (outlıned in (C)). 
A)
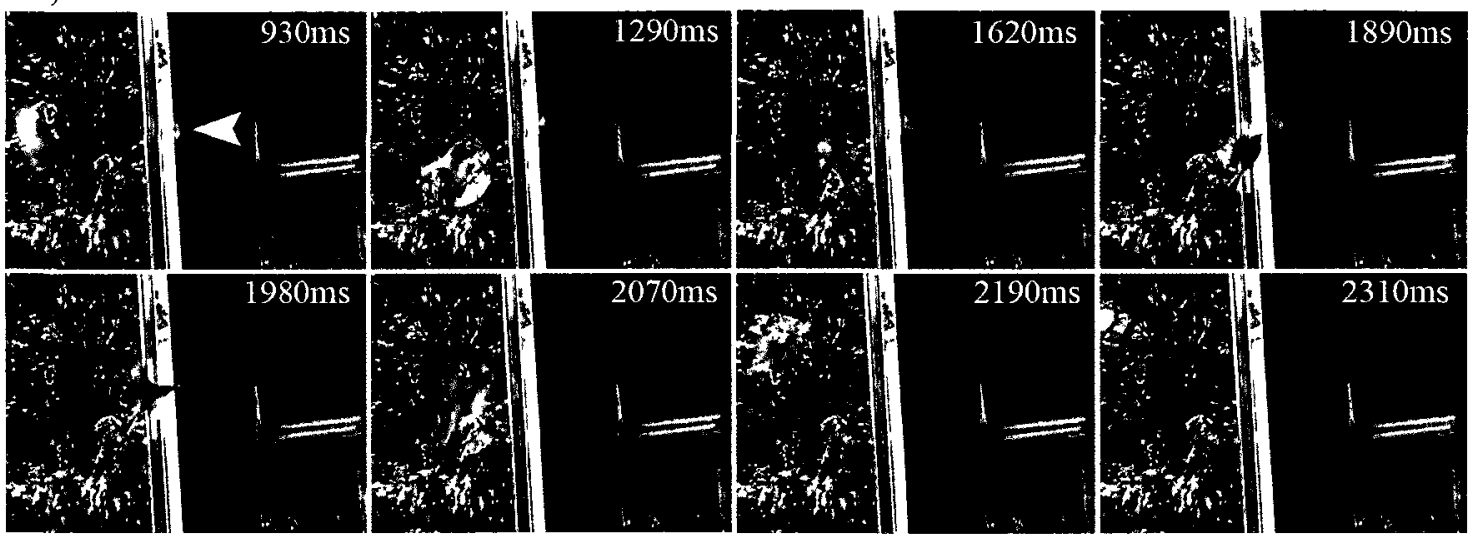

B)

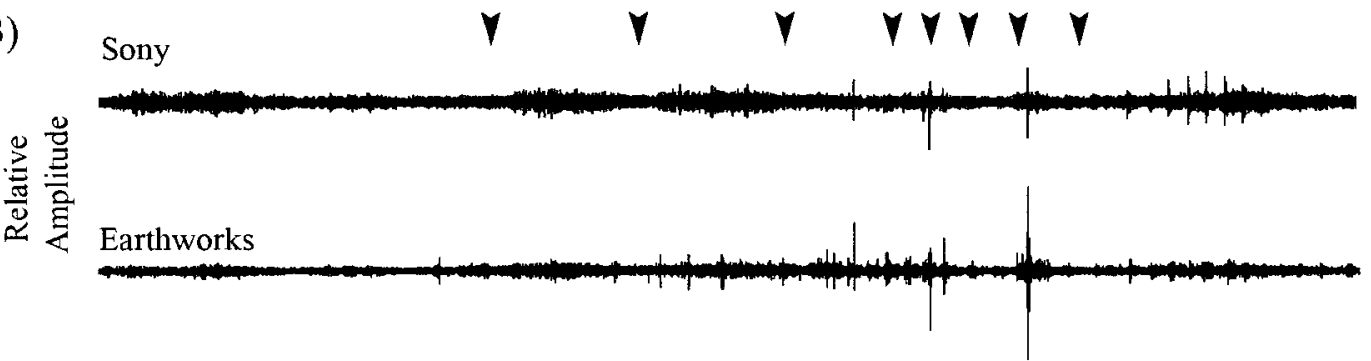

C)

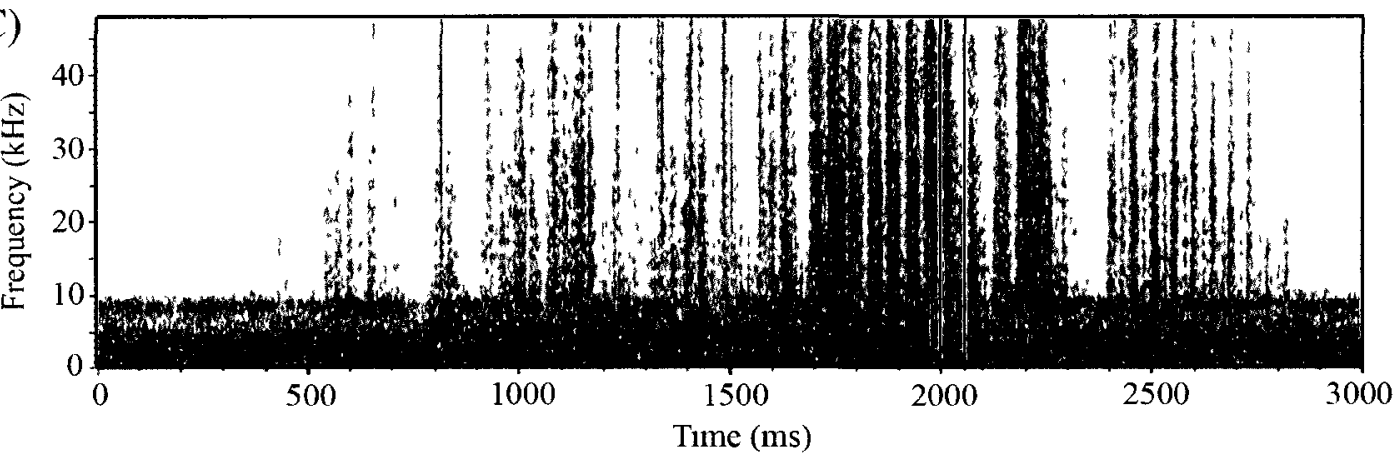

D)

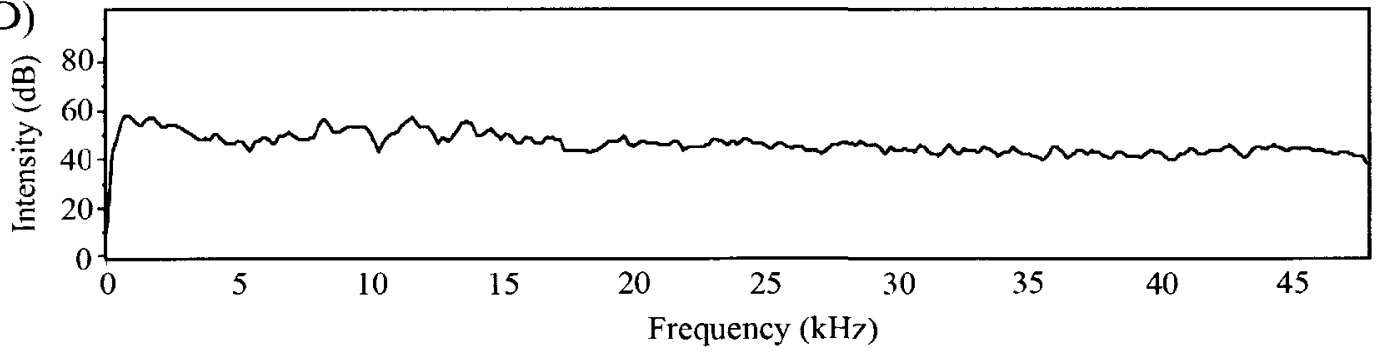

Figure 2.6. Eastern phoebe (Sayornis phoebe) performing a hover attack on a tethered moth (indicated by white arrow in first frame of (A)). A) Select video frames of the attack at QUBS. Time values correspond to the black arrows on the waveforms in (B). Phoebe remains in the vicinity of the moth for more than $1400 \mathrm{~ms}$. Moth is captured by phoebe in $5^{\text {th }}$ video frame (at $1980 \mathrm{~ms}$ ). B) Waveforms of the audio files recorded during the phoebe's attack (top waveform is from video camera Sony microphone and bottom is waveform from Earthworks QTC40 microphone; both are located outside the bottom right of the frame, $50 \mathrm{~cm}$ from moth). Black arrows indicate the video frames in (A). C) Spectrogram of the audio file recorded using the Earthworks microphone. Dotted horizontal line on spectrogram is due to unknown bird vocalizations in the background and accounts for secondary peak on power spectrum at $\sim 8 \mathrm{kHz}$. D) Power spectrum of a single filtered $(<500 \mathrm{~Hz})$ flight cycle (outlined with black lines in $(\mathrm{C})$ ). 

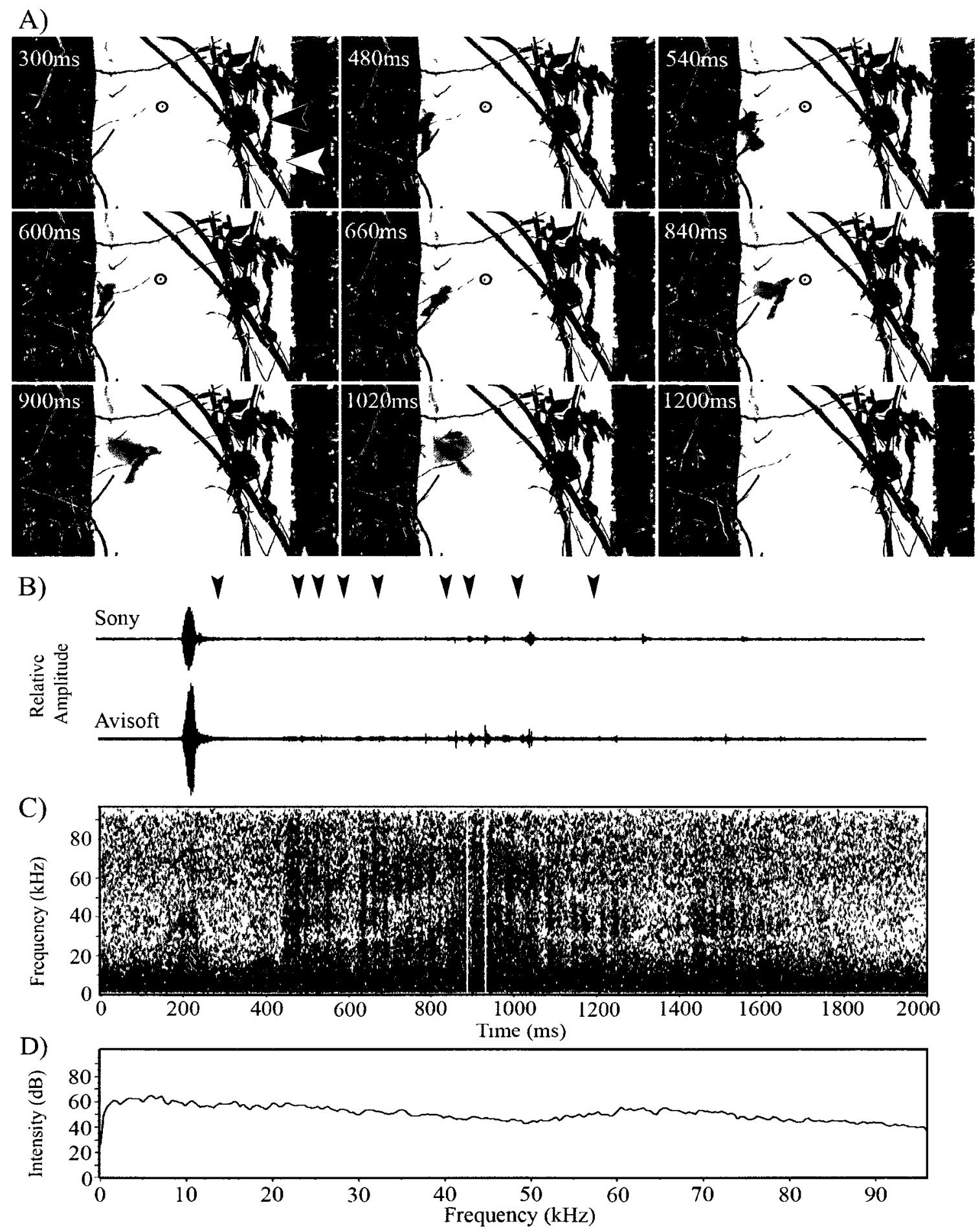

Figure 2.7. Eastern phoebe (Sayornis phoebe) performing a hover attack on a tethered moth (moth is circled in black). A) Select video frames of the attack at QUBS. Time values correspond to the black arrows on the waveforms in (B). Phoebe remains in the vicinity of the moth for more than $900 \mathrm{~ms}$. Moth is captured by phoebe in $7^{\text {th }}$ video frame (at $900 \mathrm{~ms}$ ). White arrow in first frame indicates position of Sony ECM-MS907 microphone. Black arrow indicates position of Avisoft CM16 microphone. B) Waveforms of the audio files recorded during the phoebe's attack. Black arrows indicate the video frames in (A). Unknown bird call is present at $200 \mathrm{~ms}$. C) Spectrogram of the audio file recorded using the Avisoft microphone. D) Power spectrum of a single flight cycle (outlined with white lines in (C)). 


\section{A)}
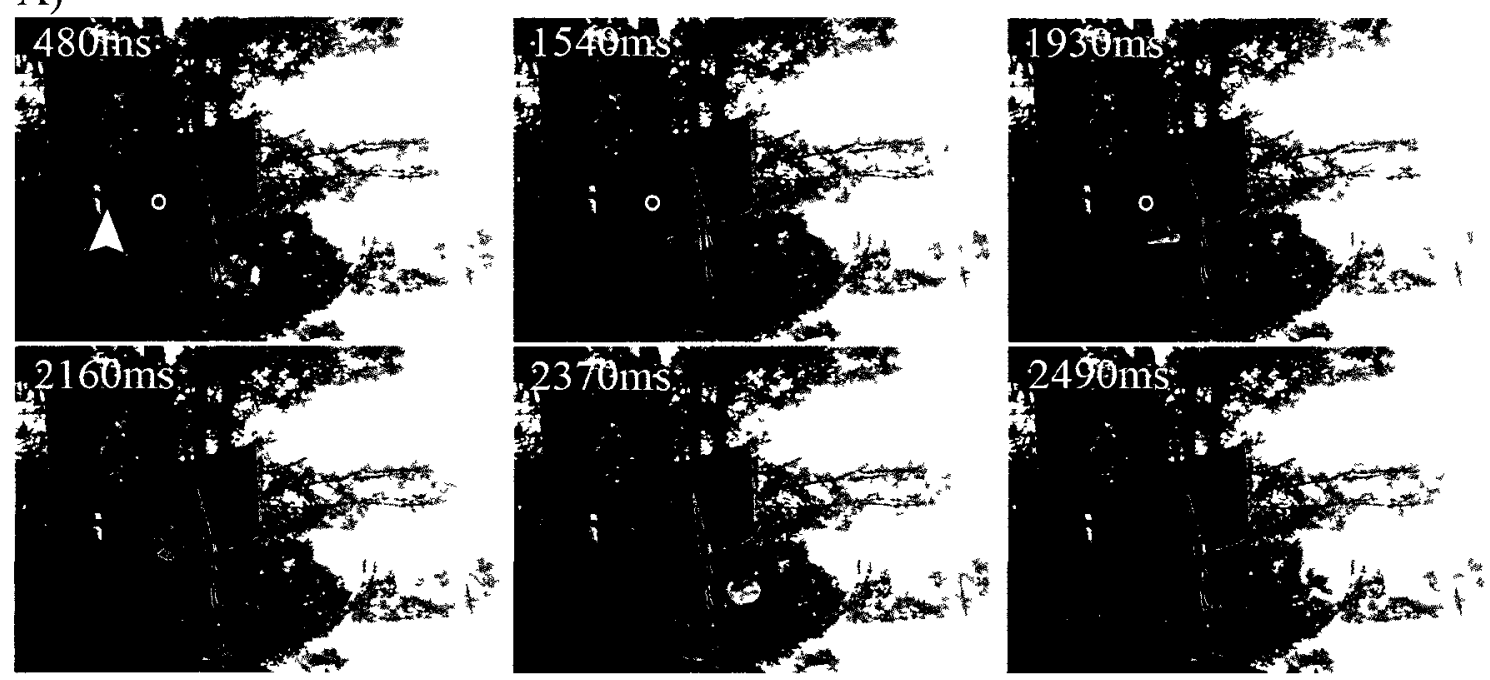

B)
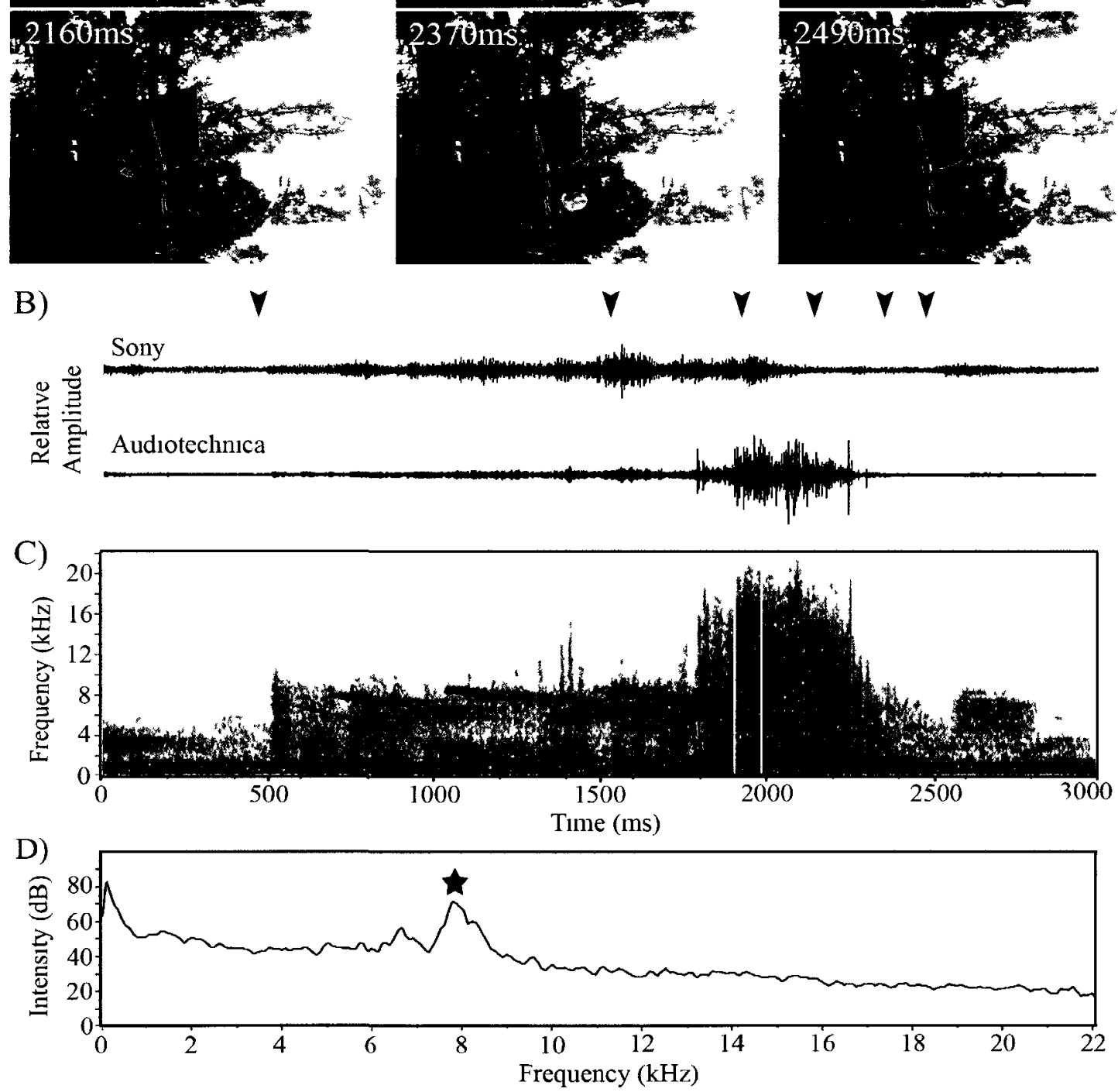

Figure 2.8. Eastern phoebe (Sayornis phoebe) performing an aerial glean attack on a tethered moth, restıng on foliage A) Select video frames of the attack at QUBS. Time values correspond to the black arrows on the waveforms in (B). Phoebe remains in the vicinity of the moth for more than $2000 \mathrm{~ms}$. Moth is captured by phoebe in $4^{\text {th }}$ video frame (at $2160 \mathrm{~ms}$ ) White arrow in first frame indicates position of Audiotechnica ATM10a microphone. Sony ECM-MS907 microphone cannot be seen behind tree. Waveforms of the audio files recorded during the phoebe's attack (top waveform is from video camera Sony ECM-MS907 microphone and bottom is waveform from Audio-technica ATM10a microphone). B) Waveforms of the audio files recorded durıng the phoebe's attack Black arrows indicate the video frames in (A) C) Spectrogram of the audio file recorded using an Audio-technica microphone. D) Power spectrum of a single flight cycle (outlined with white lines in (C)). Black star at $8 \mathrm{kHz}$ indicates peak that is an artıfact due to a vocalization of an unknown bird. 
A)
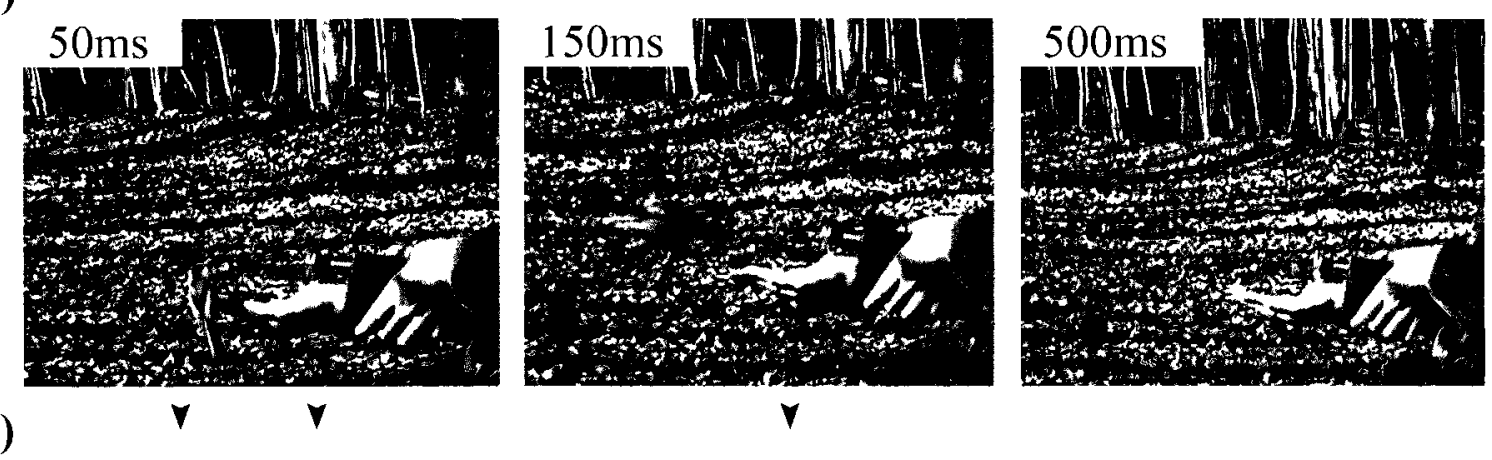

B)
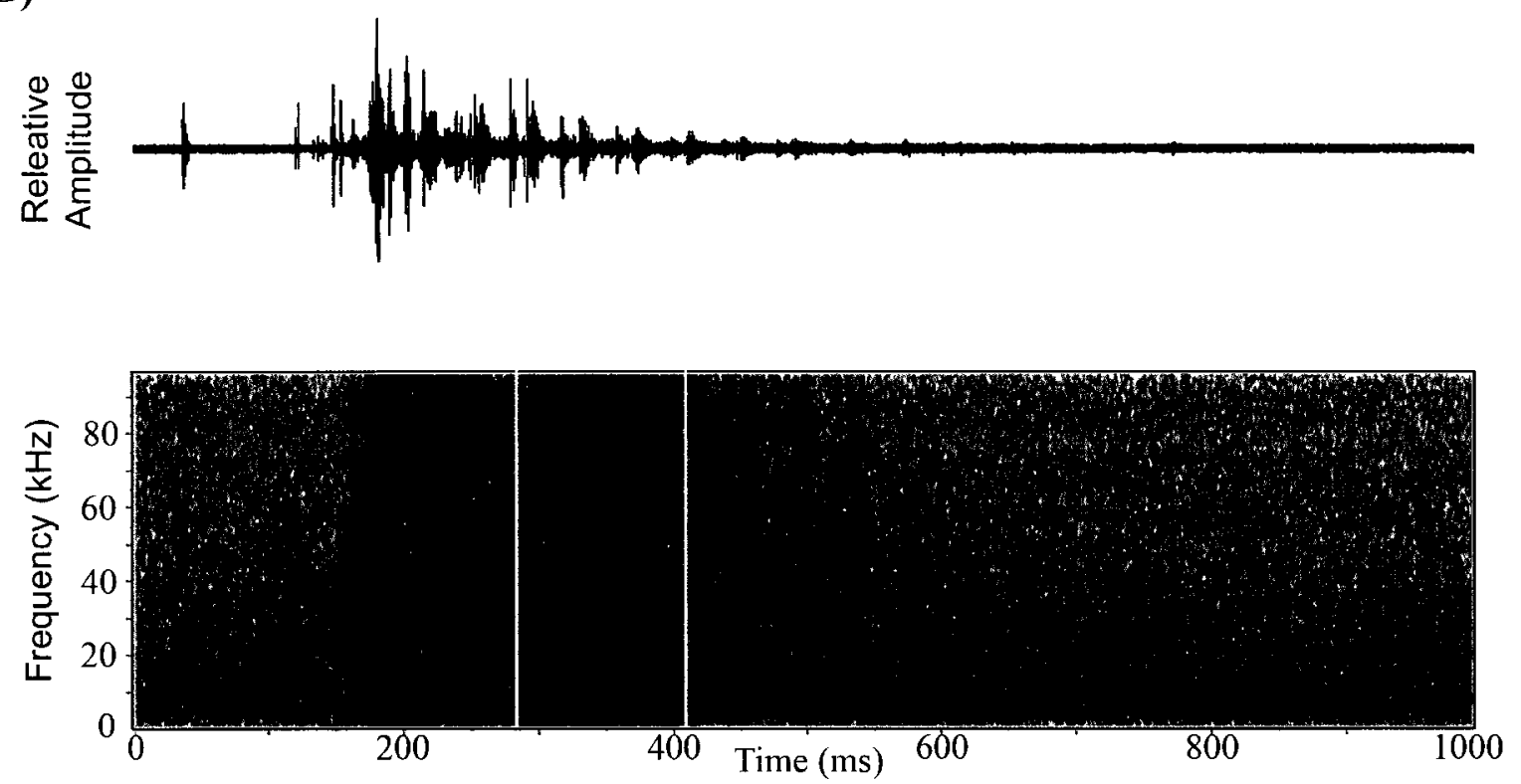

C)
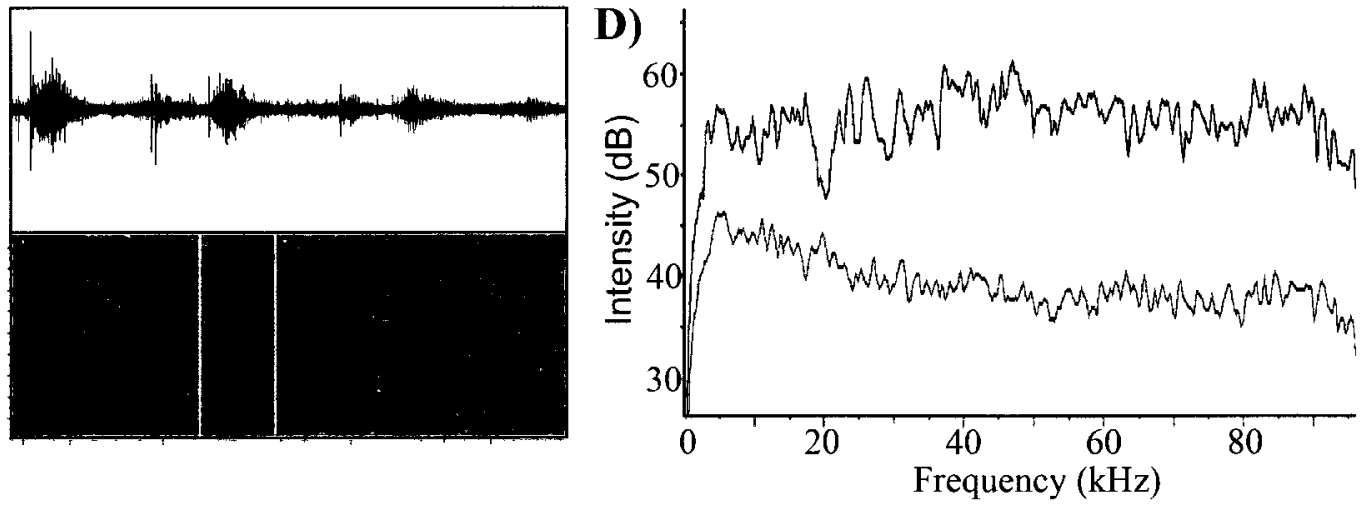

Figure 2.9. Black-capped chickadee (Poecile atricapillus) taking off from my hand full of seed. A) Select video frames of the departure at the Mer Bleue Bog. Time values correspond to the black arrows on the waveform in (B). B) Waveform and spectrogram of the recorded departure made using an Avisoft CM16 microphone. C) Close-up of waveform and spectrogram of four flight cycles taken from (B) (outlined with lines). D) Power spectrum of a single down-stroke (outlined with white lines in (C)) is shown in black trace. The power spectrum of a section of ambient background noise in the recording environment is shown in grey trace. 

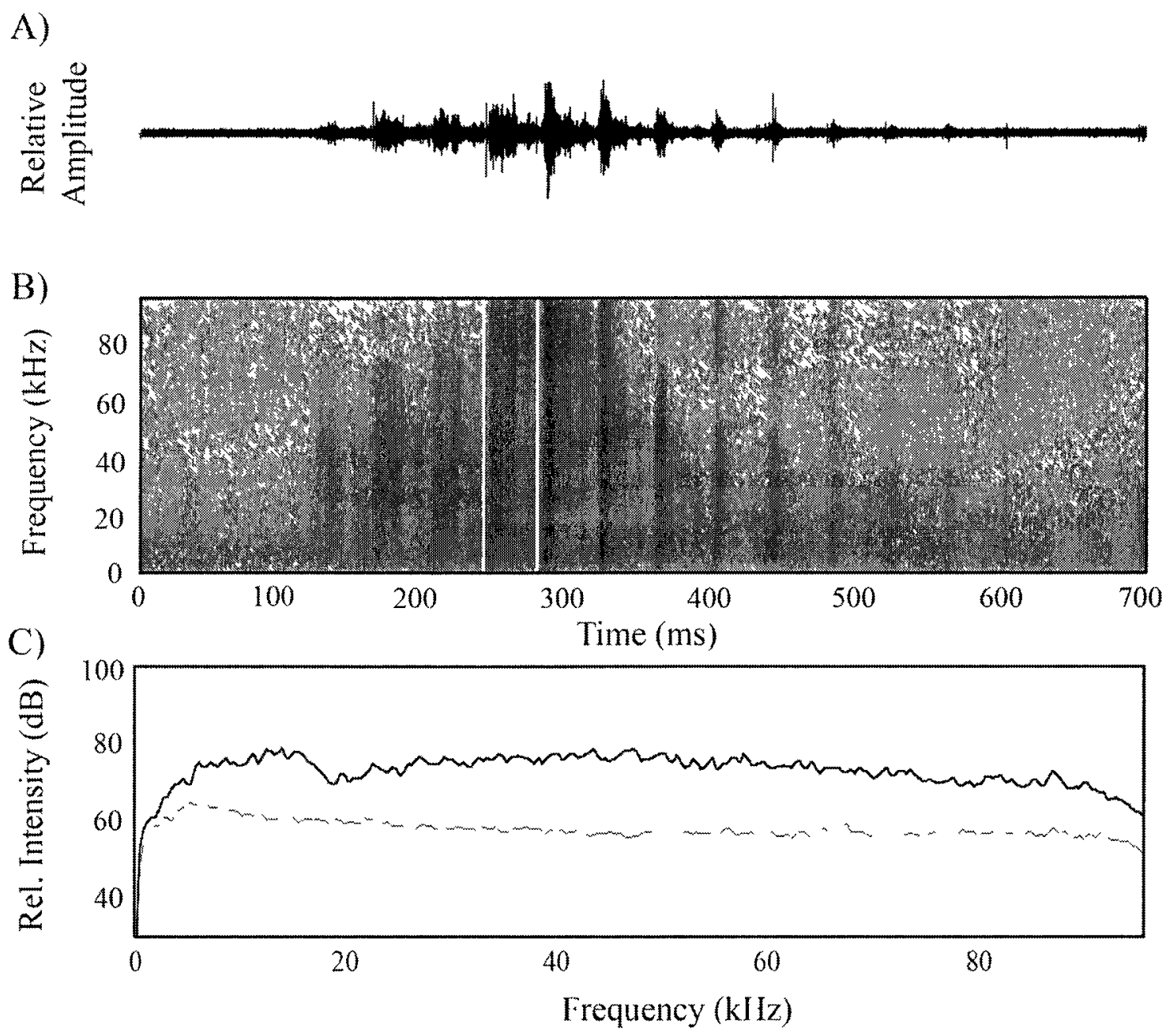

Figure 2.10. Black-capped chickadee (Poecile atricapillus) approaching and taking off from my hand full of seed. A) Waveform of the recorded approach and take-off flight made using an Avisoft CM16 microphone B) Spectrogram of the approach and take-off flight C) Power spectrum of a single flight cycle of a chickadee as it approaches my hand (from flight cycle outlined with white lines in (B)) is shown in black trace. The power spectrum of a section of ambient background noise in the recording environment is shown in grey trace. 


\subsubsection{Temporal Analysis}

Sounds produced by attacking birds were analyzed for the following two temporal measurements: (1) the relative duration (s) of the sound event (above background noise) during the attack; (2) the wing-beat frequency $(\mathrm{Hz})$ (i.e. number of wing-beat cycles per second) of each foraging technique was measured as the bird approached the tethered moth (phoebe) or the feeding station (chickadee).

\subsubsection{Relative Duration}

The relative duration of the sounds potentially available to eared insect prey during an avian attack were estimated using audio recordings of the event. Only recordings made with the Earthworks microphone were used for relative duration measurements. Recordings with the Earthworks microphone had the greatest sample size and covered the range of frequencies in which the phoebe's peak frequency was found. Relative duration was therefore only measured for direct attacks, hover attacks, and for birds that used both attack techniques (The aerial gleaning event $(n=1)$ and swift-like attack event $(n=1)$ were recorded on separate microphones). The average relative duration, based on phoebe direct and hover attacks, was $0.94 \pm 0.18 \mathrm{~s}(\mathrm{n}=11)$, and $1.66 \pm$ $0.33 \mathrm{~s}(\mathrm{n}=10)$, respectively (Table 2.1$)$. The relative durations of direct and hover attack techniques were found to be significantly different from one another (Independent t-test, $\mathrm{t}=6.19, \mathrm{p}<0.001$ ). Birds that used both direct and hover attack techniques (due to failure of first attack attempt) had a relative duration of $2.60 \mathrm{~s}(\mathrm{n}=2)$. 


\subsubsection{Wing-Beat Frequency}

The average wing-beat frequency (WBF) (i.e. cycles per second) was measured during the approach phase of each attack technique. Birds utilizing the direct attack technique had an average WBF of $18.4 \pm 1.7 \mathrm{~Hz}(\mathrm{n}=11)$. Birds utilizing the hover attack technique had a WBF of $18.6 \pm 2.3 \mathrm{~Hz}(\mathrm{n}=10)$. The WBF of the single gleaning attack was $12.0 \mathrm{~Hz}(\mathrm{n}=1)$. The WBF for the swallow-like attack could not be measured due to the bird being in a fast downward glide (i.e. wings not flapping) $(n=1)$. The WBF of chickadees during approach flight was $20.7 \pm 2.5 \mathrm{~Hz}(n=11)$. The WBF of both bird's attack techniques are summarized in Table 2.1. A One-way Analysis Of Variance (ANOVA) of chickadee and phoebe direct and hovering attack techniques showed a significant difference in their $\operatorname{WBF}(\mathrm{F}(2,33)=4.49, \mathrm{p}=0.019)$. A post-hoc Tukey HSD analysis showed that chickadee WBF was significantly greater than both phoebe direct $(\mathrm{M}=18.4,95 \% \mathrm{CI}[17.45,19.35], \mathrm{p}=0.027)$ and hover $(\mathrm{M}=18.4,95 \%$ CI $[16.78,20.02]$ $\mathrm{p}=0.047$ ) attack techniques. There was no difference in WBF between direct and hover attack techniques, $\mathrm{p}>0.05$.

Table 2.1. Temporal characteristics of eastern phoebe (Sayornis phoebe) $(\mathrm{N}=8)$ and black-capped chickadee (Poecile atricapillus) $(\mathrm{N}=11)$ foraging techniques, with standard deviation.

\begin{tabular}{|c|c|c|c|c|}
\hline & & Rel. Duration (s) & Wing-Beat Freq. (Hz) & Recording Microphone \\
\hline Phoebe & Direct $(\mathbf{n = 1 1})$ & $0.94 \pm 0.2$ & $18.4 \pm 1.7$ & Earthworks \\
\hline & Hover $(\mathbf{n = 1 0})$ & $1.66 \pm 0.3$ & $18.6 \pm 2.3$ & Earthworks \\
\cline { 2 - 5 } & Swift-like (n=1) & $/$ & $/$ & Avisoft \\
\cline { 2 - 5 } & Glean (n=1) & $/$ & $12 \pm 0$ & Audio-technica \\
\hline Chickadee & Approach (n=11) & $/$ & $20.7 \pm 2.5$ & Avisoft \\
\hline
\end{tabular}




\subsubsection{Spectral Analysis}

Spectral analysis of phoebe flight sounds revealed that sounds were broadband with peak energy found at $863.2 \pm 101.5 \mathrm{~Hz}$ for direct attacks $(n=5)$ and $905.6 \pm 81.7 \mathrm{~Hz}$ for hovering attacks $(\mathrm{n}=5)$ (Earthworks QTC40 microphone) when measured $50 \mathrm{~cm}$ from the bird. The majority of energy was found in the lower sonic range (Figure 2.1); however, flight sounds are broadband to $86 \mathrm{kHz}$ at $-20 \mathrm{~dB}(\mathrm{~N}=2, \mathrm{n}=10$, Avisoft CM16 microphone) (Figures $2.3-2.5$ ). The bandwidth of the direct attacks at $-3 \mathrm{~dB}$ and $-6 \mathrm{~dB}$ from the peak was $436.2 \pm 89.2 \mathrm{~Hz}$ and $697.0 \pm 136.1 \mathrm{~Hz}$, respectively $(\mathrm{n}=5$, Earthworks QTC40 microphone). The bandwidth of the hovering attacks at $-3 \mathrm{~dB}$ and $-6 \mathrm{~dB}$ from the peak was $636.6 \pm 332.5 \mathrm{~Hz}$ and $1148.2 \pm 649.6 \mathrm{~Hz}$, respectively $(\mathrm{n}=5$, Earthworks QTC40 microphone). The peak frequencies of direct and hovering attack techniques were not found to be significantly different (Independent $t$-test, $\mathrm{df}=8, \mathrm{t}=-0.733, \mathrm{p}>0.05$ ).

Spectral analysis of chickadee flight revealed that sounds were broadband with peak energy found at $14.5 \pm 4.8 \mathrm{kHz}$ during approach flight $(\mathrm{N}=5, \mathrm{n}=5$, Avisoft $\mathrm{CM} 16$ microphone) when measured $15 \mathrm{~cm}$ from the bird. Chickadee flight sounds are broadband to $91 \mathrm{kHz}$ at $-20 \mathrm{~dB}(\mathrm{n}=5$, Avisoft CM16 microphone) (Figure 2.9). The bandwidth of the approach flight at $-3 \mathrm{~dB}$ and $-6 \mathrm{~dB}$ from the peak was $2.8 \pm 1.7 \mathrm{kHz}$ and $7.2 \pm 4.2 \mathrm{kHz}$, respectively ( $n=5$, Avisoft CM16 microphone).

Table 2.2. Spectral characteristics of eastern phoebe (Sayornis phoebe) $(\mathrm{N}=4)$ and blackcapped chickadee (Poecile atricapillus) $(\mathrm{N}=5)$ foraging techniques with standard deviation.

\begin{tabular}{|c|c|c|c|c|c|}
\hline \multicolumn{2}{|c|}{} & Peak Freq. (Hz) & $\begin{array}{c}\text { Bandwidth @ - 3 dB } \\
(\mathbf{H z})\end{array}$ & $\begin{array}{c}\text { Bandwidth @ - 6 dB } \\
(\mathbf{H z})\end{array}$ & $\begin{array}{c}\text { Bandwidth @ - 20 } \\
\text { dB (kHz) }\end{array}$ \\
\hline Phoebe & Direct (n=5) & $863.2 \pm 101.5$ & $436.2 \pm 89.2$ & $697.0 \pm 136.1$ & $88.0 \pm 5.2$ \\
\hline & Hover (n=5) & $905.6 \pm 81.7$ & $636.6 \pm 332.5$ & $1148.2 \pm 649.6$ & $84.6 \pm 7.3$ \\
\hline Chickadee & Approach (n=5) & $14500 \pm 4800$ & $2770.0 \pm 1651.7$ & $7202.0 \pm 4185.7$ & $90.8 \pm 9.5$ \\
\hline
\end{tabular}




\subsubsection{Sound Level Analysis}

Phoebe flight sound levels were indirectly measured and found to be $72.9 \mathrm{~dB}$ SPL at $30 \mathrm{~cm}(\mathrm{~N}=4, \mathrm{n}=5$, Earthworks QTC40). At peak frequency, sounds were $14.3 \mathrm{~dB} \mathrm{SPL}$ $(n=5)$ above ambient background noise levels. The intensity of chickadee flight sound was found to be $84.1 \mathrm{~dB}$ SPL at $15 \mathrm{~cm}(\mathrm{~N}=5, \mathrm{n}=5)$, using a hand-held sound level meter. At peak frequency, sounds were $21.8 \mathrm{~dB}$ SPL $(n=5)$ above ambient background noise levels. 


\subsection{Discussion}

In this study I investigated bird flight in order to determine if birds produce sound while foraging and to determine the characteristics of this sound cue. Using eastern phoebes (Sayornis phoebe) and black-capped chickadees (Poecile atricapillus), this study presents the first investigation into the flight sounds produced by insectivorous birds while foraging. Analysis of their temporal, spectral, and intensity characteristics was performed in addition to describing the characteristics of the bird's foraging tactics. Bird flight generates sounds which are pulsed in nature due to repetitive beating of the wings. The unit of sound production in bird flight is the flight cycle (one down-stroke followed by one up-stroke). The flight sounds produced by birds while foraging were found to contain peak energy below $1 \mathrm{kHz}$ and approximately $15 \mathrm{kHz}$ and were broadband (86 $\mathrm{kHz}$ and $91 \mathrm{kHz}$ at $-20 \mathrm{~dB}$ ) for phoebes and chickadees, respectively. I found bird flight produces sounds audible to the human ear from over 3 meters away with phoebe flight sound intensity measuring $72.9 \mathrm{~dB}$ SPL at a distance of $30 \mathrm{~cm}$ and chickadee flight sound intensity measuring $84.1 \mathrm{~dB} \mathrm{SPL}$ at a distance of $15 \mathrm{~cm}$. At peak frequency, flight sounds were approximately $15 \mathrm{~dB}$ SPL or more above background noise levels. These findings are significant in that they provide the first empirical evidence of bird flight producing sound at levels potentially detectable by eared insect prey. Based on these results it is now possible to determine which insects may be capable of detecting bird flight sound cues and this will be addressed directly in chapter 3 . In this discussion I will compare and contrast the foraging techniques used by insectivorous birds and explain how these findings may be important to eared insect prey. 


\subsubsection{Variation in the Foraging Techniques of the Eastern Phoebe}

Eastern phoebes use a variety of attack techniques when foraging for flying insects. Direct attacks and hovering attacks were the two most common foraging techniques of the four techniques I observed. The single aerial gleaning event only occurred after the bird had watched the moth flutter and land on the foliage. Flycatchers of the genus Sayornis use gleaning capture methods less than 25 percent of the time when foraging (Verbeek, 1975). The "swift-like" attack was also only witnessed once and this form of aerial hawking is rare among tyrant flycatchers (Tyrannidae) (Fitzpatrick, 1980); however, flycatchers of the genus Sayornis are known for their wide diversity of foraging techniques (Verbeek, 1975). Together, direct and hovering attack techniques were used 94 percent of the time, and for this reason I will focus this discussion on them.

The only difference between phoebe direct and hover attack techniques was in the temporal domain. The hover attack technique was approximately $800 \mathrm{~ms}$ longer than the direct attack technique and this additional portion of time was spent hovering. The bird would approach the tethered prey item and once it was approximately $30 \mathrm{~cm}$ away from the insect, the bird halted its forward flight motion and began hovering flight before darting forward to capture they prey. The addition of the hovering component of the attack may be used to increase the amount of time the bird has to assess the palatability of the prey item, as well as judge the movement of the prey before attempting capture. From a distance the phoebe may be able to determine that there is a flying insect in close proximity and begin to pursue it in flight; however, the bird may require a closer visual inspection to spot warning colorations and verify that the prey is indeed palatable. The 
added $800 \mathrm{~ms}$ of time available to the bird when performing a hover attack may be used in deciding to attack the insect or not.

During the flight recording sessions I witnessed the majority of phoebes initiating hover attacks when first presented with a novel food source before they switched to direct attacks. The phoebes may make use of the hovering attack to investigate the prey and once they determine the prey is palatable, they switch to direct attacks in order to save time and energy. Another possible use of a hovering attack over a direct attack is to allow more time for the phoebe to judge the movement of the flying insect prey in order to capture it. If the insect prey is flying erratically, or is very large, or possesses a defense structure such as a stinger, the phoebe may hover for a moment to judge how and where it will intercept and grasp the prey. For example, during one of my recording sessions I had presented the pair of phoebes with a variety of moths with wingspans smaller than $3 \mathrm{~cm}$. The phoebes initiated hovering attacks before switching to direct attacks, as described above. I then presented to the birds a moth with a much larger wingspan; more than 10 $\mathrm{cm}$. The phoebes reacted by reverting to hovering attacks and sometimes ending the hover without attempting to capture the prey. The prey was likely too large and the bird used a hovering attack to inspect the prey before choosing not to attempt capture.

\subsubsection{Variation of Eastern Phoebe Flight Sound Cues}

The differences in the attack techniques used to capture insects may be important for the eared insects which are eaten by birds. If flying insect prey are capable of detecting the flight sounds of approaching birds then the use of direct attacks over hovering attacks could increase the success rate of the bird. A hovering attack would 
provide insect prey with additional time to detect and evade an avian predator. Therefore, phoebes may compromise between a safe and slow hover attack and a risky and fast direct attack. Lastly, the single "swift-like" attack deserves mention here. If insect prey are indeed capable of detecting the sounds of an approaching phoebe, the high velocity of this rare attack technique may prove to be the most efficient of them all. This attack technique was very short in duration and would provide insect prey with little time to detect and evade an attacking phoebe. Future studies should investigate phoebe attack technique efficiency on wild prey items in order to determine which techniques produce the greatest success rate.

\subsubsection{Foraging Techniques of the Black-Capped Chickadee}

The foraging technique I examined in black-capped chickadees differs from the foraging of aerial insectivores. The foraging technique used by chickadees involved flying up to and landing on my hand before taking-off. This technique was used to obtain seed; however, it is very similar to the method used by a chickadee to glean insects off the forest floor, bark, or foliage (Robinson and Holmes, 1982; Remsen and Robinson, 1990). Fitzpatrick (1980) described this exact foraging technique (in flycatchers) and named it a "landing and gleaning" event. The chickadee flight sounds I have characterized should resemble the acoustic cues sensed by insects resting on the substrate when being attacked by a chickadee. Therefore, chickadee flight sound spectral and intensity characteristics are relevant to perched insects. Chickadee flight sound cues may be used for playback studies to non-flying eared insects, in order to determine if they are capable of detecting the sounds of avian predators. Due to the similarities in spectral, 
temporal, and intensity characteristics between chickadees and phoebes, further discussion of chickadee flight sound as a predatory cue will be addressed below.

\subsubsection{Avian Flight Sound Cues}

Eastern phoebe and black-capped chickadees produce similar sounds during flight in that they are both pulsed, broadband acoustic cues produced above background noise levels. These characteristics may be important to the eared insects which are preyed upon by birds. The discovery of bird flight producing a pulsed sound composed of repetitive elements (i.e. flight cycles) is of possible significance to eared insect prey. Many of the insects that show an acoustic startle response to ultrasound only do so if the sound stimulus is pulsed (Roeder, 1964; Yager and May, 1990; Fullard et al., 2008). Roeder (1964) found moths to physiologically respond greatest to ultrasound when broadcast in short pulses, whereas continuous ultrasonic tones resulted in auditory cell responses adapting quickly (i.e. decreasing in rate and number of spikes). In support of Roeder's findings, Fullard et al. (2008) found the continuous ultrasonic calls of a cicada were incapable of eliciting an escape response in a species of noctuid moth, which was known to avoid bats with escape maneuvers. The pulsed sounds produced by an approaching insectivorous bird fulfill one of the requirements in eliciting an acoustic startle response in insects.

The second requirement of the adequate stimulus is frequency composition. For an insect to acoustically detect an approaching predator it must have a hearing structure that is sensitive to the frequencies emitted by that predator. The acoustic cues produced by both chickadees and phoebes during flight contain the majority of energy in the sonic 
range and are broadband $(\sim 95 \mathrm{kHz})$ at approximately -20 to $-25 \mathrm{~dB}$, respectively. Due to the wide range of frequencies produced by bird flight it is possible that many eared insect prey species are capable of detecting this predatory cue. The large ultrasonic component of bird flight is of significance to insects that are known to demonstrate an escape response to bat echolocation. Insects such as moths, mantises and lacewings all require ultrasonic stimuli to elicit escape maneuvers (Roeder, 1964; Yager and May, 1990; Fullard et al., 2008). The low frequency portion of bird flight, in particular the peak frequency of phoebe flight at approximately $1 \mathrm{kHz}$, is an interesting result, as it may also have implications for butterfly hearing. Currently, the ears of some nymphalid butterflies have no known function attributed to them, and since birds impose a heavy selection pressure on butterflies it is possible that hearing in this group functions in the detection of avian predators.

For insects to detect predatory cues or signals in general, the intensity of the sound must be produced above background noise levels found in the environment. Chickadee and phoebe flight sound cues were found to be approximately 22 and $14 \mathrm{~dB}$ SPL above natural ambient background noise levels at peak frequency, when measured at distances of 15 and $30 \mathrm{~cm}$, respectively. This finding provides evidence that bird flight sound cues may be produced at intensities that are biologically relevant to eared insect prey. If insects are found to be capable of detecting bird flight sound cues, further study should investigate the distances at which insect prey are capable of detecting avian predators and determine if insects have sufficient time to elicit an appropriate escape response. 


\subsubsection{Comparison of Avian Flight Sound Cues and Signals}

The passive flight sounds that I have characterized differ from the active flight sounds produced by the courtship signals of manakins and hummingbirds and the alarm signals of pigeons and doves (Bostwick and Prum, 2003; Coleman, 2008; Clark, 2008; Hingee and Magrath, 2009). The bird flight sounds described in this chapter are passive flight cues as they are not intentionally produced nor do they have an intended receiver (two very important criteria for a sound to be considered a true signal (Endler, 1993; Bradbury and Vehrencamp, 1998)). Instead, they are a byproduct of locomotion and a result of turbulent airflow over the wings (Bachmann et al., 2007). They lack distinct spectral structure and are highly variable, as can be seen from the standard deviations of peak frequency and bandwidth results. In comparison, active flight signals produced in manakins, hummingbirds, and pigeons contained a greater degree of acoustic structure (i.e. distinct frequency characteristics and modulation of temporal elements) (Table 2.3). The non-vocal active signals produced by these birds are a result of specialized soundproducing feather modifications and complex kinematic movements of these structures (Bostwick and Prum, 2003; Bostwick et al., 2010) (Table 2.3). The most complex, are the signals produced by manakins (Pipridae). Collectively, manakins are known to produce 11 distinct feather sonations and is the only family known to produce sounds while perched. Pigeons and hummingbird flight sounds, as well as many manakin flight sounds, are intimately linked to actual flight (Coleman, 2008; Clark, 2008; Hingee and Magrath, 2009). Although there are a variety of kinematic mechanisms used for the production of flight sounds, the sounds themselves are characterized as short, broad-frequency pulses (Prum, 1998; Bostwick and Prum, 2003; Coleman, 2008; Clark, 2008; Hingee and 
Magrath, 2009). The only exception is the flight sound produced by the anna's hummingbird, which produces a broad-frequency sound of short duration; however, it occurs only once (i.e. not a repetitive pulse) at the final stages of its courtship dive display (Clark and Feo, 2008). It has been proposed that flight signals, which function in courtship display, have arisen through sexual selection (Prum, 1998; Clark, 2008). Manakins and hummingbirds employ courtship displays to attract potential mates. During the courtship displays, males perform a variety of acrobatic movements that in addition to producing passive flight sounds may have produced incidental flight sounds. Female preference for males that produced novel flight sounds may have led to further elaboration of flight sounds and ultimately to the evolution of complex flight sound signals (Prum, 1998; Clark, 2008).

In summary, passive flight sound cues are different than active flight sound signals in that they are not intentionally produced, they are not composed of complex kinematic movements (i.e. not different than regular flight movements), and their acoustic structure is more variable. However, both passive and active flight sounds are characterized as short duration, broad-frequency pulses. The passive flight sounds characterized in this chapter are therefore not only important as a potential sound cue to insect prey but also of importance in understanding the evolution of active flight sound signals. This study has shown that the overall temporal and spectral characteristics of passive and active flight sounds are different but also share similarities. Interestingly, Bostwick's (2006) description of one species of manakin's flight sounds, the "whirr", shares many similarities to the passive flight sounds described in this chapter. The "whirr" sound was produced at all times the bird was in flight (i.e. unintentionally 
produced), its pulse rate matched the wing-beat frequency of the bird, and spectrally, it was broadband with no discernable peak. The proposed role of this "signal" was said to function in territorial displays; however, it is possible that this flight sound is not an active signal, but instead a passive flight sound cue. The passive sounds produced by the wings of the territory holder may simply be enough to alert another male of its presence and that the territory is occupied.

\begin{tabular}{|c|c|c|c|c|c|c|c|c|c|}
\hline Famıly & $\begin{array}{l}\text { Sonation } \\
\text { Type }\end{array}$ & $\begin{array}{c}\text { Peak } \\
\text { Frequency } \\
(\mathbf{k H z})\end{array}$ & Pulsed & Structure & $\begin{array}{l}\text { Kınematic } \\
\text { Mechanism }\end{array}$ & $\begin{array}{c}\text { Proposed } \\
\text { Acoustic } \\
\text { Mechanism } \\
\end{array}$ & Function & $\begin{array}{l}\text { Associated } \\
\text { with Flight }\end{array}$ & Reference \\
\hline \multicolumn{10}{|l|}{ Pipridae } \\
\hline \multirow[t]{11}{*}{ (41 species) } & Snap & $46 \pm 09$ & Yes & Wings & Wing-clap & Percussion & $\begin{array}{l}\text { Courtshıp } \\
\text { Display }\end{array}$ & Yes & $1,2,3$ \\
\hline & Roll-snap & $39 \pm 07$ & Yes & Wings & Wing-clap & Percussion & Territorial & No & $1,2,3$ \\
\hline & Click & $48 \pm 13$ & Yes & Wings & Wing-flıck & Wing-flick & $\begin{array}{l}\text { Courtshıp } \\
\text { Display }\end{array}$ & No & $1,2,3$ \\
\hline & Rub-snap & $45 \pm 12$ & Yes & Wings & Wing rubs taıl & Friction & $\begin{array}{l}\text { Courtship } \\
\text { Display }\end{array}$ & No & $1,2,3$ \\
\hline & Clap & $45 \pm 13$ & Yes & Wings & $\begin{array}{l}\text { Wing-flick + Wing } \\
\text { hits body }\end{array}$ & $\begin{array}{c}\text { Wing-flick + } \\
\text { Percussion }\end{array}$ & $\begin{array}{l}\text { Courtship } \\
\text { Display }\end{array}$ & No & $1,2,3$ \\
\hline & Snort & $23 \pm 04$ & Yes & Wings & Wing-flıck & Wing-flıck & $\begin{array}{l}\text { Courtshıp } \\
\text { Display }\end{array}$ & No & $1,2,3$ \\
\hline & Rattle & $24 \pm 03$ & Yes & Wings & Unknown & Unknown & Territorial & Yes & $1,2,3$ \\
\hline & whirr & B B & Yes & Wings & Normal flight & Resonance & Territorial & Yes & $1,2,3$ \\
\hline & Fanning & B B & Yes & Wings & Wing-flick & WIng-flıck & Territorial & No & $1,2,3$ \\
\hline & Humm & $018 \pm 05$ & Yes & Wings & Take-off flıght & Resonance & $\begin{array}{l}\text { Courtship } \\
\text { Display }\end{array}$ & Yes & $1,2,3$ \\
\hline & Swoop & $066 \pm 06$ & No & Wings & Diving flight & Resonance & $\begin{array}{l}\text { Courtship } \\
\text { Display }\end{array}$ & Yes & $1,2,3$ \\
\hline \multicolumn{10}{|l|}{ Trochilidae } \\
\hline \multirow[t]{2}{*}{ (6 species) } & Whirr & $086 \pm 05$ & Yes & Wings & Diving flight & Resonance & $\begin{array}{l}\text { Courthip } \\
\text { Display }\end{array}$ & Yes & 4,6 \\
\hline & Chirp & $41 \pm 02$ & No & Taıl & Diving flight & Resonance & Courtship & Yes & 5,6 \\
\hline \multicolumn{10}{|l|}{ Columbidae } \\
\hline (2 species) & Whistle & $13 \pm 01$ & Yes & Wings & Take-off flıght & Resonance & Alarm & Yes & 7,8 \\
\hline
\end{tabular}

Table 2.3. Summary of bird flight sound characteristics produced by species with modified feather structures. Family: The number of species known to produce flight sounds in a family is given in brackets. Peak Frequency: B.B. describes a sound that was broadband and showed no distinct peak. Structure: The structure responsible for sound production is listed. Kinematic mechanism: The physical action employed by the bird that has been proposed responsible for sound production. Wing-clap - Feathers of wing or modified rachis are hit together to produce sound; Wing-flick - Similar sound to wingclap; however, only one wing is used to produce sound. Wing is rapidly swung then stopped and this process results in sound production. References: 1-Prum, 1998; 2Bostwick, 2006; 3-Bostwick and Prum, 2003; 4-Clark, 2008; 5-Clark and Feo, 2008; 6Hunter and Picman, 2005; 7-Coleman, 2008; 8-Hingee and Magrath, 2009. 
This investigation into bird flight sounds has examined the flight sounds of only two insectivorous bird species, both of which produce flight sounds while foraging for insects. Further study of bird flight sounds in more species of insectivorous birds may provide examples of birds that have adapted wing and feather modifications for the function of producing silent flight, which may result in a greater success rate of capturing eared insect prey for the bird. The flight sounds of birds with unmodified feathers, as described in this chapter, will be played back to eared insect neural preparations in order to determine if these sounds are indeed a biologically relevant predatory cue. 


\section{Chapter 3}

\section{Are Insects Capable of Detecting Avian Flight Sound Cues?}

\subsection{Introduction}

The purpose of recording and characterizing bird flight sounds was to determine if tympanate insects may be capable of detecting this previously uncharacterized predatory sound cue. In the previous chapter it was demonstrated that insectivorous birds produce sounds audible to humans and potentially insect prey while attacking insects in flight. Bird flight sound cues had peak energies of approximately $1 \mathrm{kHz}$ with a bandwidth of 86 $\mathrm{kHz}$ at $-20 \mathrm{~dB}$ (phoebe) and $15 \mathrm{kHz}$ with a bandwidth of $91 \mathrm{kHz}$ at $-20 \mathrm{~dB}$ (chickadee). The sound cue is composed of repetitive elements (i.e. wing-beats, $\sim 19 \mathrm{~Hz}$ ) and has a natural intensity of $72.9 \mathrm{~dB}$ SPL at $30 \mathrm{~cm}$ (phoebe) and $84.1 \mathrm{~dB}$ SPL at $15 \mathrm{~cm}$ (chickadee). These findings present a previously uncharacterized sound source, passively produced by avian predators while foraging. The sound is passive in the sense that the avian predator does not actively produce the sound, as is the case with echolocating bats (Surlykke and Kalko, 2008) or cetaceans (Dudok van Heel, 1962), but instead, it is a result of the animal's movement through the air. Based on the characteristics of the bird flight sound cue, I predict that many eared insects would be capable of hearing some or all the frequency components of bird flight sound and use these cues to avoid capture. The objective of this chapter is to determine if eared insects are capable of detecting bird flight sound cues. In this chapter I will review hearing in insects that are depredated upon by birds. I will also review the anti-predator mechanisms employed by insect prey and describe what is known of insects detecting the passive cues provided by predators. 


\subsubsection{Insect Ears: Single or Multi-F unctional}

There are many insects that possess hearing organs, and in many cases hearing is thought to be dedicated to performing specific tasks (Fullard, 1988; Hoy et al., 1998; Yager, 1999,). For example, crickets and katydids use hearing primarily for conspecific communication and mate location, moths and mantids use hearing primarily for predator detection, and some species of parasitoid fly use hearing primarily for eavesdropping on the calls of their prey (Waters, 2003; Yack, 2004; Manley et al., 2007). In order to perceive sounds from a specific source, whether it is a mate, predator, or prey, the receiver may possess a narrowly tuned hearing structure that is most sensitive to the frequencies which dominate the emitted sound (Krebs and Dawkins, 1984). This allows for the receiver to detect the important information in the signal even when in an environment that may be flooded with the sounds of other calling insects, mammals, and birds. A prime example of this is the courtship calling of the male cricket, Gryllus campestris, to potential female mates. Male crickets produce a chirping courtship call with a carrier frequency of $5 \mathrm{kHz}$ (Kleindienst et al., 1981). In turn, female tympanal organs are most sensitive to frequencies around $5 \mathrm{kHz}$. This allows females to detect and home in on calling males, even in a 'noisy' nocturnal environment. In nocturnal insects, some species have hearing structures tuned to the sounds emitted by their primary predator. For example, over 14 families of moths have tympanal ears that are adapted to detect the echolocation calls of bats (Fullard, 1988; Waters, 2003). Some species show remarkable tuning to a specific bat's call, as is the case with moths in Hawaii, where only one species of bat is found (Fullard, 1984). However, some species possess hearing structures that are more broadly tuned to detect the calls of many of the bat species found 
in their environment (Fullard, 1988). Broadly tuned ears may serve a function other than bat avoidance, and moths are not the only insects to possess hearing organs sensitive to a large range of frequencies.

Hearing may not be as dedicated to one function as the literature suggests and therefore hearing in some insects may serve more than one function. For example, some insects have broad tuning curves that are sensitive to a wide range of frequencies. Some species of parasitoid flies and crickets are sensitive to two distinct frequency ranges. The parasitoid fly, Ormia ochracea, detects sounds in the lower sonic range in order to eavesdrop on the calls of its orthopteran host, Teleogryllus oceanicus (Walker, 1993). Ormia is also sensitive to sounds in the ultrasonic range and until recently no function had been attributed to this second area of best hearing (Robert et al., 1992). Rosen, et al. (2009) found Ormia to elicit an acoustic startle response to ultrasonic stimuli, much like that of their orthopteran hosts. Both the parasitoid fly and its cricket host use hearing for a function other than predator avoidance, yet due to their nocturnal lifestyle and exposure to predators, possess hearing structures that secondarily have evolved to function in predator detection. These findings emphasize the lability of specialized insect auditory systems under changing ecological conditions.

Insects may also show a mismatch between the sounds emitted from the sender and their own best hearing (Mason and Schildberger, 1993). Some cricket species possess hearing structures that are sharply tuned to frequencies other than the carrier frequency of their calls (Bailey and Romer, 1991; Mason, 1991). Male crickets of the Haglidae family 
produce a calling song with a carrier frequency of $12 \mathrm{kHz}$, which may be used for courtship and/or maintaining territories (Mason, 1991). However, both males and females possess ears that are sharply tuned to low frequencies (Best Frequency $=2 \mathrm{kHz}$ (Mason, 1991). Haglidae hearing, at the carrier frequency of the call $(12 \mathrm{kHz})$, is $20-30 \mathrm{~dB}$ above best hearing threshold (Mason, 1991). Mason and Schildberger (1993) proposed that the poorly developed tympanal organ may be primitive or the low frequency tuning of the ear may reflect an auditory function unrelated to the calling song. Species that show a mismatch in the sounds emitted from the sender and their own best hearing, may use hearing secondarily for predator detection.

Some insects, like locusts and butterflies, possess sensitive ears that respond physiologically to sound, yet the specific function of these ears is currently unknown. Locusts for example, possess sophisticated ears and have received much scientific attention over the past 50 years (Mason, 1969; Robert 1989; Dawson et al., 2004). Locusts are sensitive to a wide range of frequencies $(1-30 \mathrm{kHz})$ and are one of the few insects capable of frequency discrimination (Romer, 1976). The broadly tuned ears of the locust have been proposed to function in bat detection (Robert, 1989), preventing malemale aggression (Kalmring, 1975), and the maintenance of group cohesion during swarming events (Haskell, 1957). Despite the amount of work performed on locust hearing, structure, and function, these hypotheses have not been directly supported, and the function of hearing is still unknown.

More recently, some species of butterflies have been found to possess functional hearing organs. Butterflies of the Nymphalidae family have a tympanal ear called the 
Vogel's organ found at the base of their forewings (Vogel, 1912). Through extracellular recordings of the tympanal nerve, these butterflies have been found to be most sensitive to frequencies in the lower sonic range (Yack et al., 2000; Mahony, 2006; Lane et al., 2008; Lucas et al., 2009). For example, The blue morpho butterfly, Morpho peleides, has been found to be most sensitive to low frequencies, $2-4 \mathrm{kHz}$ at median thresholds of 58 dB SPL (Lane et al., 2008; Lucas et al., 2009). The tympanal membrane of Morpho peleides is unique among other butterflies in that the membrane has a dome-shaped structure in its center (Lane et al., 2008). Low frequency sound (1 - $5 \mathrm{kHz}$ ) has been demonstrated to vibrate the outer portion of the tympanal membrane, while higher frequency sound ( $5-20 \mathrm{kHz}$ ) causes the entire tympanal structure to vibrate (Lucas et al., 2009). These findings suggest frequency discrimination may be possible, yet still the functional significance of hearing in this species and most butterflies tested to date remain unknown. Since these butterflies are mute and diurnal, both conspecific communication and bat avoidance can be ruled out as possible functions. The broadband sounds produced by bird flight covers the best hearing ranges of both locusts $(\sim 5 \mathrm{kHz})$ and butterflies $(\sim 3 \mathrm{kHz})$, and given that birds impose a strong selection pressure on both these insect taxa, hearing may serve to detect the passive sounds of avian predators.

\subsubsection{Could Insects be Listening for Passive Cues from Predators?}

How do insects avoid predators? Insects have a variety of ways to avoid being detected, attacked, and consumed by predators. Many insects avoid detection by predators through a variety of morphological adaptations that allow them to become cryptic within their environment (Ruxton et al., 2004). Behaviourally, some insects 
remain out of sight by hiding under foliage or restricting foraging times (Heinrich, 1979; Fullard and Napoleone, 2001). Once detected and attacked by a predator, insects may use morphological adaptations such as sharp spines or dense hairs that make consumption of these insects difficult for the predator (Vermeij, 1982; Murphy et al., 2010). When attacked, some insects will startle or warn predators by producing high intensity sounds (Masters, 1979; Ewing, 1989; Brown et al., 2007; Bura et al., 2009). One way of avoiding detection or attack is to detect and escape from the predator first. Many nocturnal insects utilize their acoustic senses for detection and avoidance of their primary predator - bats (Hoy et al., 1989; Yager, 1999; Stumpner and von Helversen, 2001). The classic example of this evolutionary arms race is the moth-bat interaction (Waters, 2003). The previous example describes prey listening for the active hunting signals of a predator. Some insects detect the passive cues produced by predators. For example, some leaf-miner caterpillars are capable of detecting the passive seismic vibrations produced by predatory wasps and stinkbugs probing their leaf shelters (Bacher et al., 1996; Castelanos and Barbosa, 2006). Passive cues are also produced by the rapid movement of a predatory insect's wings when in flight. Some caterpillars possess filiform hairs that are capable of detecting the airborne vibrations created by the flight of an approaching predatory wasp (Tautz and Markl, 1978; Taylor, 2008). Birds exert a strong selection pressure on insects and since they too produce passive cues when aerially foraging for insects, the capability of detecting this predatory cue would be highly adaptive. 


\subsubsection{Defenses Against Avian predators}

Many insects are preyed upon by birds and in response have developed a large repertoire of defenses. For example, moths and butterflies possess wings which are camouflaged to match their surroundings (Kettlewell, 1973; Lees and Creed, 1975). Others rely on eye-spots, which resemble the predators of birds, to startle and scare birds away (Vallin et al., 2005; Stevens et al., 2008). Other insects may rely on hearing to detect and evade avian predators. Lepidoptera, Orthoptera, Hemiptera, Diptera, Dictyoptera, Coleoptera, and Neuroptera all have tympanal hearing organs (Stumpner and Von Helverson, 2001; Yack, 2004; Yack and Dawson, 2008) and are all reported to be preyed upon by birds (Butterflies: Pinheiro, 1996, 2003; Moths: Jacobs et al., 2008; Locusts: Alsop, 1979; Crickets and katydids: Gradwohl and Greenberg, 1982; Cicadas flies: Holmes et al., 1979; Mantids: Alsop, 1979; Tiger and Scarab beetles: Pearson, 1988; Green Lacewings: Riek, 1970). In a study of South American insectivorous bird stomach contents, Poulin and Lefebvre (1997) found that among the seven superfamilies with ears, coleopterans and lepidopterans composed the majority of insects in their diets. Insectivorous birds may impose strong selection pressures on insect sensory systems, for which a "bird detector" would be of adaptive value.

\subsubsection{Chapter Objectives}

In this chapter I will test the hypothesis that moths are physiologically capable of detecting the passive flight sounds produced by a foraging bird. I predict that the frequencies of bird flight will match the best hearing range of moths, and that moths will show a physiological response to bird flight sounds. I will use the noctuid moth, 
Trichoplusia ni, as my model species to test these predictions. The goals of this chapter are to: 1) conduct tuning curves in order to determine if the bird flight sound cue matches the hearing of my model insect, and 2) perform playbacks of bird flight sounds to a physiological preparation of a moth to determine if moths are capable of detecting bird flight sound cues. 


\subsection{Methods and Methods}

\subsubsection{Animals}

Pupae of the moth Trichoplusia ni (Noctuidae) were obtained from the Insect Production Unit of the Canadian Forest Service in Sault Ste. Marie. All pupae were placed in large glass jars on top of moist paper towels laid over Vermiculite (Perlite Canada Inc., Montreal). The pupae were maintained at $25^{\circ} \mathrm{C}$ on a natural light cycle in the Carleton greenhouse and allowed to emerge. Both males and females were used for neurophysiology recordings.

\subsubsection{Extracellular Physiology}

\subsubsection{Moth Preparation}

Using instructions in Roeder (1969) and the dorsal dissection technique described by Fullard (1984), Trichoplusia ni moths were dissected to expose the auditory nerve (IIIN1b) (Nuesch, 1957). Upon removal of the head and legs, a moth was placed dorsalside up on a small block of modeling clay with the wings and abdomen restrained using staples. Small grooves were made in the clay to accommodate the body and to allow sound stimuli to reach the tympanal organs without any obstructions. Using a paintbrush, the scales on the mesonotum (scutum and scutellum) were removed, and a shallow incision was made around the perimeter of the mesonotum. This was followed by two small incisions on each side of the thorax, medial to the forewing alula. These cuts allowed for the flight muscle and alimentary canal to be removed. The flight muscles were then removed to expose the thoracic ganglia and nerve branches, including the 
IIIN1b auditory nerve. The thoracic cavity was bathed in lepidopteran physiological saline (Paul, 1974) to prevent desiccation.

\subsubsection{Recording Set-Up}

Action potentials were recorded using an electrolytically etched stainless steel hook electrode. The IIIN1b nerve was hooked with the recording electrode and lifted slightly out of the saline bath. Once isolated, all excess saline was removed and the thoracic cavity was filled with petroleum jelly to prevent desiccation. Another stainless steel electrode was inserted into the moth's thoracic flight muscle to serve as reference. Extracellular impulses were amplified with a Grass Instruments P-55 preamplifier (West Warwick, RI, USA), viewed on a Tectronix (Beaverton, ON, Canada) THS720A digital oscilloscope, and monitored using an A-M Systems, Inc. audio monitor (model 3300; Sequim, WA, USA). The neural response and playback signals were recorded onto a Fostex FR-2 data recorder (Gardena, CA, USA) at a sampling rate of $44.1 \mathrm{kHz}$ as .wav files. All files were later analyzed using Raven Pro 1.3 software (see 3.3 Data Analysis). All neurophysiological recordings were performed within a Faraday cage lined with sound attenuating foam.

\subsubsection{Stimulus}

Audiograms

Auditory threshold curves (audiograms) were constructed to determine the auditory range of Trichoplusia ni and compare it with the bird flight sound cue. Synthetic acoustic stimuli between $5-45 \mathrm{kHz}$ were broadcast as trapezoidal sound pulses of $30 \mathrm{~ms}$ 
duration (5ms rise/fall, linear ramp). Broadcast sounds were shaped using PC Tucker Davis software (RPvdsEX, v. 5.4; Alachua, FL, USA) and synthesized by a Tucker Davis Technologies (TDT) digital signal processor (RX6 multifunction processor). Sound pulses were attenuated using a TDT PA5 programmable attenuator and broadcast from a calibrated Pioneer Ribbon Tweeter speaker (model ART-54F; Kanagawa, Japan) (tested from $2-80 \mathrm{kHz}$ ). The speaker was placed $30 \mathrm{~cm}$ away from the preparation ipsilateral to the recording electrode. The speaker was calibrated by broadcasting equal amplitude continual tones to a 0.25 " in Brüel and Kjaer Type 4939 microphone (Naerum, Denmark) connected to a Brüel and Kjaer Nexus conditioning amplifier. This recording set-up was connected to a Tektronix TDS2002 oscilloscope to measure the tone's waveform amplitude as $\mathrm{mV}$ peak-to-peak, which was later converted into dB SPL (r.m.s. re $20 \mu \mathrm{Pa}$.). Moths were tested for sensitivity to frequencies from 5 to $45 \mathrm{kHz}$. Each frequency was broadcast in random order, at $5 \mathrm{kHz}$ intervals. Threshold at each frequency was determined by systematically attenuating the acoustic stimuli in $0.5 \mathrm{~dB}$ increments. The auditory threshold was defined as the lowest sound level at which neural spikes could be clearly heard (audio speaker) or seen (oscilloscope) in synchrony with the sound stimulus by two independent observers (e.g. Jackson et al., 2010). Audiograms were constructed using 10 animals (5 males and 5 females).

Playbacks of Sayornis phoebe flight sounds

Flight sounds recorded from foraging wild phoebes, Sayornis phoebe, described in chapter two, were used for playbacks to moth neural preparations. Phoebe flight recordings were made as the aerial insectivore attacked a tethered moth. Original, 
unfiltered flight recordings (Earthworks QTC40) were divided into single flight cycle, 4 flight cycle, and full attacks using Raven Pro 1.3 software. The moth neural preparation was subjected to one or more of the following three playback conditions:

(a) A full duration phoebe attack ( $\sim 3$ seconds)

(b) A bout of 4 flight cycles ( $200 \mathrm{~ms}$ taken from a full duration phoebe recording)

(c) A single flight cycle ( $\sim 50 \mathrm{~ms}$ taken from a full duration phoebe recording)

All playbacks were broadcast using an Avisoft ScanSpeak speaker $(1-120 \mathrm{kHz})$ at 30 $\mathrm{cm}$ from the moth neural preparation. Avisoft Recorder software, in combination with the Avisoft USG Player116, was used to loop and control intensity of playbacks of bird flight signals to moth neural preparations. Sound levels of playbacks were controlled using a volume dial on USG Player116 and broadcast at volumes $0.25,0.5,1.0,1.5,2.0,2.5,3.0$, and 4.0, which equates to playback sound levels of $58.0,59.5,62.5,63.5,67.0,69.5$, 71.0, and 76.0 dB SPL, respectively. $\mathrm{dB}$ SPL values were obtained using the Bruel and Kjaer Type 2239 sound level meter. Due to the frequency sensitivity of this device (1$18 \mathrm{kHz}$ ) the above-mentioned dB SPL values are a measurement of the phoebe's flight sound level at $1 \mathrm{kHz}$ (i.e. the most intense frequency component of the flight sound). Relative to the sound level at $1 \mathrm{kHz}$ (i.e. peak frequency of phoebe flight), the sound level at the $25 \mathrm{kHz}$ component of phoebe flight sound (i.e. the frequency component that Trichoplusia $n i$ is most sensitive to (Figure 3.2)) is on average $10 \mathrm{~dB}$ less. Therefore, the frequency component of bird flight sound that the moths are most sensitive to $(\sim 25 \mathrm{kHz})$ is approximately $10 \mathrm{~dB}$ less than the measured $\mathrm{dB}$ values I report in the results. 


\subsubsection{Data Analysis}

All neural response characteristics measured were correlated with increasing bird flight sound playback sound level (dB SPL). Single phoebe flight cycle playbacks were used to measure average relative latency (ms), average number of A1 cell spikes, average A1 cell inter-spike interval (ms) for both down-stroke and up-stroke, and average A1 cell inter-burst interval within a wing-beat (ms). See Figure 3.5 (in Results) for a summary of A1 cell response characteristics measured. Relative latency is defined as the time period between the onset of the one flight cycle playback and the peak of the first action potential. Due to the nature of the flight sound and its lack of a distinct onset (i.e. the flight sound level gradually rises to a maximum amplitude), I used the onset of the playback signal to measure latency. The number of A1 cell spikes is defined as the total number of spikes elicited by one flight cycle playback. The A1 cell inter-spike interval is defined as the amount of time between two consecutive spikes. The Al cell inter-burst interval within a flight cycle is defined as the amount of time between the first group of A1 cell spikes (elicited by the down-stroke of the flight cycle) and the second group of A1 cell spikes (elicited by the up-stroke of the flight cycle) (i.e. each single flight cycle playback is composed of the bird's wings performing a down-stroke followed by an upstroke). If the A1 cell inter-burst interval is capable of being measured, it effectively signifies the moth is responding to both the phoebe's down-stroke and up-stroke.

Four flight cycle phoebe playbacks were used to measure the average number of A2 cell spikes per individual flight cycle, and the average A1 cell inter-burst interval between flight cycles. The number of A2 cell spikes is defined as the number of A2 cell firings elicited in response to each flight cycle of the playback (See Results section for a 
description of A2 cell spikes (Figure 3.1)). The A1 cell inter-burst interval between flight cycles is defined as the amount of time between the last spike elicited by one flight cycle and the first spike elicited by the following flight cycle. Full phoebe and chickadee flight playbacks were used to assess the moth's ability to maintain its firing response throughout the duration of the foraging event. The response to full flight playbacks was quantified by measuring the $\mathrm{A} 1$ cell inter-burst interval between every flight cycle from the onset of the playback up to the point the phoebe captured the insect.

All statistical analysis was performed using SPSS software V13.0 (IBM, New York, NY, USA). A Pearson correlation analysis was used in single flight cycle playbacks to correlate phoebe playback sound levels with relative latency, number of A1 cell spikes, A1 cell inter-spike interval for the down-stroke, A1 cell inter-spike interval for the up-stroke, and A1 cell inter-burst interval within a flight cycle. A Pearson correlation analysis was used in 4 flight cycle playbacks to correlate phoebe playback sound levels with Al cell inter-burst interval between flight cycles. 


\subsection{Results}

\subsubsection{Are moths capable of hearing bird flight sounds?}

Audiograms

In order to illustrate the response of the IIIN1b auditory nerve, an $18 \mathrm{kHz}$ pure tone sound stimulus $(83 \mathrm{~dB} \mathrm{SPL}, 30 \mathrm{~cm})$ was presented to a Trichoplusia ni neural preparation (Figure 3.1). Both the activity of the moth's A1 cell and the less sensitive A2 cell can be observed in response to the sound stimulus.

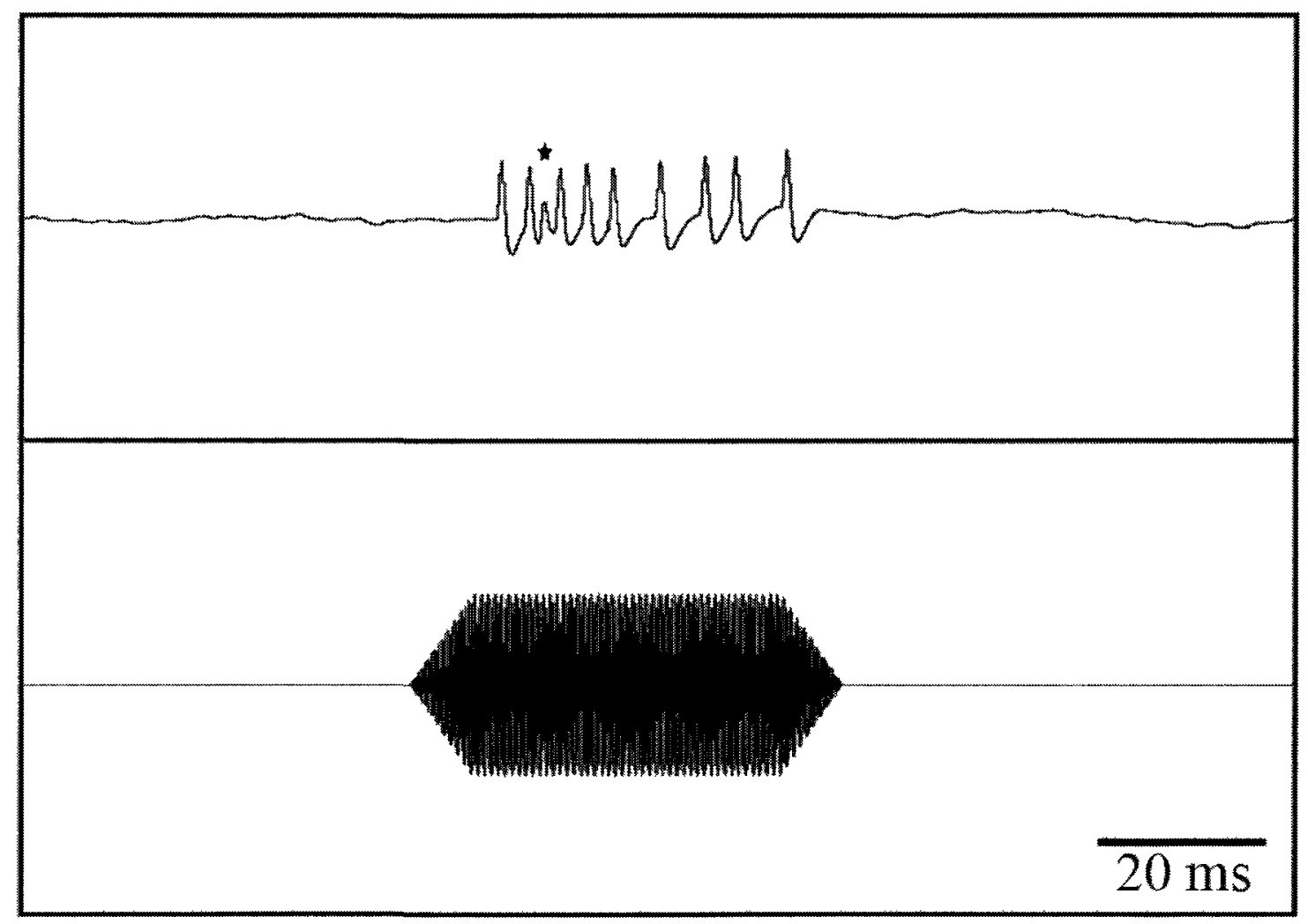

Figure 3.1. A typical Trichoplusia ni neural response to an $18 \mathrm{kHz}$ tone broadcast at 83 $\mathrm{dB}$ SPL from $30 \mathrm{~cm}$. The black star in the neural trace indicates the position of a single A2 cell spike. All other spikes evoked by the sound stimulus are A1 cell spikes. 
Moths responded to all frequencies between 5 to $45 \mathrm{kHz}$ (Figure 3.2). The audiogram obtained from 10 Trichoplusia ni moths shows high sensitivity to frequencies between $15-30 \mathrm{kHz}$ with a peak sensitivity of $25 \mathrm{kHz}$ at $44.1 \mathrm{~dB}$ SPL.

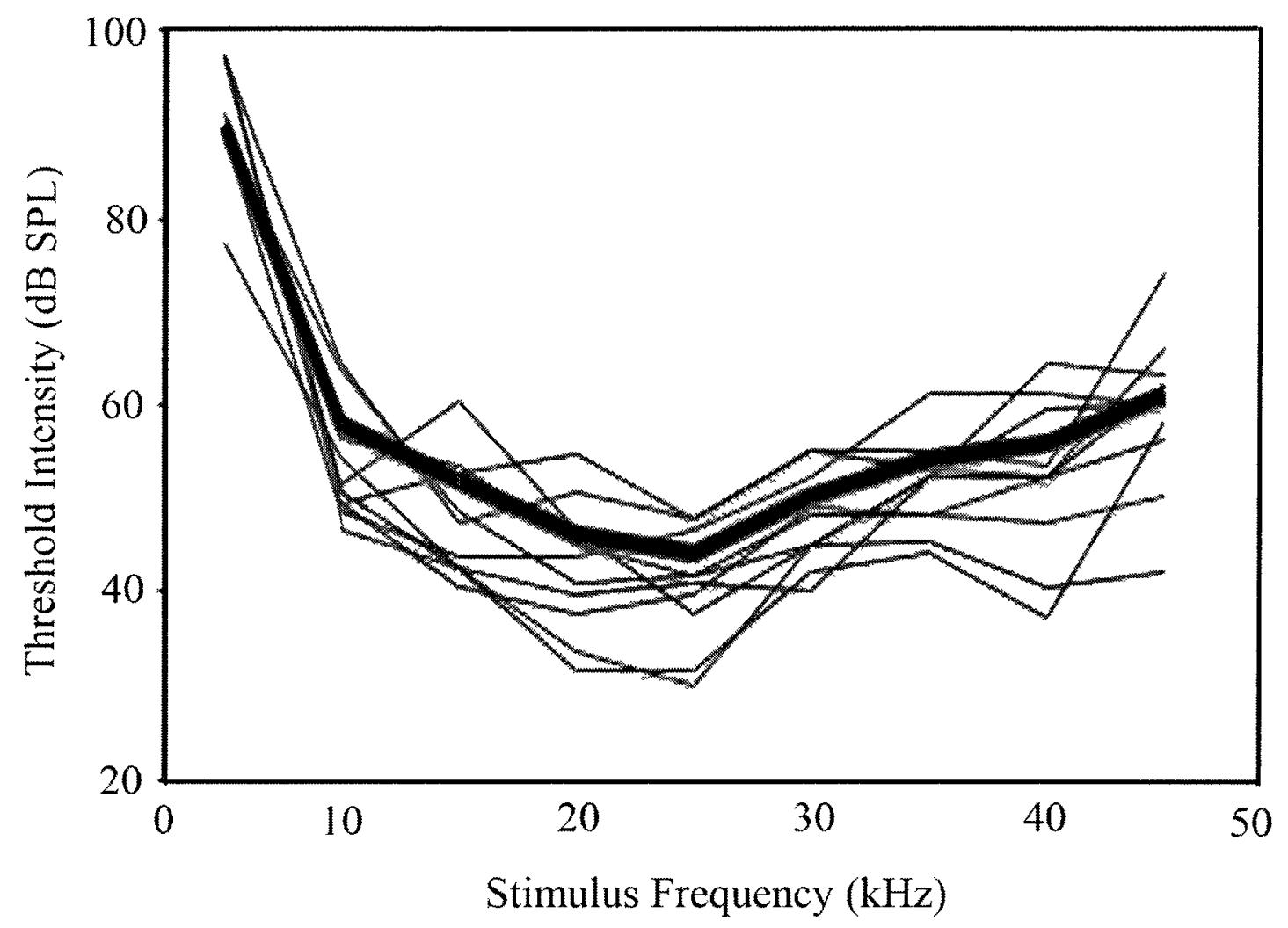

Figure 3.2. Auditory sensitivity curve of the Trichoplusia ni A1 auditory cell. Audiogram was produced using responses of 10 individual moths ( 5 male +5 female). Median line is traced in bold.

The overlap between the power spectra of the phoebe flight sound and the hearing range of Trichoplusia $n i$ is depicted in Figure 3.3. Areas where the bird flight power spectrum overlaps with the Trichoplusia ni tuning curve indicate the frequency components potentially audible to moths. 


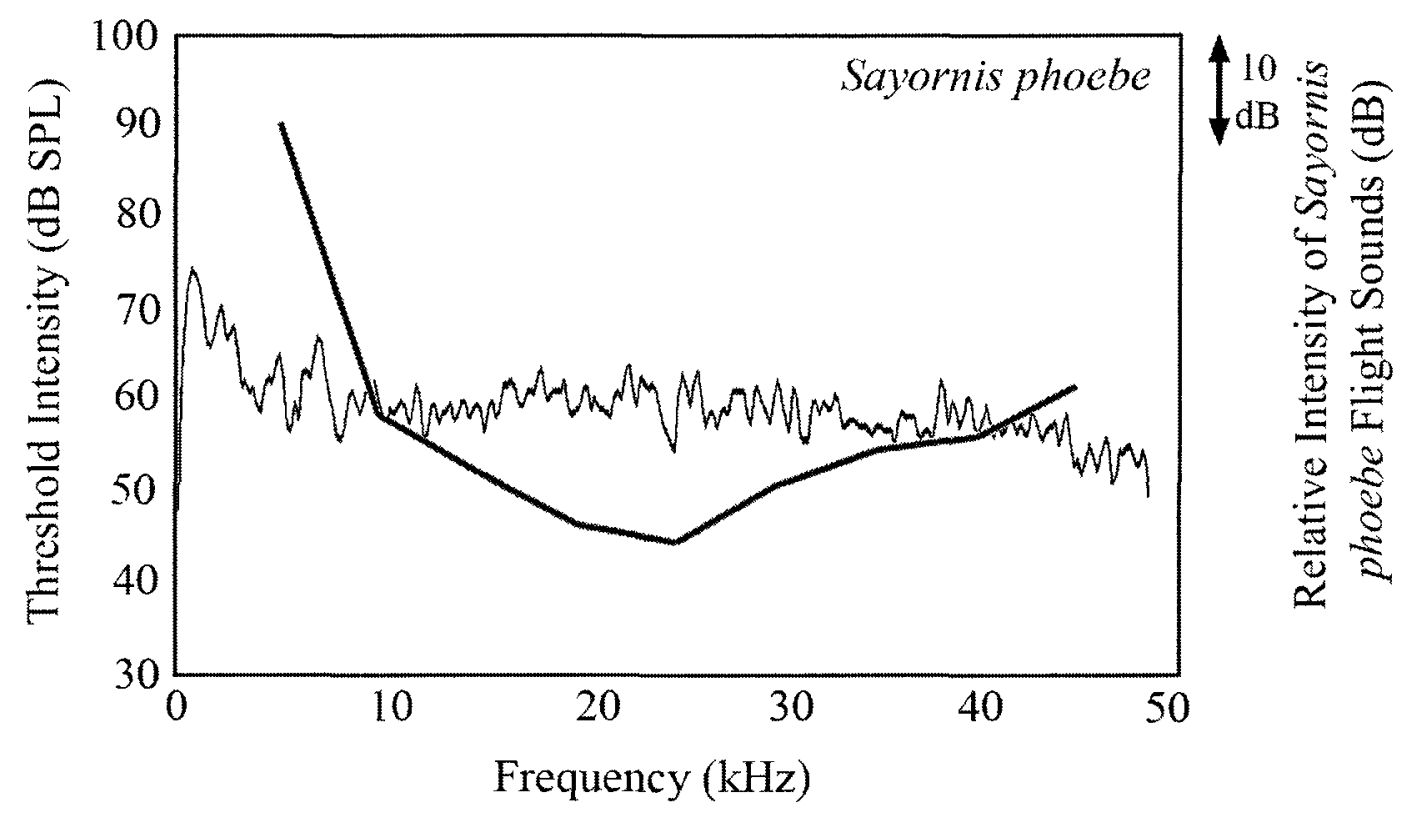

Figure 3.3. The auditory sensitivity curve of the Trichoplusia ni A1 auditory cell overlapped with the bird flight sound power spectrum. Figure shows the Trichoplusia ni tuning curve (thick trace, left axis) overlaid with a representative power spectrum of Sayornis phoebe flight sound (right axis).

\subsubsection{Bird Flight Sound Playbacks}

All Trichoplusia ni neural preparations responded to bird flight sound playbacks ( $\mathrm{N}=8$ moths to chickadee playbacks and $\mathrm{N}=16$ moths to phoebe playbacks) with their complete two-celled auditory repertoire (A1 and A2 cells) (A2 cell activity was elicited only at higher sound levels, see below). The regular firing of the non-auditory B-cell was also observed during playbacks and was not formally studied. Figure 3.4.A shows a typical auditory response to the flight sounds of an approaching phoebe at $73 \mathrm{~dB}$ SPL. Both the activity of A1 and A2 auditory cells can be observed at this playback intensity, which equates to an approximate distance of $60 \mathrm{~cm}$ in nature. In Figure 3.4.B the A1 cell can be seen firing a burst of spikes after the down-stroke, followed by a short A1 cell 
inter-burst interval within the flight cycle, followed by another burst of A1 cell spikes in response to the up-stroke and repeats for each consecutive flight cycle. Figure 3.4.B provides a close-up view of (A), which shows the A2 cell activity evoked by the downstroke of the flight cycle.

A)

B)
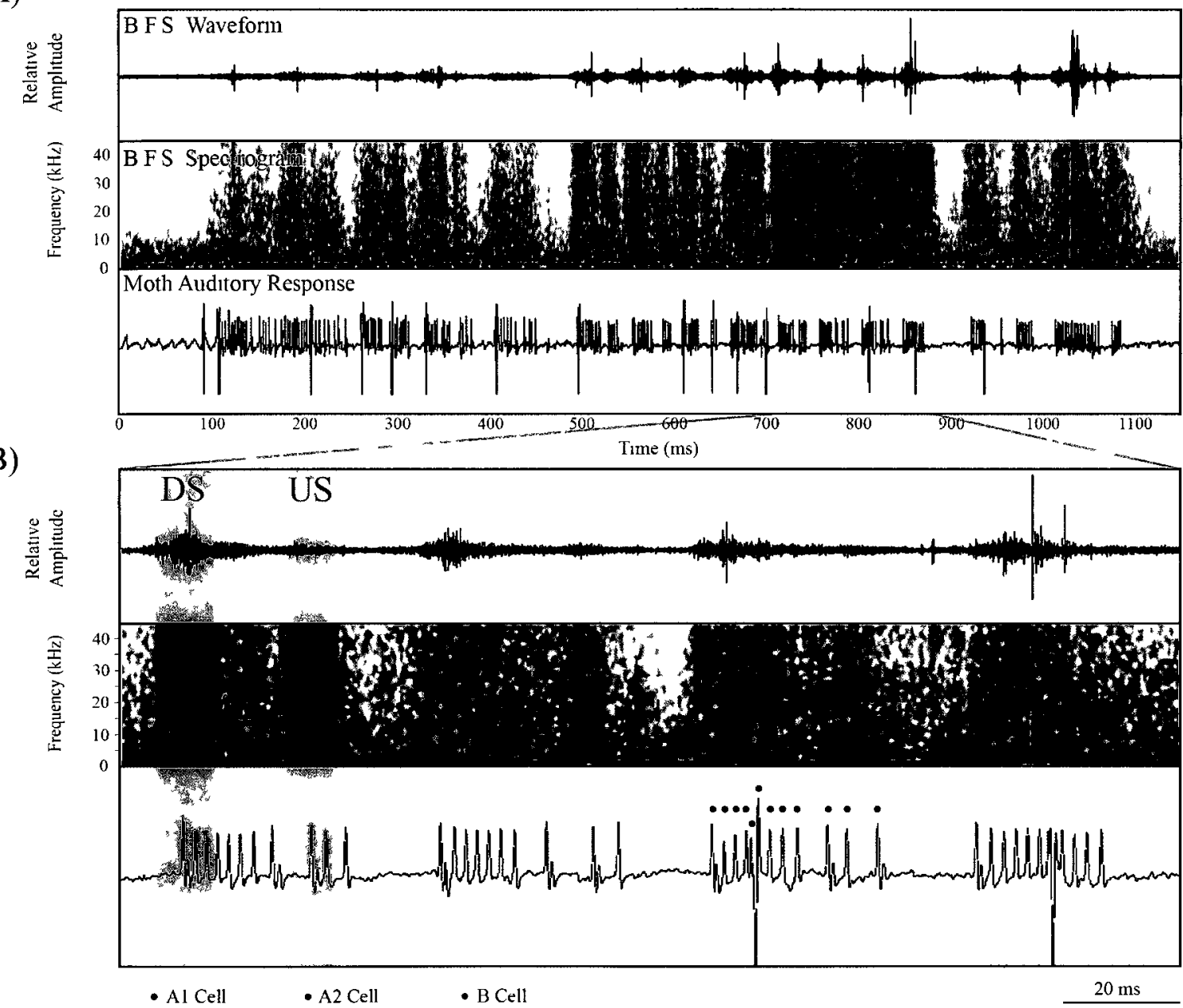

Figure 3.4. A. Representative traces of the response of Trichoplusia ni's auditory receptors (A1 and A2 cells) to the flight sounds produced by an approaching Sayornis phoebe. Top trace shows bird flight sound (BFS) waveform. Middle box shows BFS spectrogram. Bottom trace shows moth neural response. B. Time expanded view of the highlighted section from (A) showing four individual flight cycles and the resulting moth neural response. DS - Downstroke and US - Upstroke of one phoebe flight cycle. Playback intensity $\sim 73 \mathrm{~dB}$ SPL. 


\subsubsection{Single Flight Cycle Playbacks - Phoebe}

Spike analysis was performed on Trichoplusia ni moths subjected to phoebe flight sound playbacks $(\mathrm{N}=5)$. The effect of increasing playback levels caused latency to decrease (Table 3.1). A Pearson correlation analysis showed that phoebe playback level was negatively correlated with latency $\left(\mathrm{R}^{2}=-0.94, \mathrm{p}=0.002\right)$. The effect of increasing playback levels caused the number of A1 spikes elicited per flight cycle to increase (Table 3.1). A Pearson correlation analysis showed that phoebe playback level was positively correlated with number of A1 cell spikes $\left(R^{2}=0.94, p=0.001\right)$. The moth's A1 cell inter-spike interval was measured in response to the down-stroke and up-stroke at each playback level (Table 3.1). A Pearson correlation analysis showed that phoebe playback level was negatively correlated with A1 cell inter-spike interval for the downstroke $\left(\mathrm{R}^{2}=-0.85, \mathrm{p}=0.015\right)$. Interestingly, once the sound level of the playback reaches $67 \mathrm{~dB}$ SPL or above, the A1 cell inter-spike interval decreases to $2.5 \mathrm{~ms}$ and remains at this level. The A1 cell inter-spike interval in response to the up-stroke was found not to be significantly correlated with playback level $\left(\mathrm{R}^{2}=-0.68, \mathrm{p}>0.05\right)$. In single flight cycle playbacks the A1 cell inter-burst interval is defined as the amount of time between the last spike elicited by the down-stroke, to the first spike elicited by the up-stroke. At playback levels below $62 \mathrm{~dB}$ SPL the A1 cell only responds to the more intense downstroke and not the up-stroke of the flight cycle. Therefore there is no Al cell inter-burst interval (Table 3.1). Only at playback levels above $62 \mathrm{~dB}$ SPL does the Al cell respond to both the down-stroke and the up-stroke of the flight cycle separately and therefore the A1 cell inter-burst interval can be measured for these higher sound levels (Table 3.1). In

Figure 3.6, no Al cell activity is seen in response to the up-stroke for the first two 
playback levels, 58 and $61 \mathrm{~dB}$ SPL. The $65 \mathrm{~dB}$ SPL playback shows the A1 cell firing a burst of spikes in response to the down-stroke and two spikes to each up-stroke of the flight cycle. Once playback levels exceed $76 \mathrm{~dB}$ SPL the spikes elicited by the downstroke of the flight cycle merge with the spikes elicited by the up-stroke and therefore A1 cell inter-burst interval can no longer be measured. A Pearson correlation analysis showed that phoebe playback level was negatively correlated with Al cell inter-burst interval $\left(\mathrm{R}^{2}=-0.81, \mathrm{p}=0.028\right)$. Figure 3.5 summarizes the $\mathrm{A} 1$ cell response characteristic measured.

Table 3.1. Summary of Trichoplusia ni A1 cell neural response characteristics with respect to increasing playback intensity of Sayornis phoebe single flight cycles, $\mathrm{N}=5$. Standard error of each measurement is supplied. DS - Down-stroke, US - Up-stroke.

\begin{tabular}{|cc|c|c|c|c|c|}
\hline $\begin{array}{c}\text { Playback Level } \\
\text { (dB SPL) }\end{array}$ & $\begin{array}{c}\text { Relative } \\
\text { Latency (ms) }\end{array}$ & $\begin{array}{c}\text { Number of } \\
\text { Spikes } \\
\text { (ms) }\end{array}$ & $\begin{array}{c}\text { A1 Inter- } \\
\text { Spike } \\
\text { Interval DS } \\
\text { (ms) }\end{array}$ & $\begin{array}{c}\text { A1 Inter- } \\
\text { Spike } \\
\text { Interval Us } \\
\text { (ms) }\end{array}$ & $\begin{array}{c}\text { A1 Inter- } \\
\text { Burst } \\
\text { Interval } \\
\text { (ms) }\end{array}$ \\
\hline $\mathbf{5 8 . 0}(n=21)$ & $9.21 \pm 1.4$ & $4.84 \pm 0.5$ & $5.53 \pm 0.5$ & $/$ & $/$ \\
\hline $\mathbf{5 9 . 5}(n=24)$ & $8.88 \pm 0.5$ & $7.41 \pm 0.7$ & $3.49 \pm 0.1$ & $/$ & $/$ \\
\hline $\mathbf{6 2 . 5}$ & $(\mathrm{n}=18)$ & $9.13 \pm 0.4$ & $8.13 \pm 0.9$ & $3.44 \pm 0.2$ & $4.47 \pm 0.2$ & $11.56 \pm 0.8$ \\
\hline $\mathbf{6 3 . 5}(\mathrm{n}=21)$ & $9.00 \pm 0.4$ & $5.60 \pm 0.4$ & $3.56 \pm 0.1$ & $3.40 \pm 0.2$ & $8.80 \pm 0.4$ \\
\hline $\mathbf{6 7 . 0}$ & $(\mathrm{n}=25)$ & $6.75 \pm 0.3$ & $14.40 \pm 1.0$ & $2.32 \pm 0.1$ & $3.46 \pm 0.2$ & $7.81 \pm 0.7$ \\
\hline $\mathbf{6 9 . 5}$ & $(\mathrm{n}=15)$ & $5.47 \pm 0.2$ & $17.87 \pm 1.1$ & $2.33 \pm 0.1$ & $4.27 \pm 0.4$ & $7.86 \pm 0.2$ \\
\hline $\mathbf{7 1 . 0} \quad(\mathrm{n}=16)$ & $5.87 \pm 0.2$ & $14.73 \pm 0.8$ & $2.48 \pm 0.1$ & $3.42 \pm 0.1$ & $9.64 \pm 0.2$ \\
\hline $\mathbf{7 6 . 0}$ & $(\mathrm{n}=14)$ & $4.60 \pm 0.2$ & $21.60 \pm 1.1$ & $2.16 \pm 0.1$ & $3.78 \pm 0.1$ & $4.67 \pm 0.3$ \\
\hline
\end{tabular}




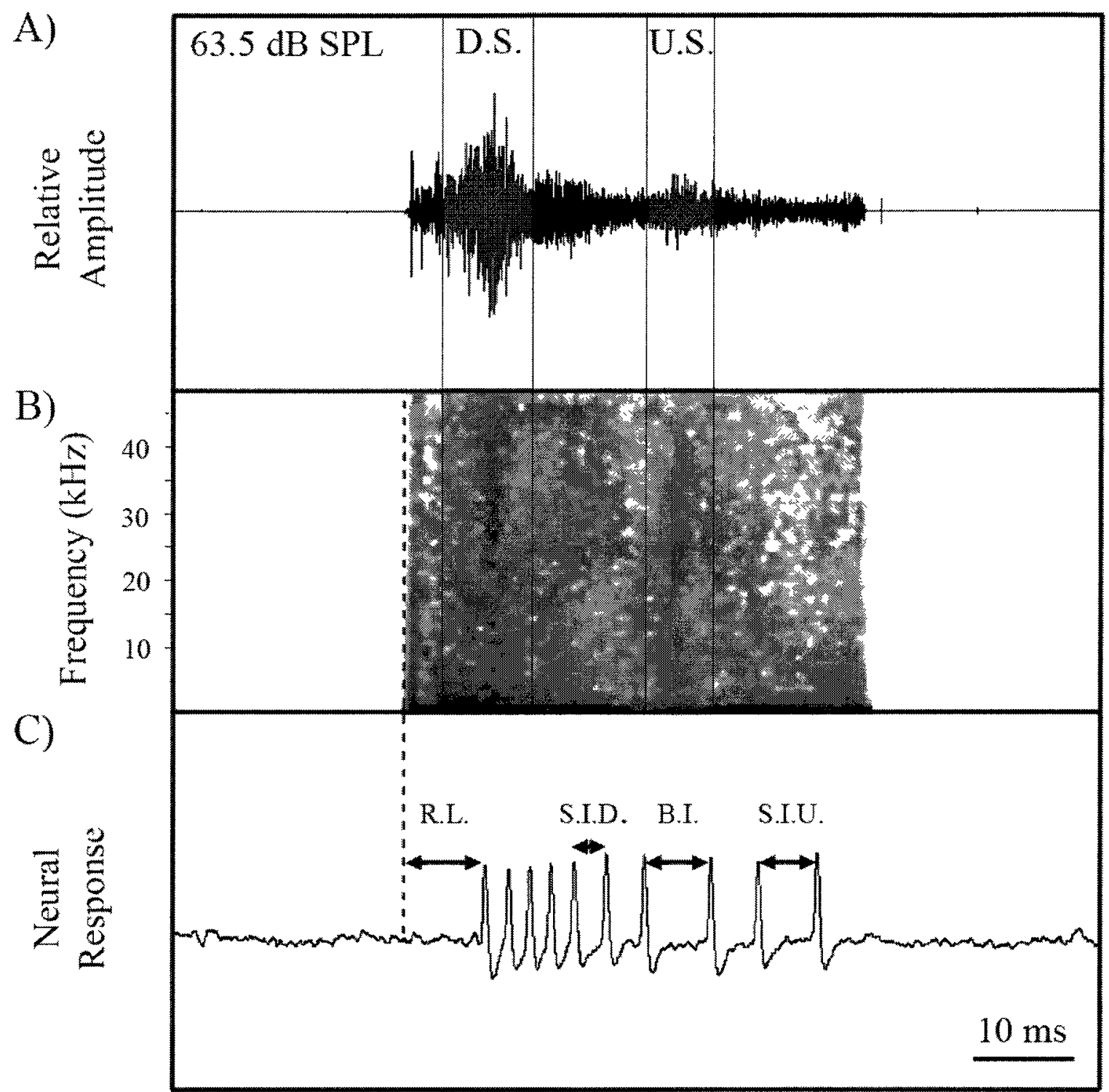

Figure 3.5. Measurements of Trichoplusia ni's A1 cell response to a single flight cycle playback of Sayornis phoebe. Waveform (A) and spectrogram (B) of phoebe flight cycle playback. Highlighted portions indicate the down-stroke (D.S.) and up-stroke (U.S). C) Trichoplusia ni neural response to playback at $63.5 \mathrm{~dB}$ SPL. R.L.-Relative latency, S.I.D.-Inter-spike interval of response to down-stroke, B.I.-Inter-burst interval within a flight cycle, S.I.U.-Inter-spike interval of response to up-stroke. 


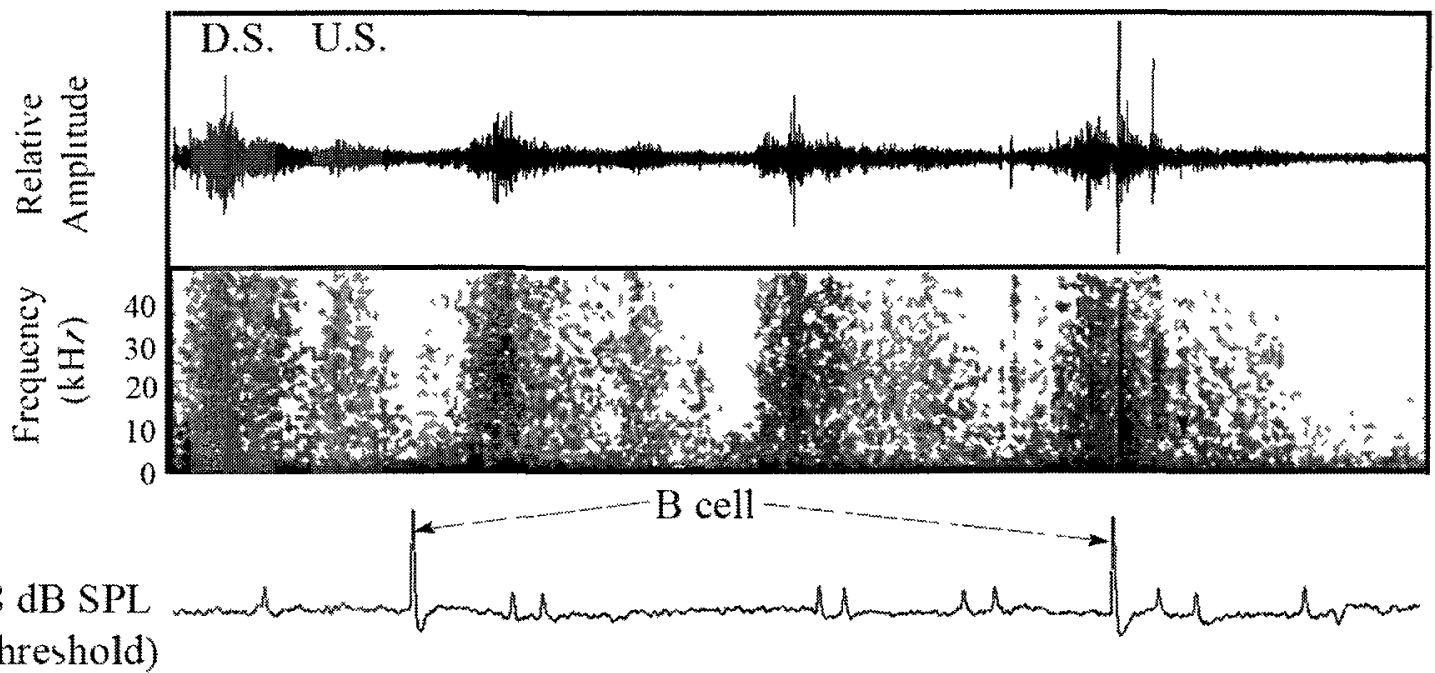

$61 \mathrm{~dB}$ SPL

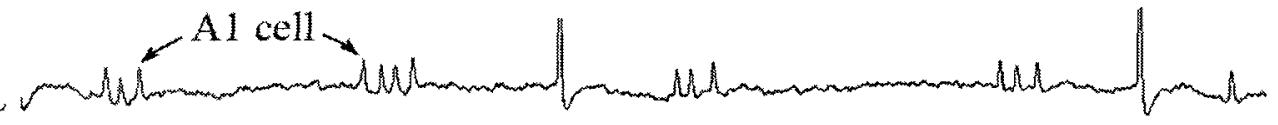

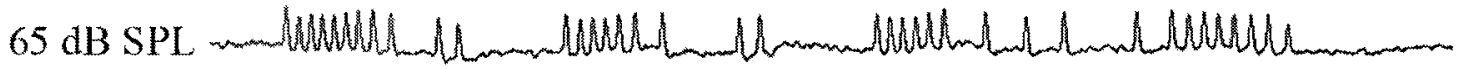

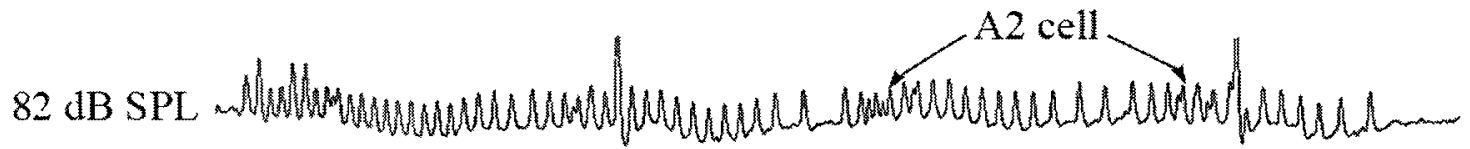

$20 \mathrm{~ms}$

Figure 3.6. Trichoplusia ni neural response to a Sayornis phoebe playback at increasing intensities. The waveform and spectrogram display the four flight cycle playback used to elicit the neural response. A1, A2, and B cell activity is indicated in the figure. D.S.phoebe flight cycle down-stroke, U.S.- phoebe flight cycle up-stroke.

\subsubsection{Four Flight Cycle Playbacks - Eastern Phoebe}

Four flight cycle playbacks (i.e. four consecutive flight cycles cut from a full duration phoebe recording) were used to measure the A1 cell inter-burst interval between flight cycles $(\mathrm{N}=5)$. In multiple flight cycle playbacks the A1 cell inter-burst interval is defined as the amount of time between the last spike elicited from one flight cycle to the first spike elicited by the next flight cycle. This parameter is limited by the nature of the 
bird flight sound stimulus and is affected by the level of the playback. Since the phoebe flight cycle is repetitive $(\sim 18 \mathrm{~Hz})$ it limits the A1 cell inter-burst interval to less than 55 ms. As the sound level of the flight playback increases, the number of A1 spikes also increases and therefore results in the amount of time between bursts decreasing (Table 3.2). At playback levels above $76 \mathrm{~dB}$ SPL the Al cell fires continuously, resulting in no inter-burst interval. A Pearson correlation analysis showed that phoebe playback level was negatively correlated with A1 cell inter-burst interval between flight cycles $\left(R^{2}=-0.88, p=0.004\right)$.

A2 cell activity was observed at playback levels of $67 \mathrm{~dB}$ SPL and above (Table 3.2). Playback levels between $67-71 \mathrm{~dB}$ SPL evoked $1-2 \mathrm{~A} 2$ cell spikes per flight cycle (Table 3.2). However, at these playback levels the A2 cell did not reliably fire in response to each flight cycle. At playback levels of 67 and $69.5 \mathrm{~dB}$ A2 cell activity was witnessed in response to 9 out of 20 (45\%) flight cycles analyzed. At 71 dB SPL the A2 cell fired in response to 13 out of $20(65 \%)$ flight cycles. At $76 \mathrm{~dB}$ SPL $1-4$ A2 cell spikes (Mean=2.1 \pm 0.2 ) were observed in response to every flight cycle analyzed (Table 3.2). A2 cell activity was always evoked by the down-stroke of flight cycles (Figure 3.4 and 3.6). 
Table 3.2. Summary of Trichoplusia ni A1 and A2 cell neural response characteristics with respect to increasing playback sound level of Sayornis phoebe 4 flight cycle playbacks, $N=5$. "Proportion of Time A2 cell Fires" is calculated by dividing the total number of samples by the number of samples in which A2 cell activity was present. Standard error of each measurement is supplied. F.C. - Flight cycle.

\begin{tabular}{|cc|c|c|c|}
\hline $\begin{array}{c}\text { Playback Level } \\
\text { (dB SPL) }\end{array}$ & $\begin{array}{c}\text { A1 Inter-Burst } \\
\text { Interval (ms) }\end{array}$ & $\begin{array}{c}\text { Number of A2 } \\
\text { Spikes Per F.C. }\end{array}$ & $\begin{array}{c}\text { Proportion Of } \\
\text { Samples With } \\
\text { A2 Activity } \\
(\%)\end{array}$ \\
\hline $\mathbf{5 8 . 0}(\mathrm{n}=20)$ & $40.0 \pm 1.2$ & 0 & $/$ \\
\hline $\mathbf{5 9 . 5}(\mathrm{n}=20)$ & $36.1 \pm 0.7$ & 0 & $/$ \\
\hline $\mathbf{6 2 . 5}(\mathrm{n}=20)$ & $16.1 \pm 0.5$ & 0 & $/$ \\
\hline $\mathbf{6 3 . 5}(\mathrm{n}=20)$ & $12.5 \pm 0.6$ & 0 & $/$ \\
\hline $\mathbf{6 7 . 0} \quad(\mathrm{n}=20)$ & $11.1 \pm 0.5$ & $1.1 \pm 0.1$ & 45 \\
\hline $\mathbf{6 9 . 5}(\mathrm{n}=20)$ & $9.4 \pm 0.4$ & $1.0 \pm 0.0$ & 45 \\
\hline $\mathbf{7 1 . 0} \quad(\mathrm{n}=20)$ & $5.9 \pm 0.3$ & $1.7 \pm 0.3$ & 65 \\
\hline $\mathbf{7 6 . 0} \quad(\mathrm{n}=20)$ & $4.0 \pm 0.2$ & $2.1 \pm 0.2$ & 100 \\
\hline
\end{tabular}

\subsubsection{Full Flight Playbacks - Phoebe and Chickadee}

Playbacks of full bird flight recordings were used to assess the moth's ability to maintain A1 cell firings throughout the duration of the entire recording. Trichoplusia ni's Al cell is physiologically capable of encoding bird flight sound without habituation, from the moment the cue is first detected, up until the point of theoretical capture (phoebe) (Figure 3.7) or up until the point the bird lands on my hand (chickadee). The A1 cell inter-spike interval, elicited by the down-stroke of phoebe flight, decreased steadily as the bird (in the recording) approached the microphone and therefore increased in amplitude (Figure 3.7). 


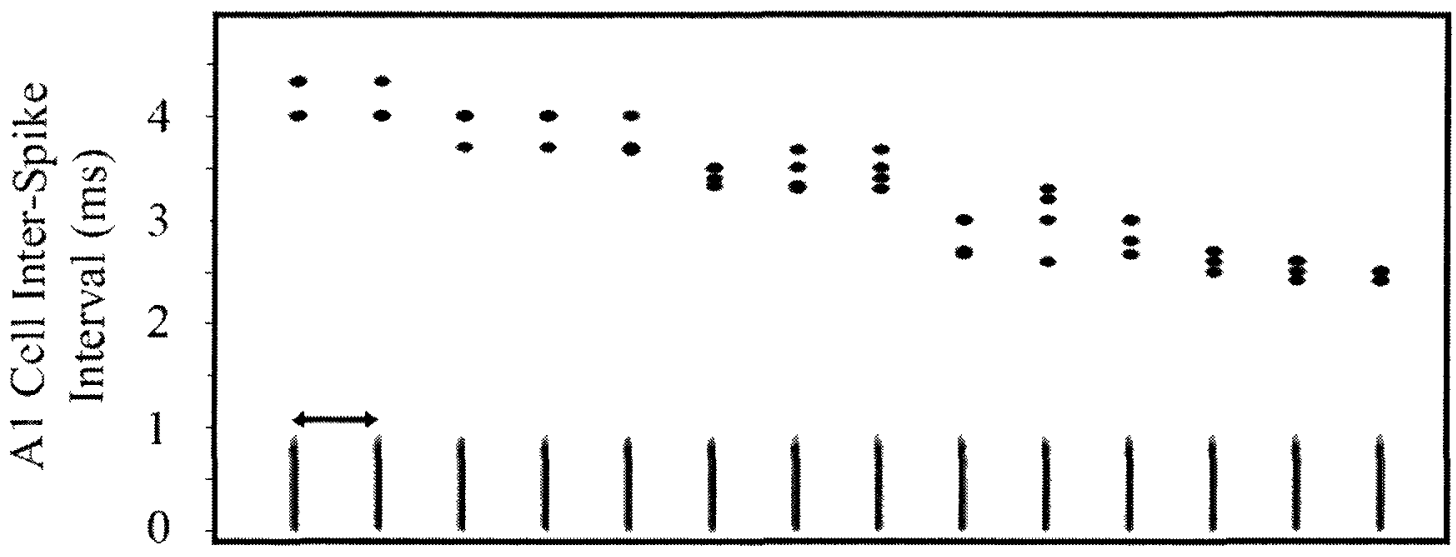

Figure 3.7. The A1 cell inter-spike intervals elicited by the down-strokes of a full phoebe flight recording, $\mathrm{N}=4,67 \mathrm{~dB}$ SPL. The dots indicate the inter-spike interval of the A1 cell's response to each down-stroke of the attack sequence. Each vertical bar denotes a phoebe down-stroke (up-strokes omitted for clarity). The full phoebe playback was composed of 14 flight cycles from an approaching bird, up until the point of capture. Horizontal scale bar $(55 \mathrm{~ms})$ depicts the time between consecutive flight cycles. 


\subsection{Discussion}

In this chapter I have shown that moth ears are physiologically capable of responding to the flight sounds of an approaching avian predator. My model species, Trichoplusia ni, of the family Noctuidae, represents the hearing range of a typical tympanate moth. The species audiogram indicates the moth has a best hearing at $25 \mathrm{kHz}$, with a threshold of $44.1 \mathrm{~dB}$ SPL and shows high sensitivity in the $15-25 \mathrm{kHz}$ range ( +6 $\mathrm{dB}$ from threshold). This hearing range is representative of the majority of moth species in North America (Fullard, 1988: Best Hearing: 20-50 kHz). This finding satisfies the prediction that moth ears are capable of physiologically responding to the flight sounds of an approaching avian predator. In this section I will discuss the possibility of moths detecting and responding to avian predators. To do so, I will review the neural response characteristics of moths to bird flight sound playbacks and the findings of others.

\subsubsection{Are Bird Flight Sounds Relevant to Moths?}

Simply because moths have been shown to physiologically respond to bird flight sounds does not directly support the hypothesis that these sounds are relevant to them. For example, moths have been shown to physiologically respond to calling cicadas that live in the same habitat; however, cicada calls do not evoke a behavioural response in moths (Fullard et al., 2008). The possibility does exist however, that moths do not use hearing solely for bat detection, and hearing may also serve to detect and avoid avian predators. Support for this hypothesis lies in the fact that birds do eat moths and moths have evolved many other defenses against these predators. Many roosting moths spend the day perched on trees and in other areas where they are susceptible to bird predation. 
Moths deal with this avian predation risk with a variety of anti-predator mechanisms including camouflaged forewings that allow them to blend into the environment they are resting on (Kettlewell, 1956; Lees and Creed, 1975). Moths also startle avian predators using eye-spots on their wings (Ruxton et al., 2004; Stevens et al., 2008). Moths use these visual defenses against birds to reduce detection, but do moths use hearing to detect and evade avian predators?

Some species of moths are diurnal and/or crepuscular and are active at similar times as birds, thereby increasing their susceptibility to predation (Fullard and Napoleone, 2001; Svensson et al., 2003). Many species that have shifted to a diurnal lifestyle also show a shift in their best hearing range (Fullard et al., 2000). Investigations into diurnal moth hearing, such as that of many dioptines, and the hearing of moths relieved of bat predation (i.e. island populations without predatory bats), have generally found a loss of ultrasonic sensitivity in these species (Fullard 1982, 1988; Fullard et al., 1997; Surlykke and Skals, 1998; Fullard et al., 2007). However, in both scenarios, moths have not lost hearing altogether; instead they show a shift from high frequency hearing to lower frequency hearing, with best hearing in the upper sonic range and lower ultrasonic range (Fullard, 1994; Surlykke and Skals, 1998; Fullard et al., 2007). Researchers have proposed that the reason behind the shift to lower frequency hearing, instead of complete hearing loss, may be attributed to conspecific communication in these species (Sanderford and Conner, 1990; Fullard, 1994). Currently, none of the species proposed to use hearing for communication have been shown to produce sound and the function of their lower frequency sensitivity remains a mystery. Due to the high diversity of avifauna found during daylight, especially on the tropical bat-free islands of Tahiti and Hawaii, 
moth ears may have secondarily shifted their sensitivity for the function of detecting avian predators (an "exaptation" - Gould and Vrba, 1982). Bird flight sounds are broadband sounds with a large ultrasonic component; however, the sound does possess the majority of energy within the sonic range. Moths with best hearing in the sonic range would be well suited for the acoustic detection of an approaching predatory bird.

\subsubsection{Are Bird Flight Sounds Capable of Eliciting a Behavioural Response in Moths?}

\section{Moths in Flight}

The neural patterns evoked by bird flight sound are theoretically sufficient to elicit an avoidance response. In regards to moths performing evasive flight maneuvers, the two important neural response characteristics are proposed to be the A1 cell's interspike interval and the inter-burst interval (Roeder, 1964). Kenneth Roeder (1964) determined that physiologically, the moth's A1 cell must be firing in bursts, with interspike intervals of $2.6 \mathrm{~ms}$ or less, and the time separating bursts of A1 cell firings must not exceed $200 \mathrm{~ms}$ in order for moth to begin evasive flight. Roeder determined these neural response parameters in two separate experiments. First, he played a variety of sounds with different spectral and temporal characteristics to moths in the field, in order to determine which were most effective in eliciting evasive maneuvers in moths. Secondly, he played back these sounds to moths in the laboratory to determine the effect that these sounds had on the moth's neural response. The neurophysiological playback experiments I performed showed the A1 inter-spike interval to fall below $2.5 \mathrm{~ms}$ at playback levels of $67 \mathrm{~dB}$ SPL or above (Table 3.1). Secondly, the A1 cell inter-burst interval is well below 
$200 \mathrm{~ms}$ due to nature of the bird flight sound stimulus. Bird flight sound is pulsed $(\sim 18-$ $20 \mathrm{~Hz}$ ) due to the constant beating of the bird's wings. Therefore, since the sound stimulus is repeating itself approximately every $50-55 \mathrm{~ms}$ and a portion of this time is filled with bursts of Al cell spikes, the inter-burst interval is well below $200 \mathrm{~ms}$ (Table 3.1 and 3.2). Based on Roeder's (1964) findings, the neural response evoked by the sounds of an approaching avian predator is sufficient to elicit evasive flight maneuvers in moths.

In addition to my own results, two important studies provide potential support for the hypothesis that moths respond behaviourally to bird flight sounds. The first, by Svensson et al. (2003), demonstrated that moths respond differently to ultrasound during the night and during the day. Moths responded during the day by flying more erratically and increasing flight velocity, whereas at night they responded by falling to the ground. The authors hypothesized that this response is an adaptation to the predators found in their environment at different times of day. Daytime hunting visual predators such as birds would have more difficulty capturing a fast, erratically flying moth than one that fell to the ground, whereas bats are highly agile but have difficulty finding prey against a solid surface (Faure and Barclay, 1994). In effect the moth is tailoring its anti-predator strategy to the predator that is attacking it. The authors in this study don't explicitly state why they played ultrasonic signals to the moths during the daytime. Birds are an important predator for moths and maybe the moth's behavioural response to ultrasound during the daytime is related to the possibility that these moths are responding to the ultrasound found in bird flight. The avoidance behaviour elicited by ultrasound during the daytime is remarkably similar to the avoidance behaviour of diurnal butterflies in 
response to predatory birds (Chai and Srygley, 1990). It is interesting that the moths in this study performed bird-like evasive flight maneuvers without a visual bird-like stimulus. This infers that pulsed ultrasound may not only be a bat-like sound stimulus but also be a bird-like sound stimulus.

A second study by Jacobs et al. (2008) observed birds foraging for diurnal moths. They characterized the multiple foraging techniques used by the birds to capture moths and found the birds were only successful in gleaning moths from the foliage. If the moth was to take to the air, birds were found to be incapable of capturing these flying moths due to their fast, erratic flight. Again, these findings imply that moths have some ability to acoustically detect avian predators. In this scenario the sight of an avian predator may elicit an escape response in the moth; however, what predatory stimulus does the moth require in order to maintain evasive flight until the danger has passed? If fleeing from a predatory bird, visual and olfactory cues are unlikely, yet detection of bird flight sound cues would be adaptive since birds do not actively produce these sounds. If bird-like sound cues are detectable, a bird-like predator is in the vicinity. My findings in combination with the findings of Svensson et al. (2003) and Jacobs et al. (2008), show that 1) birds produce ultrasound while attacking flying insects, 2) moths react to pulsed ultrasound with fast, erratic flight during daylight hours and 3) this form of escape flight is effective in escaping avian predators.

\section{Moths at Rest}

During the daytime many moths are roosting (Fullard and Napoloene, 2001). A major defense against bat predation for moths is to simply not fly when bats are active 
(Fullard and Napoloene, 2001). This defense is not functional against visual hunters such as birds. A moth resting against the bark is not invincible to a bird like a moth against a substrate is to an aerial hawking bat. This is where camouflage and mimicry play a role for moths (Kettlewell, 1956; Lees and Creed, 1975). If a resting moth were to detect the flight cues of an approaching bird, it may be more adaptive for them to respond with a behavioural response that is different than the escape flight described in the previous section. It is possible that the detection of an approaching bird may promote a moth to remain still and rely on its camouflaged wings to prevent attack, instead of risking detection and attempting escape flight. Future researchers may want to investigate the behavioural response of moths exposed to the flight sounds of gleaning birds such as chickadees and warblers.

\subsubsection{Detection Distances}

The distances at which moth neural responses are evoked by bird flight sound cues are biologically relevant for escaping moths. The playback studies performed in this chapter have demonstrated how the moth's auditory nerve responds to bird flight sound cues at various sound levels. If moths are to respond to bird flight sound cues with evasive flight then it is important to consider the distance that a moth may first be capable of detecting the presence of an avian predator. Detection distance was estimated using the inverse square law for sound attenuation over distance (Greenfield, 2002). This law states that for every doubling of distance from the sound source, there is a $6 \mathrm{~dB}$ SPL reduction in sound level. By using this formula in combination with the natural sound level $(\mathrm{dB}$ SPL) of bird flight at the peak frequency, the moth's A1 cell response threshold (dB SPL) 
to phoebe playback sound level at peak frequency, and the relative $\mathrm{dB}$ level measurements of Raven Pro 1.3 (based on a linear scale), the detection distance and time were estimated. The difference in flight sound levels from the loudest point of the phoebe attack (i.e. point of capture) to the first detected flight cycle detected by the Earthworks microphone is $15 \mathrm{~dB}$ SPL. I set the point of capture (i.e. loudest point of the flight recording on Raven Pro 1.3) to $73 \mathrm{~dB}$ SPL (i.e. phoebe flight sound level in nature at 30 $\mathrm{cm}$ ) which results in the first detected flight cycle of $58 \mathrm{~dB}$ SPL (i.e. $73 \mathrm{~dB}$ SPL $-15 \mathrm{~dB}$ SPL). $58 \mathrm{~dB}$ SPL is also the moth's A1 cell response threshold. Therefore, the first flight cycle picked up by the Earthworks microphone (at $30 \mathrm{~cm}$ away from the moth) is effectively the first flight cycle the moth would detect of the approaching bird. Using Raven Pro 1.3, the difference in time between the first flight cycle detected by the microphone and the point of capture is on average $900 \mathrm{~ms}$ for direct attacks and $1600 \mathrm{~ms}$ for hover attacks. Using the inverse square law for the known reduction in $\mathrm{dB}$ level from the point of capture to the $\mathrm{dB}$ level that is first detected by the moth, and the distance from which the natural flight sound level was measured (i.e. $30 \mathrm{~cm}$ ), a detection distance of approximately $200 \mathrm{~cm}$ is calculated. As the bird approaches and its flight sound level reaches $67 \mathrm{~dB} \mathrm{SPL}$, at approximately $450 \mathrm{~ms}$ before capture and at a distance of approximately $60 \mathrm{~cm}$ for direct attacks, the moth's A1 cell inter-spike interval decreases to $2.48 \mathrm{~ms}$ or lower. Based on Roeder's (1964) neural requirements for evoking evasive flight behaviour (inter-spike interval $<2.6 \mathrm{~ms}$ and inter-burst interval $<200 \mathrm{~ms}$ ), moths would begin evasive flight maneuvers when the flight sound cue reached $67 \mathrm{~dB}$ SPL and the bird was $60 \mathrm{~cm}$ away. This gives the moth on average $450 \mathrm{~ms}$ to initiate an escape response before being captured by a bird performing a direct attack. Hovering attacks 
could not be determined precisely due to the various distances the bird hovers from the moth (i.e. the point at which the bird's flight sound reaches $67 \mathrm{~dB}$ SPL is at a different distance for each attack). The detection distance values for moths detecting avian predators are much lower than those values found for moths detecting bat predators; 2.5 meters versus $50-60$ meters, respectively (Roeder, 1962 and 1964). Bat echolocation calls are emitted at much higher sound levels than the passive cues produced by the flapping wings of an approaching predatory bird; Eptesicus spp: $94-140 \mathrm{~dB}$ SPL at 10 cm versus Poecile atricapillus: $84.1 \mathrm{~dB}$ SPL at $15 \mathrm{~cm}$ and Sayornis phoebe: $72.9 \mathrm{~dB}$ SPL at $30 \mathrm{~cm}$ (Roeder, 1966; Surlykke and Moss, 2000). The temporal characteristics of bat echolocation calls may also aid moths in detecting bats at greater distances than birds. As previously stated, Roeder (1964) found that using sounds with a pulse repetition rate of $30 \mathrm{~Hz}$ was best in eliciting escape responses in moths. In comparison, bird flight sound is pulsed with a lower wing-beat frequency of $18-20 \mathrm{~Hz}$. Nonetheless, based on playing back flight sound cues at increasing intensity (i.e. the effect of an approaching bird) moths may detect bird flight sound in advance of being captured and if so, this time window may allow moths to initiate evasive maneuvers.

\subsubsection{A2 Cell Firing Patterns - A Possible Safety Mechanism}

The activity of the moth's less sensitive auditory cell, the A2 cell, was also observed during playbacks. The function of the A2 cell in eliciting evasive maneuvers in moths has been heavily debated for over 50 years (Fullard et al., 2003; Waters, 2003). Roeder (1974) suggested that A1 cell activity indicated a "far bat" scenario and the moth responded with negative phonotaxis, while the activity of the A2 cell indicated a "near bat" scenario and the 
moth began evasive flight maneuvers. However, studies have shown the A2 cell is not required for evasive flight behaviour to commence since some moths (e.g Notodontidae) have only one auditory cell (A1 cell) yet are capable of performing evasive flight maneuvers (Fullard, 1984; Surlykke, 1984). Bird flight sound cue playbacks were found to elicit A2 cell activity at levels of $67 \mathrm{~dB}$ SPL and above. Playback sound levels between 67 and $76 \mathrm{~dB}$ SPL did not reliably elicit A2 cell activity (Table 3.2). The A2 cell reliably fired short bursts ( 2 or 4 spikes) when bird flight sound cue levels were above $76 \mathrm{~dB}$ SPL. Interestingly, when playbacks were above this specific sound level, the A1 cell is no longer responding with bursts of spikes but instead is firing continuously with no gaps between bursts (i.e. no interburst interval) (Figure 3.6). Roeder's (1964) findings state that the A1 cell must be bursting with inter-burst intervals of $200 \mathrm{~ms}$ or less in order to begin evasive flight maneuvers. The continuous firing of the A1 cell at high sound levels may indicate that the moth would prematurely cease evasive flight maneuvers at a critical point prior to being captured. Higher order inter-neurons may interpret this continuous firing as a response to a pure tone and filter it out (Boyan and Fullard, 1988). Roeder (1966) discovered that phasically firing inter-neurons responded only to pulsed sounds and these cells may be necessary for evoking escape behaviours. Fullard et al. (2003) found a similar scenario with moths during the final attack phase of bat calls prior to capture. When the bat's echolocation call pulse period decreased beyond a critical point $(<6 \mathrm{~ms})$, the moth's A1 cell ceased bursting and began firing continuously, as though responding to a continuous tone. Therefore I propose a new functional role for the A2 cell as a "safety" mechanism for sustained escape flight in the presence of a very close aerial predator. When an approaching bird's flight sounds become so intense that the A1 cell responds by continuously firing, the moth's CNS would no longer 
be receiving temporal information about the approaching predator. At these high intensities, the A2 cell was found to fire only during the down-stroke of the bird's flight cycles, thereby possibly providing crucial temporal information to higher order inter-neurons in the central nervous system about the intense pulsed stimulus (i.e. a pulse marker). This additional information may allow the moth to maintain evasive flight maneuvers and prevent capture. Instead of the A1 and A2 cells being responsible for separate behaviours, as proposed by Roeder (1974), they may instead serve the same function, yet under different stimulus intensities and through a separate neural mechanism.

The function of moth hearing has long been solely thought to function in the avoidance of their primary nocturnal predator, echolocating bats (Fullard, 1998). This study provides physiological evidence of moths responding to the sounds of another predator, birds, with both its auditory cells (A1 and A2). The A1 cell's inter-spike interval and interburst interval, at a bird flight sound playback intensity of $67 \mathrm{~dB}$ SPL which represents a bird approximately $120 \mathrm{~cm}$ away, are theoretically sufficient to elicit evasive flight maneuvers. Based on these findings, an investigation into the behavioural responses of resting and flying moths to the sounds of an approaching avian predator should be conducted to test that moth hearing functions to not only to detect the sounds emitted from nocturnal bats, but also diurnal birds. 


\section{Chapter 4.}

\section{General Conclusion}

There are many examples of prey detecting the active hunting signals of predators, such as the bat-moth interaction described earlier. Much less is known of the means by which prey may be exploiting passive cues. This study demonstrated that birds produce sound while foraging and that these sounds are physiologically detected by noctuid moths.

Current research into the flight sounds produced by birds has only investigated birds with highly modified feather structures that function in sound production or reduction (Prum, 1998; Bostwick and Prum, 2003; Clark and Feo, 2008; Hingee and Magrath, 2009; Bachmann, 2010). Despite the great selection pressure posed on many insects by birds it is surprising that the passive flight cues produced by birds have not been studied. The flight sounds of two species of birds, one with a generalist diet, Poecile atricapillus, and another with a specialist (insectivorous) diet, Sayornis phoebe, have now been characterized. These two species allow for a comparison of the flight sounds produced by birds of different size, flight-type, and foraging tactic. Birds are a strong predation pressure against many tympanate insects, and by recording, characterizing, and performing playbacks of this avian predator cue we can determine if insects utilize these available sound cues as part of their predator avoidance strategy. In this study playbacks

of bird flight sound cues were broadcast to a tympanate moth, Trichoplusia ni, to test if they could physiologically detect the sounds produced by an approaching predator. This study demonstrated for the first time that eared insects respond physiologically to the passive flight sound cues produced by predatory birds. 
Passive avian flight sound cues may be relevant to many eared insects that are consumed by birds. In particular, butterflies of the nymphalid family have been found to possess functional hearing organs, the Vogel's Organ, yet no specific ecological function has been attributed to this ear (Lane et al., 2008). Many nymphalid butterflies are diurnal and mute and therefore do not use hearing to detect bats, or to communicate with conspecifics. Hearing in these species is restricted to the lower sonic range and it has been proposed that eared butterflies may be listening for avian vocalizations or flight sounds (Ribaric and Gogala, 1996; Mahony, 2006; Lane et al., 2008). This study has demonstrated that bird flight sounds are pulsed, broadband in frequency, contain peak frequencies in the sonic range, and are produced above background noise levels. Future research in butterfly hearing should begin with neurophysiological and behavioural playback studies of bird flight sounds to butterflies in order to determine the ultimate function of hearing.

Little is known about the flight sound characteristics of the vast majority of birds. Future research into bird flight sounds should incorporate a larger diversity of bird species when recording and characterizing flight sounds, in addition to examining feather morphology in order to determine the structures and mechanisms responsible for sound production. This study has described the flight sounds of two predatory bird species; however, there may be examples of other predatory species with highly modified flight feathers that function in sound reduction. Swifts and swallows employ a remarkably different foraging technique than do the flycatchers examined in our study (Bartlett, 1956). It is possible that these highly agile insectivorous birds have evolved a combination of sound reducing feather modifications and foraging tactics to overcome 
the acoustic startle response of tympanate insects. Novel structures which function in sound production and/or reduction may be discovered, and a library of bird flight sound recordings from many different species may allow for interesting comparative studies between the sounds made from one family, genus, species, to the next. Overall, the area of bird flight sound research and the insects that detect these cues is new and very little is known. Like the predator-prey co-evolutionary arms race relationship between nocturnal bats and moths, it may be that the relationship between bird flight sound cues and butterfly hearing will become one of neuroethology's big questions. 


\section{References}

Ackery, P.R., de Jong, R., and Vane-Wright, R.I. (1999). The Butterflies: Hedyloidea, Hesperoidea and Papilionoidea. In Handbook of Zoology. Bol. 4. Arthropoda: Insecta. Lepidoptera, Moths and Butterflies. Vol. 1. Evolution, Systematics, and Biogeography. (Ed. N.P. Kristensen), pp. 263-300. Berlin: Walter de Gruyter.

Airola, D.A. and Barrett, R.H. (1985). Foraging and habitat relationships of insectgleaning birds in a Sierra Nevada mixed-coniferous forest. Condor. 87(2), 205-216.

Alsop, F.J. (1979). Mantids (Tenodera aridisola) selected as prey by blue grosbeaks (Guiraca caerula). Wilson. Bull. 91, 131-132.

Bacher, S., Casas, J., and Dorn, S. (1996). Parasitoid vibrations as potential releasing stimulus of evasive behaviour in a leafminer. Physiol. Entomol. 21, 33-43.

Bachmann, T., Klan, S., Baumgartner, W., Klass, M., Schoder, W., and Wagner, H. (2007). Morphometric characterisation of wing feathers of the barn owl Tyto alba pratincola and the pigeon Columba livia. Front. Zool. 4(23).

Bailey, W.J. (1990). The anatomy of the tettigoniid hearing system. In The Tettigoniidae: biology, systematics and evolution. (Ed. Bailey, W.J. and Rentz, D.C.F.). pp. 217-247. Bathhurst: Springer Verlag.

Bailey, W.J. and Romer, H. (1991). Sexual differences in auditory sensitivity: mismatch of hearing threshold and call frequency in a tettigoniid (Orthoptera, Tettigoniidae: Zaprochilinae). J. Comp. Physiol. 169, 349-353.

Baker, M.C. (1977). Shorebird food habits in the eastern Canadian arctic. Condor. 79(1), 56-62.

Bartlett, L.M. (1956). Observations on birds "hawking" insects. Auk. 73(1), 127-128.

Barth, F.G. (2002). Spider senses - technical perfection and biology. Zoology. 105(4), 271-285.

Bennet-Clark, H.C. and Ewing, A.W. (1970). The love song of the fruit fly. Sci. Am. 223, 84-92.

Bertram, B.C.R. (1977). Variation in the wing-song of the flappet lark. Anim. Behav. 25, 165-170.

Bostwick, K.S. (2006). Mechanisms of feather sonation in Aves: unanticipated levels of diversity. Acta. Zool. 52, 68-71. 
Bostwick, K.S. and Zyskowski, K. (2001). Mechanical sounds and sexual dimorphism in the crested doradito. Condor. 103, 861-865.

Bostwick, K.S. and Prum, R.O. (2003). High-speed video analysis of wing-snapping in two manakin clades (Pipridae: Aves). J. Exp. Bio. 206, 3693-3706.

Bostwick, K.S., Elias, D.O., Mason, A., and Montealegre, F. (2010). Resonating feathers produce courtship song. Proc. R. Soc. Lond. B. 277, 835-841.

Bowers, D.M., Brown, I.L., and Wheye, D. (1985). Bird predation as a selective agent in a butterfly population. Evolution. 39(1), 93-103.

Boyan, G.S. and Fullard, J.H. (1988). Information processing at a central synapse suggests a noise filter in the auditory pathway of the noctuid moth. J. Comp. Physiol. 164, 251-258.

Bradbury, J.W. and Vehrencamp, S.L. (1998). Principles of animal communication. Sunderland, Massachusetts: Sinauer.

Brown, C.R., Brown, M.B., and Shaffer, M.L. (1991). Food-sharing signals among socially foraging cliff swallows. Anim. Behav. 42, 551-564.

Brown, S.G., Boettner, G.H., and Yack, J.E. (2007). Clicking caterpillars: acoustic aposematism in Antheraea polyphemus and other Bombycoidea. J. Exp. Biol. 210, 9931005.

Bura, V.L., Fleming, A.J., and Yack J. E. (2009). What's the buzz? Ultrasonic and sonic warning signals in caterpillars of the great peacock moth (Saturnia pyri). Naturwissenschaften 96, 713-718.

Castellanos, I. and Barbosa, P. (2006) Evaluation of predation risk by a caterpillar using substrate-borne vibrations. Anim. Behav. 72, 461-469.

Catchpole, C.K. and Slater, P.J.B. (2003). Bird song: biological themes and variations. pp. 35-36. Cambridge University Press.

Chai, P. and Srygley, R.B. (1990). Predation and the flight, morphology, and temperature of neotropical rainforest butterflies. Am. Nat. 135, 748-765.

Chai, P. (1996). Butterfly visual characteristics and ontogeny of responses to butterflies by a specialized tropical bird. Biol. J. Linn. Soc. 59, 166-189.

Chapman, F.M. (1935). The courtship of gould's manakin (Manacus vitellinus itellinus) on Barro Colorado, Canal Zone. Bull. Am. Mus. Nat. Hist., 68, 471-525. 
Charif, R.A., Clark, C.W. \& Fristrup, K.M. (2007). RAVEN Pro 1.3 user's manual. Ithaca, NY: Cornell Laboratory of Ornithology.

Christ, J.C. (1958). Some Observations of the nesting habits of the eastern phoebe. Amer. Biol. Teach. 20(5), 157-159.

Clark, J.C. (2008). Fluttering wing feathers produce the flight sounds of male streamertail hummingbirds. Biol. Lett. 4, 341-344.

Clark, J.C. and Feo, T.J. (2008). The anna's hummingbird chirps with its tail: a new mechanism of sonation in birds. Proc. R. Soc. B. 275(1637), 955-962.

Coleman, S.W. (2008). Mourning dove (Zenaida macroura) wing-whistles may contain threat-related information for con- and hetero-specifics. Naturwissenschaften. 95, 981986.

Darwin, C. (1871). The Descent of Man, and Selection in Relation to Sex. London: John Murray.

Dawson, J.W., Kutsch, W., and Robertson, R.M. (2003). Auditory-evoked evasive maneuvers in free-flying locusts and moths. J. Comp. Physiol. 190, 69-84.

Dudok van Heel, W.H. (1962). Sound and Cetacea. Neth. J. Sea. Res. 1(4), 407-507.

Endler, J.A. (1993). Some general comments on the evolution and design of animal communication systems. Phil. Trans. Roy. Soc. L. 340(1292), 215-225.

Eiserer, L.A. (1980). Effects of grass length and mowing on foraging behavior of the American robin (Turdus migratorius). Auk. 97(3), 576-580.

Ewing, A.M. (1989). Arthropod Bioacoustics: Neurobiology and Behavior. New York: Cornell University Press.

Faure, P.A. and Barclay, R.M.R. (1994). Substrate gleaning versus aerial hawking: plasticity in the foraging and echo-location behaviour of the long-eared bat, Myotis evotis. J. Comp. Phys. 174, 651-660.

Field, L.H. and Matheson, T. (1998). Chordotonal organs of insects. Adv. Insect. Physiol. 27, 1-228.

Fenton, M.B. and Fullard, J.H. (1979). The influence of moth hearing on bat echolocation strategies. J. Comp. Physiol. 132 (1), 77-86.

Fitzpatrick, J.W. (1980). Foraging behaviour of neotropical tyrant flycatchers. Condor. 82(1), 43-57. 
Forrest, T.G., Read, M.P., Farris, H.E., and Hoy, R.R. (1997). A tympanal hearing organ in scarab beetles. J. Exp. Biol. 200, 601-606.

Fullard, J.H. (1982). Echolocation assemblages and their effects on moth auditory systems. Can. J. Zool. 60, 2572-2576.

Fullard, J.H. (1984). Listening for bats: pulse repetition rate as a cue for defensive behaviour in Cycnia tenera (Lepidoptera: Arctiidae). J. Comp. Physiol. 154, 249-252.

Fullard, J.H. (1988). The tuning of moth ears. Experientia. 44, 423-428.

Fullard, J.H. (1990). The Sensory Ecology of Moths and Bats: Global Lessons In Staying Alive. In Insect Defenses: Adaptive Mechanisms and Strategies of Prey and Predator. SUNY Press.

Fullard, J.H., Simmons, J.A., and Saillant, P.A. (1994). Jamming bat echolocation: the dogbane tiger moth Cycnia tenera times its clicks to the terminal attack calls of the big brown bat Eptesicus fuscus. J. Exp. Biol. 194(1), 285-298.

Fullard, J.H., Dawson, J.W., Otero, L.D., and Surlykke, A. (1997). Bat-deafness in day-flying moths (Lepidoptera Notodontidae, Dioptinae). J. Comp. Physiol. A. $181,477-483$.

Fullard, J.H., Otero, L.D., Orellana, A., and Surlykke, A. (2000). Auditory sensitivity and diel flight activity in neotropical Lepidoptera. Ann. Entomol. Soc. Am. 93, 956-965.

Fullard, J.H. and Napoleone, N. (2001). Diel flight periodicity and the evolution of auditory defences in the Macrolepidoptera. Anim. Behav. 62, 349-368.

Fullard, J.H., Ratcliffe, J.M. and ter Hofstede, H.M. (2007) Neural evolution in the bat-free habitat of Tahiti: partial regression in an anti-predator auditory system. Biol. Lett. 3, 26-28.

Fullard, J.H., Ratcliffe, J.M., and Jacobs, D.S. (2008). Ignoring the irrelevant: auditory tolerance of audible but innocuous sounds in the bat-detecting ears of moths. Naturwissenschaften. 95, 241-245.

Gerhardt, H.C. and Huber, F. (2002). Acoustic communication in insects and anurans: Common Problems and Diverse Solutions. Chicago, IL: Chicago University Press.

Goerlitz, H.R., Greif, S., and Siemers, B.M. (2008). Cues for acoustic detection of prey: insect rustling sounds and the influence of walking substrate. J. Exp. Biol. 211, 2799-2806.

Gnatzy, W. and Kamper, G. (1990). Digger wasp against crickets. II. An airborne signal produced by a running predator. J. Comp. Physiol. 167, 551-556. 
Gould, S.J. and Vrba, E.S. (1982). Exaptation - a missing term in the science of form. Paleobiology. 8, 4-15.

Gradwohl, J. and Greenberg, R. (1982). The effect of a single species of avian predator on the arthropods of aerial leaf litter. Ecology. 63(2), 581-583.

Graham, R.R. (1934). The silent flight of owls. J. Roy. Aero. Soc. 38, 837-843.

Greenfield, M.D. (2002). Signalers and receivers: mechanisms and evolution of arthropod communication. New York, NY: Oxford University Press.

Haff, T.M. and Magrath, R.D. (2010). Vulnerable but not helpless: nestlings are finetuned to cues of approaching danger. Anim. Behav.. 79, 487-496.

Haskell, P.T. (1957). The influence of flight noise on behaviour in the desert locust Schistocerca gregaria (Forsk.) J. Insect Physiol. 1, 52-75.

Hasson, O. (1994). Cheating signals. J. Theor. Biol. 167(3), 223-238.

Higgins, P.J. and Davies, S.J.J.F. (1996). Handbook of Australian, New Zealand and Antarctic birds. Volume 3: snipe to pigeons. Melbourne, Australia: Oxford University Press.

Hingee, M. and Magrath, R.D. (2009) Flights of fear: a mechanical wing whistle sounds the alarm in a flocking bird. Proc. R. Soc. B. 10, 1098-1110.

Holmes, R.T., Schultz, J.C., and Nothnagle, P. (1979). Bird predation on forest inescts: An exclosure experiment. Science. 206(4417), 462-463.

Hoy, R.R., Nolen, T., and Brodfuehrer, P. (1989). The neuroethology of acoustic startle and escape in flying insects. J. Exp. Biol. 146, 287-30.

Hoy, R.R. and Robert, D. (1996). Tympanal hearing In insects. Annu. Rev. Entomol. 41, 433-450.

Hoy, R.R. (1998). In Comparative Hearing: Insects (Eds. Hoy, R.R., Popper, A.N., and Fay, R.R.) pp. 1-17. New York, New York: Springer.

Hunter, T.A. and Picman, J. (2005). Characteristics of the wing sounds of four hummingbird species that breed in Canada. Condor. 107, 570-582.

Jackson, M.E., Asi, N.S., and Fullard, J.H. (2010). Auditory sensitivity and ecological relevance: the functional audiogram as modeled by the bat detecting moth ear. J. Comp. Physiol. 196(7), 453-462. 
Jacobs, D.S., Ratcliffe, J.M., and Fullard, J.H. (2008). Beware of bats, beware of birds: the auditory responses of eared moths to bat and bird predation. Behav. Ecol. 19, 1333-1342.

Kalmring, K. (1975). The afferent auditory pathway in the ventral nerve cord of Locusta migratoria (Acrididae). I. Synaptic connectivity and information processing among the auditory neurons of the ventral cord. J. Comp. Physiol. 104, 103-141.

Kamper, G. (1984). Abdominal ascending interneurons in crickets: responses to sound at the $30-\mathrm{Hz}$ calling song frequency. J. Comp. Physiol. 155, 507-520.

Kaufmann, J.H. (1986). Stomping for earthworms by wood turtles, Clemmys insculpta: a newly discovered foraging technique. Copeia. 1986(4), 1001-1004.

Kettlewell, H.B.D. (1973). The evolution of melanism, the study of a recurring necessity. Clarendon Press, Oxford.

King, J. (2008). Butterfly hearing: A comparative study. Undergraduate thesis, Carleton University, Ottawa, Canada.

Kleindienst, H.U., Koch, U.T., and Wohlers, D.W. (1981). Analysis of the cricket auditory system by acoustic stimulation using a closed sound field. J. Comp. Physiol. 141, 283-296.

Krebs, J. R. and Dawkins, R. (1984). Animal signals: mind-reading and manipulation. In: Behavioural Ecology. An Evolutionary Approach (Ed. by J. R. Krebs \& N. B. Davies). pp. 380-402. Oxford: Blackwell Scientific Publications.

Kristensen, N.P. and Skalski, A.W. (1999). Phylogeny and Palaeontology. In Handbook of Zoology. Bol. 4. Arthropoda: Insecta. Lepidoptera, Moths and Butterflies. Vol. 1. Evolution, Systematics, and Biogeography. (Ed. N.P. Kristensen), pp. 7-25. Berlin: Walter de Gruyter.

Kroeger, R., Gruschka, H., and Helvey, T. (1971). Low speed aerodynamics for ultraquiet flight. AFFDL. 71-75, 1-55.

Kroodsma, D.E. and Byers, B.E. (1991). The function(s) of bird song. Amer. Zool. 31, 318-328.

Lane, K.A., Lucas, K.M. and Yack, J.E. (2008). Hearing in a diurnal, mute butterfly, Morpho peleides (Papilionoidea, Nymphalidae). J. Comp. Neurol. 508, 677-686.

Lees, D.R. and Creed, E.R. (1975). Industrial melanism in Biston betularia: The role of selective predation. J. Anim. Eco. 44(1), 67-83. 
Lilley, G.M. (1998). A study of the silent flight of the owl. AIAA Paper, pp. 2004-2186.

Lohrey, A.K., Clark, D.L., Gordon, S.D., and Uetz, G.W. (2009). Antipredator responses of wolf spiders (Araneae: Lycosidae) to sensory cues representing an avian predator. Anim. Behav. 77, 813-821.

Lucas, K.M. (2008). Hearing in two tropical butterflies, Morpho peleides and Caligo eurilochus (Nymphalidae: Satyrinae). M.Sc. thesis, Carleton University, Ottawa, Canada.

Lucas, K.M., Windmill, J.F.C., Robert, D., and Yack, J.E. (2009). Auditory mechanics and sensitivity in the tropical butterfly Morpho peleides (Papilionoidea, Nymphalidae). J. Exp. Bio. 212, 3533-3541.

Magrath, R.D., Pitcher, B.J. and Dalziell, A.H. (2007). How to be fed but not eaten: nestling responses to parental food calls and the sound of a predator's foot-steps. Anim. Behav. 74, 1117-1129.

Mahony, S. (2006). Hearing in the speckled wood butterfly, Pararge aegeria (Nymphalidae: Satyrinae). M.Sc. thesis, Carleton University, Ottawa, Canada.

Manley, G.A., Fay, R.R., and Popper, A.N. (2007). Active processes and otoacoustic emissions in hearing. Springer Handbook of Auditory Research. 30, 192-201,

Mason, A.C. (1991). Hearing in a primitive ensiferan: the auditory system of Cyphoderris monstrosa (Orthoptera: Haglidae). J. Comp. Physiol. 168, 351-363.

Mason, A.C. and Schildberger, K. (1993). Auditory interneurons in Cyphoderris monstrosa (Orthoptera: Haglidae). J. Comp. Physiol. 171, 749-757.

Mason, A.C. and Bailey, W.J. (1998). Ultrasound hearing and male-male communication in Australian katydids (Tettigoniidae, Zap- rochilinae) with sexually dimorphic ears. Physiol. Entomol. 23, 139-149.

Mason, J.B. (1969). The tympanal organ of Acridomorpha (Orthoptera). Revista Espanola de Entomologla XLIV, 267-355.

Masters, W. M. (1979). Insect disturbance stridulation: its defensive role. Behav. Ecol. Sociobiol. 5, 187-200.

Maynard Smith, J. and Harper, D. (2003). Animal Signals. Oxford: Oxford University Press.

McCloskey, J.T. and Thompson, J.E. (2000). Aging and sexing common snipe using discriminant analysis. J. Wildl. Manage. 64(4), 960-969.

Michelsen, A. (1979). Insect ears as mechanical systems. Am. Sci. 67, 696-706. 
Michelsen, A. and Larsen, O.N. (1985). Hearing and sound. In Comprehensive insect physiology, biochemistry, and pharmacology. (Ed. Kerkut, G.A, and Gilbert, L.I.). pp. 495-556. New York: Pergamon Press.

Miller, L.A. and Surlykke, A. (2001). How some insects detect and avoid being eaten by bats: tactics and countertactics of prey and predator. Bioscience. 51, 571-582.

Minet, J., and Surlykke, A. (2003) Sound producing and auditory organs. In Handbook of zoology/hanbuch der zoologie. Lepidoptera, moths and butterflies, morphology and physiology, vol. 2. (Ed. Kristensen, P.), pp. 289-323. Berlin: Walter de Gruyter.

Monge-Nájera, J., Hernández, F., González, M.I., Soley, J., Araya, J. and Zolla, S. (1998). Spatial distribution, territoriality and sound production by tropical cryptic butterflies (Hamadryas, Lepidoptera: Nymphalidae): Implications for the 'Industrial Melanism' debate. Rev. Biol. Trop. 48, 297-329.

Mongraine, J. (2009) Butterfly hearing: What is it used for? B.Sc. Honours thesis, Carleton University, Ottawa, Canada.

Murphy, M. (2010). Unraveling the auditory system of Drosophila. Curr. Opin. Neurobiol. 20(3), 281-287.

Murphy, S.M., Leahy, S.M., Williams, L.S. and Lill, J.T. (2010). Stinging spines protect slug caterpillars (Limacodidae) from multiple generalist predators. Behav. Ecol. 21, 153-160.

Neuhaus, W., Bretting, H., and Schweizer, B. (1973). Morphologische und funktionelle Untersuchungen über den,,lautlosen" Flug der Eulen (Strix aluco) im Vergleich zum Flug der Enten (Anas platyrhynchos). Biol. Zbl. 92, 495-512.

Novacek, M. J. (1985). Evidence for echolocation in the oldest known bats. Nature, 315, 140-141.

Otero, L.D. (1990). Estudio de algunos caracteres para su uso en la clasificación de Eurytelinae (Lepidoptera: Nymphalidae). Bol. Ent. Venez. 5, 123-138.

Otten, H. (2000). Vibrational sounding: a sophisticated host-searching strategy of the pupal parasitoid Pimpla tutrionellae. Diss. Naturwissenschaften. ETH Zürich.

Otten, H., Wackers, F. L., Battini, M., and Dorn, S. (2000). Efficiency of vibrational sounding in the parasitoid Pimpla turionellae is affected by female size. Anim. Behav. 67, 560-573.

Paul, D.H. (1974). Responses to acoustic stimulation of thoracic interneurons in noctuid moths. J. Insect. Physiol. 20, 2205-2218 
Payne, R.B. (2008). Wingflap dialects in the flappet lark Mirafra rufocinnamomea. IBIS. $115(2), 270-274$.

Pearson, D.L. (1988). Biology of tiger beetles. Ann. Rev. Entomol. 33, 123-147.

Pinheiro, C.E.G. (1996). Palatability and escaping ability in neotropical butterflies: tests with wild kingbirds (Tyrannus melancholicus, Tyrannidae). Biol. J. Linn. Soc. 59, 351365 .

Pinheiro, C.E.G. (2003). Does Mullerian mimicry work in nature? Experiments with butterflies and birds (Tyrannidae). Biotropica. 35, 356-364.

Platzen, D. and Magrath, R.D. (2004). Parental alarm calls suppress nestling vocalization. Proc. R. Soc. B. 271, 1271-1276.

Poulin, B., Lefebvre, G., and McNeil, R. (1994). Diets of land birds from northern Venezuela. Condor. 96(2), 354-367.

Poulin, B. and Lefebvre, G. (1997). Estimation of arthropods available to birds: Effect of trapping technique, prey distribution, and bird diet. J. Field. Ornithol. 68(3), 436-442.

Prum, R.O. (1998). Sexual selection and the evolution of mechanical sound production in the manakins (Aves: Pipridae). Anim. Behav. 55, 977-994.

Pulliam, R.H. (1974). On the theory of optimal diets. Amer. Nat. 108(959), 59-74.

Rayner, J.M. (1985). Bounding and undulating flight in birds. J. Theor. Biol. 117(1), 4777.

Remsen, J.V. and Robinson, S.K. (1990). A classification scheme for foraging behaviour of birds in terrestrial habitats. Stud. Avian. Biol. 13, 144-160.

Ribaric, D. and Gogala, M. (1996). Acoustic behaviour of some butterfly species of the genus Erebia (Lepidoptera: Satryidae). Acta. Ent. Slov. 4, 5-12.

Rieke, E.F. (1970). Neuroptera. In The insects of Australia, pp. 472-94.

Robert, D. (1989). The auditory behaviour of flying locusts. J. Exp. Biol. 147, 279.301.

Robert, D., Amoroso, J., and Hoy, R.R. (1992). The evolutionary convergence of hearing in a parasitoid fly and its cricket host. Science. 258, 1135-1137.

Robinson, S.K. and Holmes, R.T. (1982). Foraging behaviour of forest birds: The relationship among search tactics, diet, and habitat Structure. Ecology. 63(6), 1918-1931. 
Roeder, K.D. (1962). The behaviour of free flying moths in the presence of artificial ultrasonic pulses. Anim. Behav. 10, 300-304.

Roeder, K.D. (1967). Turning tendency of moths exposed to ultrasound while in stationary flight. J. Insect. Physiol. 13, 873-888.

Roeder, K.D. (1964). Aspects of the noctuid tympanic organ having significance in the avoidance of bats. J. Insect. Physiol. 10, 529-546.

Roeder, K.D. (1974). Responses of the less sensitive acoustic sense cells in the tympanic organs of some noctuid and geometrid moths. J. Insect. Physiol. 20, 55-66.

Roeder, K.D. (1975). Neural factors and evitability in insect behaviours. J. Exp. Zool. 194, 75-88.

Rojas, R.A.F. and Stappung, E.S.C. (2005). Seasonal diet of the Aplomado Falcon (Falco femoralis) in an agricultural area of Araucanía, Southern Chile. J. Raptor. Res. 39, 55-60.

Romer, H. (1976). Die informations verarbeitung tympanaler Rezeptor elemente von Locusta migratoria (Acrididae, Orthoptera). J. comp. Physiol. 109, 101-122.

Romer, H. and Tautz, J. (1992). Invertebrate auditory receptors. Adv. Comp. Environ. Physiol. 10, 185-212.

Rosen, M.J., Levin, E.C., and Hoy, R.R. (2009). The cost of assuming the life history of a host: acoustic startle in the parasitoid fly Ormia ochracea. J. Exp. Biol. 212(24), 4056-4064.

Ruxton, G.D., Sherratt, T.N. and Speed, M.P. (2004). Avoiding Attack: The Evolutionary Ecology of Crypsis, Warning Signals and Mimicry. New York: Oxford University Press.

Rydell, J., Jones, G., and Waters, D. A. (1995) Echolocating bats and hearing moths: who are the winners? Oikos. 73, 419-424.

Rydell, J., Skals, N., Surlykke, A., and Svensson, M. (1997). Hearing and bat defense in geometrid winter moths. Proc. R. Soc. Lond. B. 264, 83-88.

Rydell, J., Kaerma, S., Hedelin, H., and Skals, H. (2003). Evasive response to ultrasound by the crepuscular butterfly Manataria maculata. Naturwissenschaften, 90, 80-83.

Sanderford, M.V. and Conner, W.E. (1990). Courtship sounds of the polka-dot wasp moth. Naturwissenschafien. 77, 347-347. 
Sarasola, J.H., Santillán, M.A., and Galmes, M.A. (2003) Food habits and foraging ecology of American Kestrels in the semiarid forests of central Argentina. J. Raptor. Res. 37(3), 236-243.

Sargent, T.D. (1969). Behavioural adaptations to cryptic moths. Preliminary studies on an anthophlous species, Schinia florida (Noctuidae) to birds. J. N. Y. Entomol. Soc. 95, 495-503.

Shaw, S.R. (1994). Detection of airborne sound by a cockroach 'vibration detector': a possible missing link in insect auditory evolution. J. Exp. Biol. 193, 13-47.

Skutch, A.F. (1967). Life histories of Central American highland birds. Nuttall. Ornithol. Club. 7, 1-213.

Smith, W.J. (1997). Displays of Sayornis Phoebe (Aves, Tyrannidae). Behaviour. 33(3/4), 283-322.

Snow, D. (1971). Evolutionary aspects of fruit-eating in birds. Ibis. 113, 194-202.

Spangler, H.G. (1988). Moth hearing, defense and communication. Ann. Rev. Ent. 33, $59-81$.

Srygley, R.B. (1994). Shivering and its cost during reproductive behaviour in Neotropical owl butterflies, Caligo and Opsiphanes (Nymphalidae: Brassolinae). Anim. Behav. 47, 23-32.

Stettenheim, P. (1976). Structural adaptations in feathers. Proc. Int. Ornithol. Congr. 16, $385-401$.

Stevens. M., Hardman, C.J., and Stubbins, C.L. (2008). Conspicuousness, not eye mimicry, makes "eyespots" effective antipredator signals. Behav. Ecol. 19, 525-531.

Straub, J. and Lakes-Harlan, R. (2010). Neuroanatomy of the complex tibial organ in the splay-footed cricket Comicus calcaris Irish 1986 (Orthoptera: Ensifera: Schizodactylidae). J. Comp. Neurobiol. 518(22), 4567-4580.

Straw, J.A., Krementz, D., Olinde, M., and Sepik, G. (1994). American Woodcock. International Association of Fish and Wildlife Agencies. pp. 97-114.

Stumpner, A. and von Helversen, D. (2001). Evolution and function of auditory systems in insects. Naturwissenschaften. 88, 159-170.

Surlykke, A. (1984) Hearing in notodontid moths: a tympanic organ with a single auditory neurone. J. Exp. Biol. 113, 323-335. 
Surlykke, A. and Skals, N. (1998). Sonic hearing in a diurnal geometrid moth, Archiearis parthenias, temporally isolated from bats. Naturwissenschaften. 85, 36-37.

Surlykke, A. and Moss, C. F. (2000). Echolocation behavior of the big brown bat, Eptesicus fuscus, in the field and the laboratory. J. Acoust. Soc. Am. 108, 2419-2429.

Surlykke, A. and Kalko, E.K.V. (2008). Echolocating bats cry out loud to detect their prey. PLoS. ONE. 3(4), 20-36.

Svensson, M.A., Eklof, J., Skals, N., and Rydell, J. (2003). Light dependent shift in the anti-predator response of a pyralid moth. Oikos. 101, 239-246.

Tautz, J. and Markl, H. (1978) Caterpillars detect flying wasps by hairs sensitive to airborne vibration. Behav. Ecol. Socio. Biol. 4, 101-110.

Taylor, C. (2009). M.Sc. Thesis. Carleton University. Ottawa, Ontario.

Thorson, J., Weber, T., and Huber, F. (1982) Auditory behavior of the cricket II. Simplicity of calling-song recognition in Gryllus, and anomalous phonotaxis at abnormal carrier frequencies. J. Comp. Physiol. 146,361-378.

Tinbergen, N. (1960). The herring gull's world. NewYork, NewYork Basic Books, Inc.

Vallin, A., Jakobsson, S., Lind, J., and Wiklund, C. (2005). Prey survival by predator intimidation: an experimental study of peacock butterfly defense against blue tits. Proc. R. Soc. B. 272, 1203-1207.

Verbeek, N.A.M. (1975). Comparative feeding behavior of three coexisting tyrannid flycatchers. Wilson. Bull. 87, 231-240.

Vermeij, G.J. (1982). Unsuccessful predation and evolution. Amer. Nat. 120(6), 701720 .

Vogel, R. (1912). Über die Chordotonalorgane in der Wurzel der Schmetterlingsflügel. Z. Wiss. Zool. 100, 210-244.

Wackers, F.L., Mitter, E., and Dorn, S. (1998). Vibrational sounding by the pupal parasitoid Pimpla (Coccygomimus) turionellae: an additional solution to the reliabilitydetectability problem. Biol. Control. 11, 141-146.

Walker, T.J. (1993). Phonotaxis in female Ormia ochracea (Diptera:Tachinidae), a parasitoid of field crickets. J. Insect. Behav. 6, 389- 410.

Waters, D.A. (2003). Bats and moths: what is there left to learn? Phys. Ent. 28, 237-250.

Willott, J.F. (2001). Handbook of Mouse Auditory Research. CRC Press. 
Yack, J.E. (2004). The structure and function of auditory chordotonal organs in insects. Microscopy Res. Tech. 63, 315-337.

Yack, J.E. and Fullard, J.H. (1993). What is an insect ear? Ann. Ent. Soc. Am. 86(6), 677-682.

Yack, J.E. and Fullard, J.H. (2000). Ultrasonic hearing in nocturnal butterflies. Nature. 403, 265-266.

Yack, J.E., Otero, L.D., Dawson, J.W., Surlykke, A., and Fullard, J.H. (2000).

Sound production and hearing in the blue cracker butterfly Hamadryas feronia (Lepidoptera, Nymphalidae) from Venezuela. J. Exp. Biol. 203, 3689-3702.

Yack, J.E., and Hoy, R.R. (2004). Hearing. In: Encyclopedia of Insects (Ed. V.H. Resh and R. Cardé). Academic Press, San Diego, CA.

Yack, J.E., Kalko, E.K.V., and Surlykke, A. (2007). Neuroethology of ultrasonic hearing in nocturnal butterflies (Hedyloidea). J. Comp. Phys. 193, 577-590.

Yack, J.E. and Dawson, J.W. (2008). Insect Ears. The Senses: A comprehensive Reference, Vol 3. pp. 35-54. Academic Press.

Yager, D. (1990). Sexual dimorphism of auditory function and structure in preying mantises (Mantodea; Dictyoptera). J. Zool. Lond. 221, 517-537.

Yager, D. (1999). Structure, development, and evolution of insect auditory systems. Microscopy Res. Tech. 47, 380-400.

Yager, D.D. and May, M.L. (1990). Ultrasound-triggered, flight-gated evasive maneuvers in the praying mantis, Parasphendale agrionina Gerst. II. Tethered flight. J. Exp. Biol. 152, 41-58.

Yager, D., Cook, A.P., Pearson, D.L., and Spangler, H.G. (2000). A comparative study of ultrasound-triggered behavior in tiger beetles (Cicindelidae). J. Zool. Lond. 251, 355-368.

Young, A.M. (1971). Wing coloration and reflectance in Morpho butterflies as related to reproductive behavior and escape from avian predators. Oecologia. 7, 209-222. 